
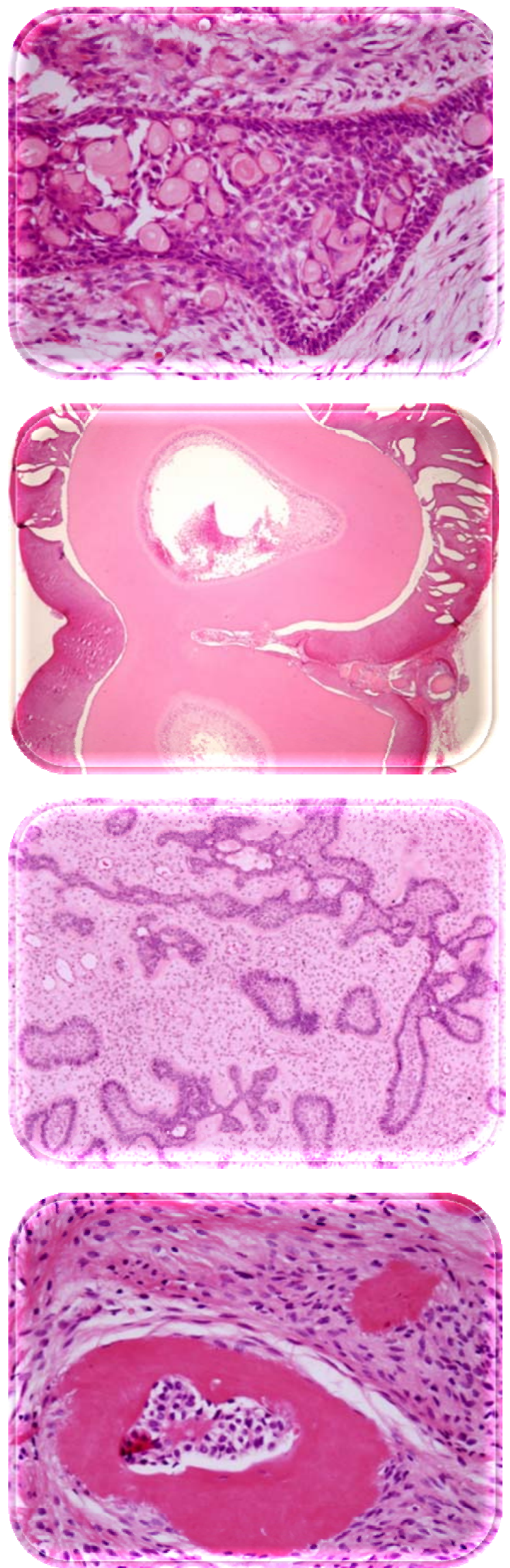

UNIVERSIDADE DE SÃO PAULO

Faculdade de Odontalogia de Bausu

Melaine de Almeida Lawall
Estuda setraspectiva de tumares adontogenicas en dais centros de estuda no Brasil e três no Mérica 
MELAINE DE ALMEIDA LAWALL

Estudo retrospectivo de Tumores Odontogênicos em dois centros de estudo no Brasil e três no México 


\section{Estudo retrospectivo de Tumores Odontogênicos em dois centros de estudo no Brasil e três no México}

Tese apresentada à Faculdade de Odontologia de Bauru da Universidade de São Paulo, como parte dos requisitos para a obtenção do título de Doutor em Odontologia.

Área de concentração: Patologia Bucal Orientador: Prof Dr Luís Antônio de Assis Taveira 


\begin{tabular}{|l} 
Lawall, Melaine de Almeida \\
L41e Estudo retrospectivo de Tumores Odontogênicos \\
em dois centros de estudo no Brasil e três no México / \\
Melaine de Almeida Lawall. - Bauru, 2009. \\
170p.: Il.; $30 \mathrm{~cm}$. \\
Tese. (Doutorado) - Faculdade de Odontologia de \\
Bauru. Universidade de São Paulo. \\
Orientador: Prof. Dr. Luís Antônio de Assis \\
Taveira
\end{tabular}

Autorizo, exclusivamente para fins acadêmicos e científicos, a reprodução total ou parcial desta dissertação, por processos fotocopiadores e outros meios eletrônicos.

Assinatura:

Data:

Comitê de Ética em Pesquisa em Humanos da Faculdade de Odontologia de Bauru

Protocolo n: 05/2008

Data: 26 de fevereiro de 2008. 


\section{DEDICATÓRIA}

Meus pais amados, Claudinê e Masia de lourdes... En näa tenba palavras para expressar tudo a que vacês sepresentam na minba vida. Se haje eston aqui e passa me argulhar da que faça e sau, deva tuda issa a vocês. Já faz alguns anas

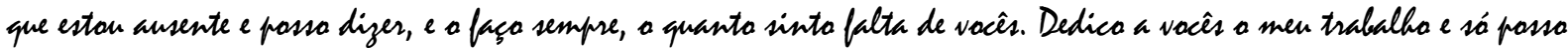
agradecer imensamente far todo a amor e apaia que vaces sempre me desam.

A minhas irmãs e ismãos, cunbadas e cunbados, e sobsinbas e sobinhos quesidos... Minha vida seria muito vazia se wäa tivesse vacês. Estar lange bá tanta tempa sá me fez ver a quanto vacês säa indispensáveis em minha vida. Morso de saudades.

A minhas avós Elşa e Diva, mulberes especiais e admisáveis.

Aos mens avôs Jahy e Waldemas, a saudade é uma constante, vacbes fazem minta falta.

Ama muita todas vacês!!!! 
"Seju a que vocî quer ses,

porque voci passui apenas uma vida e vela só se tem una chance

de fazer aquila que quer.

Tenba felicidade bastante pasa fazê-la doce.

Dificuldades pasa faze-la forte.

Tristeza para fazê-la humana.

Eesperança suficiente para fazê-la feliz.

As pessoas mais felizes nãa tèm as melhores coisas.

Elas sabem fager a melhor das oportunidades que apasecem em seus caminhos.

A felicidade aparece para aqueles que choram.

Para aqueles que se machucam.

Para aqueles que lasscam e tentam sempre.

Epara aqueles que seconbecem a impartância das pessoas que passam for suas vidas." 


\title{
AGRADECIMENTOS
}

É minto dificil falas de amigas... Essas pessoas täa especiais que entram em nossas vidas e conquistam

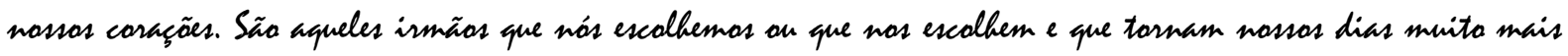
divestidos e leves... Ajudam a passas pelas hosas de tempestade e a comemoras as abonanças. A amizade compreende as coisas que palavsas nãa podem expressar, sabe les un gesto, un olbas... É um presente e seu valos wäa pode ses

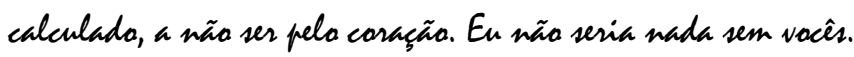

\author{
A todas os meus quesidas amigos \\ Karen, Milton, Erikinha, Brena, Carde Diega \\ Rolerta, Giscle, Vanessa e Carla \\ Simone, Janaina, Erika e Carlãa \\ Caral Preta, Carine, Arolda, Bruna e Patricia \\ Márcia, Renato, Inis, Geralda e Esivan Thairs \\ Gelorim, Luciana, Misna e Vizgínia \\ Thais Mara, Lnis Francisca, Livia e Thairs Silveira \\ Thais Cristina, Fernanda, Gismasi, Solange e Einar \\ Cardzinha, Alan Roger, Inciana, Daniel e Rafael \\ Andreia, Beatriz, Daniela, Renata e lasissa \\ Victor, Ronell e Angélica
}


À Deus pela oparturidade de aprendizado em mais uma vida.

Aa men quesida osientados Prof. Dr. Lnis Antonia de Assis Taveira, pela amizade, casinba e apaia nestes anos do doutorado. Nunca pensei que chegasia aqui, muito obrigada par acreditar em mim.

Aos professoses da Disciplina de Patologia Bucal da Faculdade de Odontalogia de Bauru, Prof. Dr. Allerto Consolara, Prof. Dri. Denise Tostes Oliveira e Prof. Dri. Vanessa Soares Lasa, pela transmissãa de conbecimentos durante a doutorada, se haje me considera uma patologista fai grą̧as a tuda que pude aprender cam voces.

À Prol. Dri. Ana Maria Pises Soublia, par todo apaia nestes anos de convivia. Obrigada pelo vasto conbecimento transmitido e par me dedicar tanta amizade. Sen amparo e conversas foram essenciais pasa que en pudesse ver que sempre bá um lado bom em todas as coisas. Sen caráter e profissionalismo säa exemplas que nunca esquecerei. Faltam-me palavisas para agsadeces.

À minha quesida familia Soublia, se hoje me sinto em casa quanda eston em Araçatuba é par tuda que voces lizeram par mim.

À familia Toral Riza, que me acolhen cama uma filha em toda a pesioda que permaneci na Méxica.

Aa Prof. Adalberta Alel Masqueda Taylar, par tada apaia e ensinamentas transmitidas, pelas bans mamentas compartilladas e pela amizade wa perioda em que estive no Méxica.

Aa Prof. Dr. Constantina Ledesma Montes, par toda colaboraçäa e solicitude.

Aos meus quesidos amigos e professoses do Departamento de Patologia e Propedentica Clínica da Faculdade de Ddontologia de Araçatuba - UNESP, vaces foram a minba inspiraçãa para seguir a carseisa acadêmica.

Ao Prol. Dr. Tadashi, pelos bous momentos compastilhadose pela amizade. 
Aas professores da Dixciplina de Anatomia Prof. Dr. Jesus Carlas Andrea e Prof. Dr. Antônia de Castra Rodrigues, pela amizade e casinba dispensadas dusante todos as mamentos de nosso convivia.

À funcionárias da Patologia, Cris, Fatiminba e Marilza, por toda casinbo e solicitude durante estes anos, que tornaram a convivência alegre e produtiva.

Aos funcianásios da setar de computaçãa e da libliateca da FOB-USP, par toda auxilia.

Aas funcionásios do Departamento de Patologia e Propedentica Clínica da Faculdade de Odontalogia de Araşatuba - UNESP, Marcela, Luzia, Cida, Elaine e Misiam par toda amizade e estimula nestes anos de convivia.

Ac Laboratória de Anatomia Patologia da Faculdade de Odantologia da Universidade Nacional Antônama da Méxica- UNAM, par ceder seus equipamentos e dependências para a sealizaçäa de parte deste trabalho.

Ao Laboratiório de Anatomia Patologia da Faculdade de Odontalogia da Univessidade Autanama

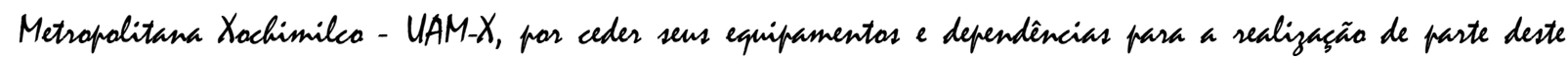
trabalka.

A todas os colegas do cursa de pós-graduaçãa: Gastãa, Erick, Masta, Leda, Rosásia, Suzana, Eliane, Renata, Sylvie, Thiaga e Michele.

As alunas de iniciaşãa cientifica, Masiana e Aline com as quais pude trabalbas e compastilbar bous mamentos.

A todas os mens quesidos alunos, que sũa a principal sazãa de minba incessante lusca par conbecimento. 
A Faculdade de Odantalogia de Baurn - USP na pessoa da excelentissima Diretar, Prof. Dr. Linz Fernanda Pegarara.

A Faculdade de Odantolagia de Araģatuba - UNESP wa pessoa do excelentissima Diretor, Prof. Dr. Pedra Felicio Estrada Bermalé.

À Faculdade de Odantologia da Universidade Nacional Autônama do México - UNAM na pessoa do excelentissima Reitar, Prof. Dr. Jasé Narra Robles.

A Faculdade de Odontalogia da Univessidade Autonama Metropalitana Xachilmilea - UAM-X na pessoa do excelentissima Reitor, Prof. Dr. Cuaubtémac Vladmir Pérez Ulanas.

À comissão de pós-graduaçãa da Faculdade de Odontalogia de Bauru, na pessoa da Presidente, Prof. Dri. Maria Apasecida de Andrade Moseira Machado.

Aa cussa de pás-graduaçãa em Patologia Bucal da Faceuldade de Odontalogia de Bauru-USP, wa pessoa da sen Coordenador Prof. Dr. Lnis Antonia de Assis Taveira.

À Prá-Reitaria de Pás-Graduaçãa da Universidade de Sãa Paula na pessoa da excelentissima Prá-Reitar Prof. Dr. Armanda Cosbani Fersaz, pelo auxilia financeira.

À Conselba Nacional de Desenvalvimenta Cientifica e Tecnalógica (CNP, ), pela cancessãa de minba bolsa de doutorado.

Aa Banca Santander, pela concessãa de minba lodsa para a Programa de Molilidade Internacional de PósGraduandor Santander/Banespa.

Ao Programa de Afaica à Pór-graduaģãa (PRDAP), pelo incentiva financeira. 


\section{EPÍGRAFE}

"Para viver de verdade, pensando e repensando a existencia, para que ela valba a pena, é preciso ser amado; e amar; e amar-se. Ter esperança; qualquer esperanga.

Questionar a que nos é impasta, sem rebeldias insensatas, mas sem demasiada sensatez. Saborear a bam, mas aqui eali enfrentar a sim. Supartar sem se sulmetes, aceitar sem se humilbar, entregar-se sem renunciar a si mesmo e á passivel dignidade.

Sonbar, parque se desistimas disso apaga-se a uiltima claridade e nada mais valerá a pena. Excapar, na liberdade da pensamento, desse espirito de manada que trabalba obstivadamente para wos enquadrar, seja lá no que for.

"E que, a minimo que a gente faça seja, a cada mamento, a melhor que afinal se conseguin fazer." 


\section{RESUMO}

Os tumores odontogênicos compõem um grupo de lesões incomuns, porém interessantes, que se forma a partir dos tecidos que dão origem aos dentes. Esses tumores vêm sendo estudados há décadas por patologistas e cirurgiões que buscam entender seus mecanismos de formação e desenvolvimento, assim como desenvolver técnicas adequadas de tratamento. Inúmeras foram as tentativas realizadas até hoje para classificar esses tumores odontogênicos, sendo a última a nova Classificação de Tumores Odontogênicos da Organização Mundial da Saúde, publicada em 2005. Assim sendo, este trabalho teve por objetivo determinar a prevalência dos tumores odontogênicos diagnosticados nos Serviços de Anatomia Patológica das Faculdades de Odontologia de Bauru (USP) e de Araçatuba (UNESP) no Brasil, e das Faculdades de Odontologia da UNAM, da UAM-X e do Laboratório privado Peribact no México, compará-las e definir um perfil da ocorrência desses tumores nessas instituições e países seguindo essa nova classificação. Todos os casos diagnosticados como tumores e cistos odontogênicos passíveis de reanálise diagnóstica foram selecionados dos arquivos dessas instituições. Os dados demográficos e os aspectos clínicos de cada lesão foram obtidos a partir dos laudos e das fichas de requisição de exame anatomopatológico e as lâminas examinadas por um avaliador. Os resultados demonstraram que a inclusão do queratocisto no grupo de tumores provocou uma alteração significante na prevalência dessas lesões. O tumor odontogênico queratocístico foi a lesão mais prevalente, seguida pelo odontoma, ameloblastoma e mixoma no Brasil e no México. Quanto aos dados demográficos e localização, nossos achados corroboram com aqueles descritos na maior parte dos trabalhos realizados em todo o mundo, com diferenças pontuais em países como a China. Entretanto, a falta de maiores conhecimentos biomoleculares e genéticos dificulta a compreensão dessas diferenças.

Palavras-chave: Tumor odontogênico. Prevalência. Classificação OMS. 


\begin{abstract}
Odontogenic tumors constitute a group of uncommon and particularly interesting lesions, arising from the odontogenic tissues. These tumors have been studied for decades by pathologists and surgeons seeking understand the mechanisms of formation and development, and trying to develop appropriate techniques of treatment. Many were the attempts made so far to classify these odontogenic tumors, the most recent being the new classification of odontogenic tumor of the World Health Organization, published in 2005. Therefore, this study aimed to determine the prevalence of odontogenic tumors diagnosed in five centers of diagnostic pathology: Laboratory of Oral Pathology, Faculty of Dentistry of Bauru USP; Laboratory of Oral Pathology, Faculty of Dentistry of Araçatuba - UNESP, in Brazil; and Department of Oral Pathology, Faculty of Dentistry - UNAM; Laboratory of Oral Pathology, Faculty of Dentistry of UAM-Xochimilco and Peribact Laboratory, a private laboratory of oral pathology, in Mexico; compare them and develop a profile of the occurrence of these tumors in these institutions and countries, following this new classification. All cases diagnosed as odontogenic cysts and tumors were selected for diagnostic review. The demographic and clinical features were obtained from the records when available. The cases were re-evaluated, and the diagnosis in each case was confirmed or modified when necessary. The results showed that the inclusion of keratocyst in the group of tumors caused a significant change in the prevalence of these lesions. The keratocyst odontogenic tumor was the most prevalent lesion, followed by odontoma, ameloblastoma and myxoma in Brazil and Mexico. Our findings corroborate with those reported arround the world, with occasional differences in countries, such as China. However, the lack of molecular and genetic knowledge precludes a better comprehension of these differences.
\end{abstract}

Key words: Odontogenic tumor. Prevalence. Who classification. 


\section{LISTA DE TABELAS}

Tabela 1 - Instituições envolvidas no estudo e período de estudo ............... 55

Tabela 2 - $\quad$ Marcas e modelos de microscópios utilizados no trabalho ............ 57

Tabela 3 - $\quad$ Instituições, tempos de estudo e total de casos ........................ 61

Tabela 4 - Casos estudados........................................................ 62

Tabela 5 - Freqüência relativa dos tumores odontogênicos nas instituições brasileiras............................................................... 76

Tabela 6 - Distribuição por gênero dos tumores odontogênicos nas instituições brasileiras.................................................... 77

Tabela 7 - Distribuição por faixa etária dos tumores odontogênicos nas instituições brasileiras.................................................... 78

Tabela 8 - Distribuição por localização dos tumores odontogênicos nas instituições mexicanas.................................................. 79

Tabela 9 - Freqüência relativa dos tumores odontogênicos nas instituições

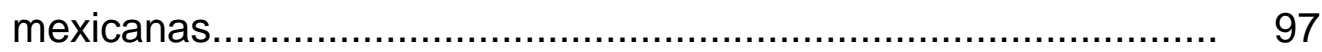

Tabela 10 - Distribuição por gênero dos tumores odontogênicos nas instituições mexicanas...................................................... 98

Tabela 11 - Distribuição por faixa etária dos tumores odontogênicos nas instituições mexicanas.

Tabela 12 - Distribuição por localização dos tumores odontogênicos nas instituições mexicanas. 


\section{LISTA DE ABREVIATURAS E SIGLAS}

\begin{tabular}{|c|c|}
\hline AS-M & Ameloblastoma sólido multicístico \\
\hline$A-U$ & Ameloblastoma unicístico \\
\hline AP & Ameloblastoma periférico \\
\hline CB & Cementoblastoma \\
\hline CAP & Carcinoma ameloblástico primário \\
\hline CAS & Carcinoma ameloblástico secundário \\
\hline CEIOP & Carcinoma epidermóide intra-ósseo primário \\
\hline CEIOPTOQ & $\begin{array}{l}\text { Carcinoma epidermóide intra-ósseo primário } \\
\text { derivado de Tumor odontogênico } \\
\text { queratocístico }\end{array}$ \\
\hline $\mathrm{COCC}$ & Carcinoma odontogênico de células claras \\
\hline FA & Fibroma ameloblástico \\
\hline FDA & Fibrodentinoma ameloblástico \\
\hline FOA & Fibro-odontoma ameloblástico \\
\hline FOC & Fibroma odontogênico central \\
\hline FOP & Fibroma odontogênico periférico \\
\hline $\mathrm{MO}$ & Mixoma odontogênico \\
\hline OC & Odontoma complexo \\
\hline OCp & Odontoma composto \\
\hline ODA & Odontoameloblastoma \\
\hline OMS & Organização Mundial da Saúde \\
\hline QAM & Queratoameloblastoma \\
\hline TOA & Tumor odontogênico adenomatóide \\
\hline TOC & Tumor odontogênico combinado \\
\hline TOCC & Tumor odontogênico cístico calcificante \\
\hline TDCF & Tumor dentinogênico de células fantasmas \\
\hline TO & Tumor odontogênico \\
\hline TOEC & Tumor odontogênico epitelial calcificante \\
\hline TONC & Tumor odontogênico não classificado \\
\hline TOQ & Tumor odontogênico queratocístico \\
\hline
\end{tabular}




\section{SUMÁRIO}

1 INTRODUÇÃO 17

2 REVISÃO DE LITERATURA 21

2.1 CLASSIFICAÇÃO DOS TUMORES ODONTOGÊNICOS 23

$2.2 \quad$ ESTUDOS EPIDEMIOLÓGICOS 36

2.2.1 Américas 37

2.2.2 Europa 41

2.2.3 Ásia 42

2.2.4 África 44

3 PROPOSIÇÃO 49

4 CASUÍSTCA E MÉTODOS 53

4.1 Amostragem 55

4.2 Dados demográficos e aspecto clínico 56

4.3 Critérios microscópicos utilizados para o diagnóstico 56

4.4 Comitê de Ética em Pesquisa 57

5 RESULTADOS 59

$\begin{array}{lll}5.1 & \text { Brasil } & 61\end{array}$

5.2 México 80

6 DISCUSSÃO 101

6.1 Classificações dos tumores odontogênicos 103

6.2 Tumor odontogênico queratocístico 108

6.3 Demais tumores odontogênicos 111

7 CONCLUSÕES 137

REFERÊNCIAS 141

ANEXOS 155

ANEXO A 159

ANEXO B 163

$\begin{array}{ll}\text { ANEXO C } & 167\end{array}$ 
1 Introdução 


\section{INTRODUÇÃO}

Os tumores odontogênicos (TOs) compreendem um grupo heterogêneo de lesões que variam de hamartomas a neoplasias benignas e malignas com diversos graus de agressividade e variado potencial metastático. São lesões que podem se originar de epitélio, mesênquima ou ectomesênquima odontogênicos, apresentando diferentes graus de interação entre esses tecidos (PINDBORG; KRAMER, 1971), o que se reflete na formação de estruturas histológicas específicas que representam vários estágios da odontogênese (OLGAC; KOSEOGLU; AKSAKALLI, 2006).

A primeira tentativa de classificar essas lesões foi publicada por Broca em 1868, e desde então, o desenvolvimento de novas tecnologias em diagnóstico imunoistoquímico, biologia molecular e genética, mostrou a necessidade de reclassificar alguns dos tumores odontogênicos de acordo com a sua provável histogênese ou de acordo com seu comportamento biológico (MOSQUEDATAYLOR, 2008). Sendo assim, em 2005 a Organização Mundial da Saúde (OMS) produziu uma nova classificação para os tumores odontogênicos, a qual introduziu uma série de modificações significativas em relação às classificações previamente utilizadas (BARNES et al., 2005).

Vários são os relatos epidemiológicos sobre tumores odontogênicos realizados em diversos países do mundo, tomando como bases casos avaliados em laboratórios de patologia, universidades e hospitais. Entretanto, é visível a falta de padronização dos dados devido à: 1) diferentes critérios diagnósticos utilizados; 2 ) tipo de amostra avaliada; 3) tempo de estudo; e 4) experiência dos patologistas envolvidos no estudo (BARNES et al., 2005; MOSQUEDA-TAYLOR et al., 1997; WU; CHAN, 1985)

Embora existam estudos retrospectivos sobre tumores odontogênicos em países de todo o mundo (ADEBAYO; AJIKE; ADEKEYE, 2005; AROTIBA; OGUNBIYI; OBIECHINA, 1997; AVELAR et al., 2008; DALEY; WYSOCKI; PRINGLE, 1994; FERNANDES et al., 2005) inúmeras questões ainda permanecem sem resposta... Qual a real prevalência dessas lesões? Existem diferenças quanto a prevalências dessas lesões em países Ocidentais e Orientais? Existem diferenças relacionadas ao poder socioeconômico dos pacientes? Existem diferenças raciais 
que influenciem essas prevalências? Existem diferenças quanto a prevalência dos TOs em diferentes tipos de serviços de anatomia patológica?

Visto que a freqüência dos tumores odontogênicos é diferente em vários países e até mesmo em regiões variadas de um mesmo país e que, além disso, existe um número reduzido de trabalhos na América Latina utilizando os critérios vigentes da nova Classificação da Organização Mundial de Saúde (2005), esse trabalho teve como objetivo determinar a freqüência dos tumores odontogênicos diagnosticados nos Serviços de Anatomia Patológica da Faculdade de Odontologia da UNAM, da Faculdade de Odontologia da UAM-X, do Laboratório privado Peribact, da Faculdade de Odontologia de Bauru - USP e da Faculdade de Odontologia de Araçatuba - UNESP, compará-las e definir um perfil da ocorrência desses tumores nessas instituições. 
2 Revisaio de Literatura 


\section{REVISÃO DE LITERATURA}

\subsection{CLASSIFICAÇÃO DOS TUMORES ODONTOGÊNICOS}

Os tumores odontogênicos (TOs) são lesões derivadas dos tecidos que dão origem aos órgãos dentais ou de remanescentes dos mesmos que permanecem contidos no interior dos ossos maxilares ou em meio aos tecidos moles adjacentes (MOSQUEDA-TAYLOR, 2008). Podem se originar de epitélio, mesênquima ou ectomesênquima odontogênicos, apresentando diferentes graus de interação entre esses tecidos (PINDBORG; KRAMER, 1972), o que se reflete em estruturas histológicas específicas que representam vários estágios da odontogênese (OLGAC; KOSEOGLU; AKSAKALLI, 2006).

A primeira tentativa de classificar os TOs foi publicada pelo médico francês Pierre Paul Broca em 1868. Em seu trabalho o autor usou o termo odontoma para designar qualquer tumor que se desenvolvesse a partir dos tecidos que dessem origem aos órgãos dentais. Segundo o autor, os odontomas eram a conseqüência de uma hipertrofia geral ou parcial desses órgãos dentais e deveriam ser classificadas de acordo com o estágio de desenvolvimento que o dente envolvido se encontrava quando do início da formação do tumor, considerando os seguintes estágios: (1) période embryoplastique (Estágio de histodiferenciação), (2) période odontoplastique (Estágio de morfodiferenciação), (3) période coronaire (Estágio de maturação coronária) e (4) période radiculaire (Estágio de formação radicular e erupção dental) (BROCA, 1868).

Além desses odontomas, Broca ainda classificou em odontomas heterotópicos os folículos de dentes supranumerários que se formavam em locais variados dos ossos maxilares e segundo o autor estavam mais expostos ao desenvolvimento de odontomas. Por fim, classificou em odontomas compostos, tumores que eram evidentemente de natureza odontogênica, mas que devido à complexidade das estruturas que o compunham e/ou devido a diversidade de lesões que se formavam próximas aos folículos adjacentes, não se enquadravam em nenhuma outra classificação. 
Em 1885, Louis Charles Malassez apresentou uma nova classificação incluindo cistos e tumores odontogênicos e com pequenas modificações em relação à classificação de Broca. Sua classificação se destacava por apresentar uma unificação na patogênese dessas lesões, baseada nos restos epiteliais paradentais. Assim como a classificação de Broca a nova classificação de Malassez não ganhou reconhecimento mundial (PHILIPSEN; REICHART, 2006).

Bland-Sutton em 1888 criou uma nova classificação baseada na gênese e na estrutura das lesões. O autor subdividiu as lesões em aberrações do órgão do esmalte, aberrações do folículo, aberrações da papila, aberrações de todo o germe dental e odontomas anômalos. A nova classificação incluiu cistos odontogênicos e tumores fibro-ósseos, entretanto manteve o termo odontoma como uma designação comum para todos os tumores de origem odontogênica (BLAND-SUTTON, 1888). Para Philipsen e Reichart, Bland-Sutton estabeleceu o que pode ser chamado de taxonomia moderna dos TOs (PHILIPSEN; REICHART, 2006).

\section{CLASSIFICAÇÃO DE BLAND-SUTTON (1888)}

A. Aberrações do órgão do esmalte

1. Odontoma epitelial

2. Odontoma epitelial calcificante

B. Aberrações do folículo

1. Cisto folicular

2. Odontoma fibroso

3. Cementomata

C. Aberrações da papila

1. Odontoma Radicular

a. Dentomata

b. Osteo-dentomata

c. Cementomata

D. Aberrações de todo germe dental

1. Odontoma composto

E. Odontomas anômalos

Em 1914 Gabbell, James e Payne elaboraram um relatório sobre odontomas através da British Dental Association apresentando uma nova classificação para os tumores odontogênicos na qual reconheciam três grupos principais de acordo com seu tecido de origem: epitelial, conjuntivo ou composto. O primeiro grupo identificado como odontomas epiteliais compreendia uma neoplasia conhecida na época como 
um cisto multilocular e também cistos não neoplásicos; o segundo grupo chamado odontomas compostos incluía as lesões formadas a partir de epitélio e/ou mesênquima odontogênicos que dessem origem a estruturas semelhantes a dentes ou mesmo estruturas mineralizadas irregulares; e o terceiro grupo dos odontomas de tecido conjuntivo incluía os tumores fibrosos e outros tumores de tecido conjuntivo formados somente a partir do mesênquima dental (GABELL et al., 1914).

Um avanço importante nas classificações aconteceu com a classificação de Thoma e Goldman (1946) que dividiu os tumores em epiteliais, mesenquimais ou mistos de acordo com suas origens. Além disso, foram os primeiros a sugerir a existência de influência indutiva dos tecidos epitelial e mesenquimal nos TOs mistos.

\section{CLASSIFICAÇÃO DE THOMA \& GOLDMAN (1946)}

I. Tumores epiteliais

1. Adamantoblastoma

2. Enameloma

II. Tumores mesenquimais

1. Fibroma odontogênico

2. Dentinoma

3. Cementoma

III. Tumores odontogênicos mistos (odontomas)

1. Odontomas moles (epitélio e mesoderma)

2. Odontomas moles e calcificados

3. Odontoma completamente formado com esmalte, dentina, polpa, cemento e membrana periodontal
a. Composto
b. Complexo

Os autores restringiram o uso do termo odontoma somente às lesões que continham tecido dental maduro e excluíram de sua classificação cistos e tumores não odontogênicos. Entretanto, mantiveram as pérolas de esmalte como uma lesão tumoral denominada enameloma (THOMA; GOLDMAN, 1946).

A classificação de Thoma e Goldman (THOMA; GOLDMAN, 1946) foi amplamente aceita nos Estados Unidos e foi utilizada como base para uma classificação criada e aprovada pela American Academy of Oral Pathology em 1950. Esta classificação foi expandida para incluir novas entidades que haviam sido descobertas e descritas neste ínterim (ROBINSON, 1952). 


\section{CLASSIFICAÇÃO AMERICAN ACADEMY OF ORAL PATHOLOGY (1951)}

Ectodérmico

Ameloblastoma simples

Adenoameloblastoma

Melanoameloblastoma

Ameloblastoma acantomatoso

Mesenquimal

Mixoma odontogênico

Fibroma odontogênico

Dentinoma

Cementoma

Fibrossarcoma odontogênico
Misto ou composto

Fibroma ameloblástico

(não calcificado)

Hemangioma ameloblástico

(não calcificado)

Sarcoma ameloblástico

(não calcificado)

Odontoma ameloblástico

(parcialmente calcificado)

Odontoma

(calcificado)

Complexo

Composto

Baseados no princípio de interação indutiva entre os tecidos epitelial e mesenquimal durante a odontogênese e sua participação na patogênese e histodiferenciação dos tumores odontogênicos, Pindborg e Clausen (PINDBORG; CLAUSEN, 1958) apresentaram em 1958 uma nova classificação para os tumores de origem odontogênica. Os autores consideraram dois grupos principais: tumores epiteliais e tumores mesodérmicos. Os tumores epiteliais eram separados em duas outras classes, a primeira compreendia tumores puramente epiteliais sem alterações indutivas no tecido conjuntivo adjacente e a segunda composta por tumores epiteliais que apresentavam alterações indutivas no mesênquima.

A classe de tumores puramente epiteliais foi dividida em ameloblastomas e tumores odontogênicos epiteliais calcificantes. Além disso, os ameloblastomas foram ainda subdivididos de acordo com as características morfológicas do tecido tumoral e do seu estroma. Já a classe de tumores epiteliais com alterações indutivas no tecido conjuntivo adjacente foi subdividida em lesões de tecido mole e lesões com tecido duro. O último grupo ainda foi subdividido em dentinomas e odontomas de acordo com o grau de maturação e estágio de desenvolvimento do tecido duro formado (PINDBORG; CLAUSEN, 1958).

Histologicamente, o grupo de tumores mesodérmicos era menos fragmentado, sendo divido somente em três grupos: fibromas odontogênicos, mixomas odontogênicos e fibromas cementificantes. No grupo dos fibromas 
cementificante o autor incluiu lesões fibro-ósseas atualmente conhecidas como displasias cemento-ósseas periapicais (PINDBORG; CLAUSEN, 1958).

\section{CLASSIFICAÇÃO PINDBORG E CLAUSEN (1958)}

I. Tumores Epiteliais

A. Sem interações indutivas no estroma

1. Ameloblastoma (Benigno ou Maligno)

B. Com interações indutivas no estroma

a. De acordo com o tecido tumoral

1. Tecido Mole

Ameloblastoma simples

a. Fibroma ameloblástico (Sarcoma)

Adenoameloblastoma

b. De acordo com o tipo de estroma

Ameloblastoemangioma

Ameloblastoneurinoma

2. Tumor odontogênico epitelial calcificante

2. Com tecido duro

a. Dentinoma

Tipo imaturo

Tipo maduro

b. Odontoma

Odontoma ameloblástico

Odontoma complexo

Odontoma composto

II. Tumores Mesodérmicos

A. Fibroma odontogênico (Fibrossarcoma)

B. Mixoma odontogênico

C. Fibroma cementificante

Em 1961, Gorlin e Chaudhry apresentaram uma nova classificação baseada na classificação de Pindborg e Clausen, na qual foram incluídas como subtipos dos ameloblastomas as variantes: folicular, plexiforme, acantomatosa, mucoepidermóide, de células granulares e, vascular. Além disso, o tumor adenomatóide ameloblástico passou a compor um novo grupo dentro dos tumores puramente epiteliais e o termo odontoma passou a ser utilizado para classificar as lesões compostas por esmalte e dentina nas quais polpa e cemento também estivessem presentes. O grupo dos tumores mesodérmicos foi dividido em duas classes: A) Mixomas e fibromas odontogênicos e B) Fibromas cementificantes, e essa última subdividida em tipo displasia fibrosa periapical e tipo gigantiforme (GORLIN; CHAUDHRY; PINDBORG, 1961). 


\section{CLASSIFICAÇÃO GORLIN E CHAUDHRY (1961)}

I. Tumores Epiteliais

A. Tumores epiteliais sem interações indutivas no tecido conjuntivo

1. Ameloblastoma (Benigno ou Maligno)

2. Tumor adenomatóide ameloblástico (adenoameloblastoma)

3. Tumor odontogênico epitelial calcificante

B. Tumores epiteliais com interações indutivas no tecido conjuntivo

1. Fibroma ameloblástico e fibrossarcoma ameloblástico

2. Dentinoma Imaturo (Tipo fibro-ameloblástico) Maduro

3. Odontoma ameloblástico e odontossarcoma ameloblástico

4. Odontoma complexo

5. Odontoma composto

II. Tumores mesodérmicos

A. Mixoma e Fibroma odontogênico (Fibrossarcoma odontogênico)

B. Fibroma cementificante (Displasia fibrosa periapical)

Tipo Displasia fibrosa periapical

Tipo Giganteforme

$\mathrm{Na}$ tentativa de demonstrar que a grupo de tumores odontogênicos representavam diferentes graus de diferenciação do epitélio odontogênico do qual se originavam e que como conseqüência o comportamento clínico dessas lesões variava de acordo com esse grau de diferenciação, Shear propôs em 1965 uma nova classificação separando as lesões em ordem crescente de diferenciação.

\section{CLASSIFICAÇÃO SHEAR (1965)}

Menos diferenciados

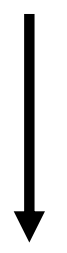

Mais diferenciados
1. Carcinoma epidermóide intra-alveolar

2. Tumor odontogênico epitelial calcificante

3. Ameloblastoma

4. Fibro-ameloblastoma

5. Ameloblastoma adenomatóide (Adenoameloblastoma)

6. Odontoma ameloblástico

7. Odontoma complexo (composite)

8. Odontoma composto (composite)

Para Shear (1965) as classificações anteriores eram desnecessariamente complicadas e falhavam ao tentar relacionar as lesões sob o ponto de vista da histogenética. 
Considerando as classificações até então utilizadas como falhas em separar os verdadeiros tumores odontogênicos de lesões tipo neoplásicas (neoplastic-like), Ernest Baden publicou (1971) uma nova classificação baseada no comportamento biológico dessas lesões. Entretanto, sua tentativa não teve reconhecimento mundial.

\section{CLASSIFICAÇÃO BADEN (1971)}

I. Neoplasias

A. Epiteliais benignas

a. Ameloblastoma

b.Tumor odontogênico epitelial calcificante

B. Epiteliais malignas

a. Carcinoma de células escamosas

(Derivado de ameloblastoma)

b. Fibrossarcoma ameloblástico

c. Sarcoma dentino-ameloblástico ou

Odontossarcoma
II. Hamartomas

A. Hamartomas epiteliais

a. Hamartoma epitelial gengival odontogênico

b.Tumor adenomatóide (adenoameloblastoma)

c. Épulide do recém-nascido

B. Hamartomas mistos

a. Mixoma ameloblástico

b. Fibroma ameloblástico

c. Dentinoma

d. Odontoma ameloblástico

e. Odontoma complexo

f. Odontoma composto

C. Displasias

a. Displasia cementária periapical

b. Cementoma gigantiforme

No final da década de sessenta, a fim de produzir uma classificação que permitisse definir os critérios clínico-patológicos necessários para diagnosticar os TOs, a Organização Mundial de Saúde (OMS) decidiu reunir um grupo de patologistas de diferentes países e criar um Centro de Referência Internacional como parte do Departamento de Patologia Bucal, no Royal Dental College em Copenhagen, na Dinamarca, chefiado pelo professor Jens Pindborg. No mesmo ano, foram incluídos nos estudos os cistos dos maxilares por idéia do professor Ivor Kramer, da Universidade de Londres. Após três anos de estudos, em 1969, foi definida uma classificação para os TOs que seria então adotada mundialmente. Dois anos depois, em 1971, a OMS publicou o primeiro guia oficial com a Classificação dos TOs denominado Tipos histológicos dos tumores odontogênicos, cistos dos maxilares e lesões afins (PINDBORG, KRAMER, 1972).

A primeira classificação oficial da OMS estava composta por quatro grupos de lesões, as neoplasias e outros tumores relacionados ao aparato odontogênico, as neoplasias e outros tumores relacionados aos ossos, os cistos epiteliais e as lesões 
não-classificadas. O grupo de TOs foi dividido em duas grandes classes de acordo com o comportamento biológico, tumores benignos e malignos. Dentro do grupo de tumores benignos estavam todos aqueles classificados anteriormente como tumores epiteliais e mesodérmicos, com exceção das lesões malignas (PINDBORG; KRAMER, 1972).

A inclusão de lesões como o cisto odontogênico calcificante ou cisto de Gorlin, descrito como uma nova entidade por Gorlin em 1962 (GORLIN et al., 1962), e de lesões malignas como o ameloblastoma maligno, fizeram desse trabalho (PINDBORG; CLAUSEN, 1958) o primeiro guia útil e padronizado para a classificação dos TOs. Sua criação impulsionou inúmeros estudos e publicações que trouxeram a tona uma nova realidade de conhecimento a respeito dessas lesões.

\section{TIPOS HISTOLÓGICOS DE TUMORES ODONTOGÊNICOS, CISTOS DOS} MAXILARES E LESÕES AFINS - CLASSIFICAÇÃO OMS (1972)

I. Neoplasias e outros tumores relacionados ao aparato odontogênico

A. Benignos

1. Ameloblastoma

2. Tumor odontogênico epitelial calcificante

3. Fibroma ameloblástico

4. Tumor odontogênico adenomatóide (adenoameloblatoma)

5. Cisto odontogênico calcificante

6. Dentinoma

7. Fibro-odontoma ameloblástico

8. Odontoameloblastoma

9. Odontoma complexo

10. Odontoma composto

11. Fibroma (fibroma odontogênico)

12. Mixoma (mixofibroma)

13. Cementomas

a. Cementoblastoma benigno (cementoma verdadeiro)

b. Fibroma cementificante

c. Displasia cementaria periapical (displasia fibrosa periapical)

d. Cementoma gigantiforme (cementomas múltiplos familiares)

14. Tumor neuroectodérmico melanótico da infância (prognoma melanótico, melanoameloblastoma) 
B. Malignos

1. Carcinomas

a. Ameloblastoma maligno

b. Carcinoma intra-ósseo primitivo

c. Outros carcinomas originados no epitélio odontogênico, incluindo os que se originam em cistos odontogênicos

2. Sarcomas odontogênicos

a. Fibrossarcoma ameloblástico (sarcoma ameloblástico)

b. Odontossarcoma ameloblástico

II. Neoplasias e outros tumores relacionados com o osso

A. Neoplasias Osteogênicas

1. Fibroma ossificante

B. Lesões ósseas não neoplásicas

1. Displasia fibrosa

2. Querubismo

3. Granuloma gigantocelular central (granuloma gigantocelular de reparação)

4. Cisto ósseo aneurismático

5. Cisto ósseo simples (cisto ósseo traumático, hemorrágico)

III. Cistos epiteliais

A. De desenvolvimento

1. Odontogênicos
a. Cisto primordial (queratocisto)
b. Cisto gengival
c. Cisto de erupção
d. Cisto dentígero (folicular)

2. Não odontogênicos
a. Cisto do ducto nasopalatino (canal incisivo)
b. Cisto globulomaxilar
c. Cisto nasolabial (nasoalveolar)

B. Inflamatórios

1. Cisto radicular

IV. Lesões não-classificadas

Vinte e um anos depois, em 1992, devido ao conhecimento adquirido quanto à embriologia oral e maxilofacial e a identificação de novas entidades tornou-se necessário a reclassificação de algumas dessas lesões. Sendo assim, uma segunda edição da classificação de TOs foi publicada pela OMS, sendo então intitulada Tipificação histológica dos tumores odontogênicos. Essa renovação da classificação permitiu a inclusão de novas neoplasias e outras lesões ósseas dos maxilares como o tumor odontogênico escamoso e o tumor odontogênico de células claras. Além das neoplasias, lesões "tumor-like" e cistos formados a partir do aparato odontogênico; foram incluídas nessa nova classificação algumas lesões dos maxilares com status ainda indefinido e outras que não eram neoplasias, mas que necessitavam ser 
diferenciadas dos tumores odontogênicos. Nessa edição, além de Kramer e Pindborg, o professor Mervyn Shear também aparece como autor (KRAMER; PINDBORG; SHEAR, 1992).

A segunda classificação da OMS considerou inicialmente o comportamento tumoral, subdividindo os TOs em lesões benignas e malignas. O grupo de lesões benignas era composto por lesões neoplásicas e outras não-neoplásicas. A subdivisão das lesões benignas foi baseada no tipo de tecido odontogênico envolvido: epitélio odontogênico sem ectomesênquima odontogênico; epitélio odontogênico com ectomesênquima odontogênico; e ectomesênquima odontogênico com ou sem epitélio odontogênico incluído.

\section{CLASSIFICAÇÃO HISTOLÓGICA DOS TUMORES ODONTOGÊNICOS CLASSIFICAÇÃO OMS (1992)}

I. Neoplasias e outros tumores relacionados ao aparato odontogênico

A. Benignos

1. Epitélio dontogênico sem ectomesênqima odontogênico
a. Ameloblastoma
b. Tumor odontogênico escamoso
c. Tumor odontogênico epitelial calcificante (Tumor de Pindborg)
d. Tumor odontogênico de células claras

2. Epitélio odontogênico com ectomesênquima odontogênico, com ou sem formação de tecido duro
a. Fibroma ameloblástico
b. Fibrodentinoma ameloblástico (dentinoma) e fibro-odontoma ameloblástico
c. Odontoameloblastoma
d. Tumor odontogênico adenomatóide (adenoameloblatoma)
e. Cisto odontogênico calcificante
f. Odontoma complexo
g. Odontoma composto

3. Ectomesênquima odontogênico com ou sem epitélio odontogênico incluído

a. Fibroma odontogênico

b. Mixoma (mixoma odontogênico, mixofibroma)

c. Cementoblastoma benigno (cementoblastoma, cementoblastoma verdadeiro)

B. Malignos

1. Carcinomas odontogênicos
a. Ameloblastoma maligno
b. Carcinoma intra-ósseo primário
c. Variantes malignas de outros tumores odontogênicos epiteliais
d. Alterações malignas em cistos odontogênicos 
2. Sarcomas odontogênicos

a. Fibrossarcoma ameloblástico (sarcoma ameloblástico)

b. Fibrodentinossarcoma ameloblástico ou fibro-odontossarcoma ameloblástico

c. Carcinossarcoma odontogênico

II. Neoplasias e outras lesões relacionadas com o osso

A. Neoplasias Osteogênicas

1. Fibroma cemento-ossificante (Fibroma cementossificante, fibroma ossificante)

B. Lesões ósseas não neoplásicas

1. Displasia fibrosa dos maxilares

2. Displasiaa cemento-ósseas

a. Displasia cementária periapical (displasia fibrosa periapical)

b. Displasia cemento-óssea florida (cementoma gigantiforme, cementomas

c. Outras displasias cemento-ósseas

3. Querubismo

4. Granuloma de células gigantes central

5. Cisto ósseo aneurismático

6. Cisto ósseo solitário (cisto ósseo traumático, simples, hemorrágico)

C. Outros tumores

1. Tumor neuroectodérmico melanótico da infância (progonoma melanótico)

III. Cistos epiteliais

A. De desenvolvimento

1. Odontogênicos

a. Cisto gengival da infância (Pérolas de Epstein)

b. Queratocisto odontogênico (Cisto primordial)

c. Cisto dentígero (folicular)

d. Cisto de erupção

e. Cisto periodontal lateral

f. Cisto gengival do adulto

g. Cisto odontogênico glandular, sialocisto odontogênico

2. Não odontogênicos

a. Cisto do ducto nasopalatino (canal incisivo)

c. Cisto nasolabial (nasoalveolar)

B. Inflamatórios

1. Cisto radicular

2. Cisto apical e lateral

3. Cisto residual

4. Cisto paradentário (colateral inflamatório, bucal infectado mandibular)

No ano 2000, a Agência Nacional de Pesquisa em Câncer (IARC), sediada em Lion na França, iniciou uma nova série de classificações de tumores baseada em critérios histopatológicos e genéticos, dentre as quais estava a classificação das lesões de cabeça e pescoço, incluindo os tumores odontogênicos, que culminaria mais tarde na criação de uma nova classificação de tumores odontogênicos da OMS. 
Em 2002, Philipsen e Reichart (PHILIPSEN; REICHART, 2002) apresentaram uma versão revisada da Classificação da OMS 1992 acrescentando novas informações a cerca da origem e das interações dos tecidos odontogênicos no desenvolvimento dos TOs, além de acrescentar descrições de novas entidades tumorais. Esse trabalho serviu como modelo para a nova classificação da OMS que estava em processo de definição.

O desenvolvimento de novas tecnologias em diagnóstico imunoistoquímico, biologia molecular e genética, assim como o seguimento clínico e epidemiológico de algumas das lesões incluídas nas edições anteriores da classificação de TOs da OMS, mostrou a necessidade de reclassificação de alguns dos tumores odontogênicos de acordo com a sua provável histogênese ou de acordo com seu comportamento biológico (MOSQUEDA-TAYLOR, 2008). Sendo assim, em 2003, após uma Conferência de Consenso Final a OMS produziu uma nova classificação para os tumores odontogênicos com a colaboração de inúmeros patologistas dos cinco continentes, chefiados pelo professor Peter Reichart, da Universidade de Berlim (BARNES et al., 2005).

Nessa nova classificação da OMS, publicada em 2005, diversas modificações foram realizadas, incluindo terminologia, classificação de lesões quanto a seu comportamento biológico e a designação de subgrupos relevantes. A exclusão dos cistos também foi uma importante alteração, sendo a nova classificação constituída apenas por TOs e lesões ósseas relacionadas (BARNES et al., 2005; REICHART; PHILIPSEN; SCIUBBA, 2006).

Enquanto nas antigas classificações da OMS a descrição dos tumores restringia-se aos aspectos microscópicos, essa última incluiu informações relevantes quanto à definição, epidemiologia, etiologia, localização, achados clínicos, imaginológicos, microscópicos, além de genética e prognóstico tumoral (BARNES et al., 2005; REICHART; PHILIPSEN; SCIUBBA, 2006). 


\section{CLASSIFICAÇÃO HISTOLÓGICA DOS TUMORES ODONTOGÊNICOS CLASSIFICAÇÃO OMS (2005)}

I. Tumores Malignos

A. Carcinomas odontogênicos

1. Ameloblastoma metastizante (maligno)

2. Carcinoma ameloblástico - tipo primário

3. Carcinoma ameloblástico - tipo secundário (indiferenciado) intra-ósseo

4. Carcinoma ameloblástico - tipo secundário (indiferenciado) periférico

5. Carcinoma de células escamosas intra-ósseo primário - tipo sólido

6. Carcinoma de células escamosas intra-ósseo primário derivado de tumor

7. Carcinoma de células escamosas intra-ósseo primário derivado de cistos

8. Carcinoma odontogênico de células claras

9. Carcinoma odontogênico de células fantasmas

B. Sarcomas odontogênicos

1. Fibrossarcoma ameloblástico

2. Fibro-odontossarcoma ou fibrodentinossarcoma ameloblástico

II. Tumores Benignos

A. Epitélio odontogênico com estroma fibroso maduro, sem ectomesênquima odontogênico

1. Ameloblastoma sólido - tipo multicístico

2. Ameloblastoma extra-ósseo - tipo periférico

3. Ameloblastoma tipo desmoplásico

4. Ameloblastoma tipo unicístico

5. Tumor odontogênico escamoso

6. Tumor odontogênico epitelial calcificante

7. Tumor odontogênico adenomatóide

8. Tumor odontogênico queratocístico

B. Epitélio odontogênico com ectomesênquima odontogênico, com ou sem formação de

1. Fibroma ameloblástico

2. Fibrodentinoma ameloblástico

3. Fibro-odontoma ameloblástico

4. Odontoma

a. Odontoma tipo complexo

b. Odontoma tipo composto

5. Odontoameloblastoma

6. Tumor odontogênico cístico calcificante

7. Tumor dentinogênico de células fantasmas

C. Mesênquima ou ectomesênquima odontogênico com ou sem epitélio odontogênico

1. Fibroma odontogênico

2. Mixoma odontogênico - Mixofibroma

3. Cementoblastoma 
III. Lesões ósseas relacionadas

1. Fibroma ossificante

2. Displasia fibrosa

3. Displasias ósseas

4. Lesão de células gigantes central (Granuloma)

5. Querubismo

6. Cisto ósseo aneurismático

7. Cisto ósseo simples

IV. Outros Tumores

1. Tumor neuroectodérmico melanótico da infância

\subsection{ESTUDOS EPIDEMIOLÓGICOS}

Os tumores odontogênicos são lesões muito infreqüentes quando comparadas com outros processos patológicos diagnosticados nos ossos maxilares. Entretanto, estudos epidemiológicos vêm sendo realizados em todo o mundo com o intuito de determinar mais precisamente a ocorrência dessas lesões nas mais diversas populações, de caracterizar o comportamento das mesmas, além de estabelecer as possíveis causas que levem ao desenvolvimento desses tumores (MOSQUEDA-TAYLOR, 2008; ORTEGA et al., 2007).

No presente estudo procuramos avaliar a distribuição dos diversos tipos de tumores odontogênicos, agrupando a literatura por blocos constituídos por continentes (Ásia, África, Europa, Américas e Oceania), traçando na medida do possível, um perfil comparativo dos aspectos demográficos, quanto às possíveis diferenças e similitudes regionais. 


\subsubsection{AMÉRICAS}

Dentre os estudos sobre prevalência de lesões bucais realizados na América destaca-se o de Bhaskar (1968) que avaliou 20.575 biópsias realizadas em consultórios odontológicos a fim de determinar a freqüência e o tipo de lesões detectadas, diagnosticadas e tratadas por cirurgiões-dentistas nos Estados Unidos da América (BHASKAR, 1968). Destas, 429 lesões (2,37\%) compunham o grupo de tumores odontogênicos, dos quais, 98 eram fibromas odontogênicos (23\%), 78 ameloblastomas (18\%), 46 cementomas (11\%), 43 odontomas compostos (10\%), 31 odontomas não classificados (7\%) e 30 odontomas císticos (7\%). O autor não especificou a classificação utilizada para determinar os tipos de tumores odontogênicos diagnosticados.

Em 1978, Regezi, Kerr e Courtney, baseando-se na primeira classificação de tumores odontogênicos publicada pela OMS (PINDBORG; KRAMER, 1972), avaliaram o material anatomopatológico submetido ao Serviço de Patologia Bucal, University of Michigan no período de 1934 a 1975. Em um total de 54.534 biópsias, foram diagnosticados 706 casos de tumores odontogênicos $(1,3 \%)$, dentre os quais foram mais freqüentes os odontomas compostos (259 - 37\%) e complexos (214 $30 \%$ ), somando mais de $65 \%$ da amostra, os ameloblastomas (71 - 11\%), os tumores odontogênicos adenomatóides (22 - 3\%) e os mixomas odontogênicos. O autor considerou em seu estudo o fibroma cementificante e a displasia cementária periapical, lesões essas que não eram classificadas como TOs, mas como lesões ósseas relacionadas ao osso.

Outro importante estudo a respeito da incidência de tumores odontogênicos, cistos odontogênicos e cisto não odontogênicos foi realizado por Daley, Wysocki e Pringle, em London no Canadá (DALEY; WYSOCKI; PRINGLE, 1994). Os autores avaliaram 40.000 biópsias dos arquivos do Serviço de Patologia Bucal, University of Western Ontário, diagnosticadas entre 1967 e 1993 e encontraram 204 odontomas (51,5\%), 79 ameloblastomas (13,5\%), 36 fibromas odontogênicos periféricos (9\%) e 25 fibromas odontogênicos centrais (4,8\%). Segundo o autor, a comparação de seus achados com os demais estudos existentes na época era indevida visto que, a maior 
parte desses trabalhos avaliou um número muito limitado de lesões ou eram demasiado antigos.

Nesse estudo (DALEY; WYSOCKI; PRINGLE, 1994), Daley e colaboradores reclassificaram os casos diagnosticados antes de 1976 utilizando critérios de classificação descritos por diferentes autores para diferentes lesões, não seguindo os critérios estabelecidos pela OMS (PINDBORG; KRAMER, 1972). Entretanto, os mesmos foram extremamente criteriosos ao incluir e excluir as amostras em seu trabalho, tornando-o uma contribuição válida e representativa quanto à prevalência dos TOs.

Para Regezi et al. (1978) e Daley et al. (1994), o conhecimento da prevalência dos diversos TOs e de suas características clínicas seria extremamente útil aos clínicos e patologistas para determinação de diferentes diagnósticos diferenciais. Além disso, essas informações poderiam fornecer indícios que auxiliariam na definição de possíveis agentes causais que levassem ao desenvolvimento desses tumores.

Mosqueda-Taylor et al. (MOSQUEDA-TAYLOR et al., 1997) realizaram um estudo retrospectivo colaborativo, no qual avaliaram a incidência de TOs em quatro centros de diagnóstico histopatológico da Cidade do México (Departamento de Patologia Bucal da Faculdade de Odontologia, Universidad Nacional Autónoma de Mexico; Laboratório de Patologia Bucal, Universidad Autónoma Metropolitana Xochimilco; Laboratório Peribact, um serviço privado de diagnóstico,e o Departamento de Patologia do Instituto Nacional de Cancerologia). Todas as lesões foram avaliadas e reclassificadas segundo a Classificação de TOs da OMS publicada em 1992 (KRAMER; PINDBORG; SHEAR, 1992).

Nesse estudo foram diagnosticados um total de 349 TOs, dos quais 121 eram odontomas (34,6\%), 83 ameloblastomas (23,7\%), 62 mixomas odontogênicos $(17,7 \%)$ e 25 tumores odontogênicos adenomatóides (7,1\%). Entretanto, esses achados não refletiram a freqüência relativa real dos tumores nos diferentes serviços de diagnóstico envolvidos no estudo, o que tornou clara a dificuldade em estabelecer uma correlação entre as prevalências dos tumores em serviços de anatomia patológica de natureza distinta, ou seja, escola, hospital ou laboratório de referência (MOSQUEDA-TAYLOR et al., 1997). 
Através desses estudos ficou claro que os odontomas eram as lesões mais prevalentes na América do Norte e que esses resultados poderiam refletir reais variações geográficas, uma vez que nos estudos realizadas na África e na Ásia o ameloblastoma sempre foi a lesão mais prevalentes (WU e CHAN, 1985; LU et al., 1998; JING et al., 2007; OKADA et al., 2007; SRIRAM e SHETTY, 2008; LUO e LI, 2008; MOSADOMI, 1975; ODUKOYA, 1995; AROTIBA, 1997; ADEBAYO et al., 2005).

No Brasil, Santos e colaboradores (2001) avaliaram a prevalência dos TOs no Rio Grande do Norte, através da análise dos Arquivos do Laboratório de Patologia Oral da Universidade Federal do Rio Grande do Norte, baseando-se na segunda Classificação de TOs da OMS (KRAMER; PINDBORG; SHEAR, 1992). Os autores encontraram 127 casos de TOs os quais representavam 2,4\% de todas as biópsias bucais diagnosticadas no período de 1970 a 1999. Dentre as lesões mais prevalentes estavam os odontomas (64 - 50\%), ameloblastomas (39 - 31\%), tumores odontogênicos adenomatóides (11 - 6,7\%) e mixomas odontogênicos (6 - 4,7\%). Para os autores, as diferenças observadas no estudo em relação a essas prevalências quando comparado aos demais trabalhos publicados na literatura estaria relacionada a variações geográficas.

Ainda na América do Sul, Ochsenius et al. (2002) revisaram 28.041 casos diagnosticados pelo Serviço de Patologia Bucal do Instituto de Referência da Universidade do Chile, diagnosticados no período de 1975 a 2000. Neste caso, as lesões mais freqüentes foram os odontomas (162 - 45\%), os ameloblastomas (74 20\%), os mixomas (32 - 9\%) e os cistos odontogênicos calcificantes (26 - 7,25), achados que se assemelhavam aos resultados de outros estudos realizados na América e diferiam daqueles estudos realizados na África e Ásia. Segundo os autores, estudos epidemiológicos realizados em populações com diferenças étnicas, complementados com pesquisas básicas, seriam ferramentas úteis para o entendimento dos TOs.

Em 2005, Fernandes et al. analisaram 19.123 amostras de biópsias bucais diagnosticadas no período de 1954 a 2004 no Serviço de Patologia Bucal da Faculdade de Odontologia da Universidade Federal de Minas Gerais, Brasil, Centro de Referência em Patologia Bucal e Maxilofacial. Dentre essas lesões foram diagnosticados 340 TOs (1,8\%), sendo 154 ameloblastomas (45,3\%), 85 odontomas 
(25\%), 31 mixomas odontogênicos (9,1\%) e 13 tumores odontogêncios adenomatóides $(3,8 \%)$. Todos os casos foram reavaliados e reclassificados pelos autores baseando-se na segunda Classificação de TOs da OMS (KRAMER; PINDBORG; SHEAR, 1992).

No ano seguinte, Buchner e colaboradores (BUCHNER; MERRELL; CARPENTER, 2006b, 2006a) avaliaram a incidência dos TOs centrais e periféricos na Carolina do Norte, baseando-se ainda na segunda classificação da OMS (KRAMER; PINDBORG; SHEAR, 1992). Em seus estudos foram avaliados 91.178 casos do Laboratório de Patologia Bucal da Faculdade de Odontologia de São Francisco, Universidade do Pacífico - CA, dos quais 1.088 eram TOs centrais $(1,2 \%)$ e 45 eram TOs periféricos (0,05\%).

Dentre os TOs centrais, as lesões mais prevalentes foram os odontomas (826 - 76\%), seguidos pelos ameloblastomas (127 - 12\%) e mixomas (24 - 2,2\%). Segundo os autores, esses achados só poderiam ser comparados aos resultados encontrados em estudos realizados em países Ocidentais, como Estados Unidos, México e Brasil, visto que nos países Orientais como África, China e Índia a maior parte dos TOs não eram tratados, não sendo por isso contabilizados neste tipo de estudo (BUCHNER; MERRELL; CARPENTER, 2006b).

O último estudo sobre a incidência dos TOs realizado no Brasil foi desenvolvido pela equipe da Universidade Federal de Pernambuco (AVELAR et al., 2008), estudo no qual os autores avaliaram as amostras diagnosticadas no Serviço de Patologia Bucal dessa Universidade no período de 1992 a 2005. Os autores basearam-se na última classificação OMS (BARNES et al., 2005), e só incluíram os casos que pudessem ter seu diagnóstico revisto e reclassificado.

Avelar et al. (2008), encontraram um total de 238 TOs, sendo o tumor odontogênico queratocístico a lesão mais freqüente (20 - 29\%). Para os autores, a inclusão do tumor odontogênico queratocístico no grupo dos TOs dificultou a comparação de seu estudo com outros anteriormente publicados, visto que não se basearam nos mesmos critérios de classificação de TOs. 


\subsubsection{EUROPA}

Na Europa, Günhan et al. (1990) avaliaram a prevalência de TOs na Turquia, a partir da análise do material proveniente dos Serviços de Patologia de quatro universidades: Universidade de Istambul, Universidade de Hacettepe, Academia Medica Militar de Gülhane e Universidade de Ankara. Os autores contabilizaram um total de 409 casos, dos quais 149 eram ameloblastomas (36,5\%), 74 odontomas (18\%), 62 cementomas (15\%) e 51 mixomas odontogênicos (12,5\%). Segundo eles, as aparentes diferenças na incidência dessas lesões poderiam ser atribuídas a não utilização de critérios universalmente aceitos para a realização do diagnóstico das mesmas.

Em 1998, Stypulkowska avaliou os dados de 164 casos admitidos no Departamento de Cirurgia Bucal e Maxilofacial, Jagiellonian University College of Medicine, entre 1956 e 1996. Desses casos, 60 eram ameloblastomas, 13 odontomas e 12 mixomas odontogênicos. Assim como os demais trabalhos que se seguem, o autor se baseou na segunda classificação da OMS, incluindo em sua amostra casos de granuloma central de células gigantes.

Através de um estudo retrospectivo colaborativo Tamme et al. (2004) avaliaram a prevalência de TOs na Estônia. O material analisado foi obtido dos Departamentos de Cirurgia e Patologia Maxilofacial do Hospital Universitário de Tartu e do Hospital de Mustamäe. Setenta e cinco casos de TOs (0,74\%) foram obtidos a partir de um total de 10.141 biópsias bucais, sendo mais prevalentes os odontomas (26 - 34,6\%), seguidos pelos ameloblastomas (19 - 25,3\%), fibromas ameloblásticos (12 - 16\%) e mixomas odontogênicos (9 - 12\%). Uma vez que todos os casos de TOs da Estônia eram tratados em um dos dois centros de referência estudados, os autores afirmaram que seus achados eram extremamente relevantes quanto a prevalência real dessas lesões, particularmente dos odontomas (TAMME et al., 2004).

Em 2006, Olgac, Koseoglu e Aksakalli, apresentaram um estudo em que avaliaram a prevalência de TOs a partir dos arquivos do Departamento de Patologia Tumoral do Instituto de Oncologia da Universidade de Istambul, na Turquia. Os 
autores encontraram um total de 527 casos de TOs (0,84\%) entre 62.565 biópsias de tumores. Dentre esses casos 133 eram ameloblastomas (25\%), 109 odontomas (21\%) 83 mixomas odontogênicos (165) e 52 fibromas odontogênicos (9,9\%).

O único trabalho realizado na Europa que usou como referência a última classificação da OMS foi o realizado por Tomás em 2007. Em seu estudo o autor revê seus arquivos, descreve todos os tumores de acordo com a nova classificação da OMS e revela que a lesão mais freqüentemente encontrada foi o odontoma, seguido pelo ameloblastoma e mixoma odontogênico. Entretanto, o autor não faz inferência quanto à prevalência do tumor odontogênico queratocístico.

\subsection{3 ÁSIA}

Assim como no resto do mundo, alguns estudos sobre prevalência de TOs foram realizados na Ásia. Jain e Kherdekar (1980) avaliaram os arquivos do Departamento de Patologia da Faculdade de Medicina do Governo em Nagpur, Índia, nos quais diagnosticaram 37 casos de TOs $(1,4 \%)$ dentre 2.545 biópsias de lesões bucais. Os autores utilizaram como critérios para classificação dessas lesões aqueles estabelecidos pela OMS em sua primeira Classificação de tumores odontogênicos, cistos dos maxilares e lesões afins (PINDBORG; KRAMER, 1972). Os ameloblastomas representaram $66,2 \%$ das lesões.

Na China Wu e Chan (1985), seguindo os mesmos critérios de classificação de TOs da OMS, avaliaram a prevalência desses tumores através da revisão dos espécimes do Departamento de Patologia da Universidade de Hong Kong, diagnosticados no período de 1963 a 1982. Os TOs representaram 17\% de todos os tumores e cistos dos maxilares, $15 \%$ de todos os tumores bucais e $0.04 \%$ de todas as biópsias avaliadas neste laboratório. Dentre as lesões mais prevalentes estavam os ameloblastomas $(51-62,2 \%)$, cementomas $(16-19,5 \%)$ e odontomas (5 $6,1 \%)$ 
Outro importante estudo realizado na China foi o de Lu et al. (1998) no qual foram recuperados 759 casos de TOs diagnosticados nos Departamentos de Patologia Bucal e Cirurgia Bucomaxilo Facial da Universidade de Ciências Médicas da China Ocidental. Esses casos foram diagnosticados no período de 1952 a 1994 e reclassificados pelos pesquisadores de acordo com a segunda Classificação da OMS (KRAMER; PINDBORG; SHEAR, 1992). No grupo de lesões mais prevalentes destacaram-se os ameloblastomas (445 - 58,6\%), os mixomas odontogênicos (64 $8,4 \%)$, os tumores odontogênicos adenomatóides (63 - 8,3\%) e os odontomas (51 $6,7 \%)$. Alta prevalência de ameloblastomas semelhante aquela apresentada por $\mathrm{Wu}$ e Chan (1985).

Outro estudo foi realizado na China por Jing et al. em 2007. Os autores avaliaram a prevalência de TOs nos arquivos da Faculdade de Estomatologia da Universidade de Sichuam, China Ocidental e encontraram 1642 TOs, casos diagnosticados no período de 1952 a 2004. Os autores observaram alta prevalência de ameloblastomas (661 - 40,3\%), tumores odontogênicos queratocísticos (588 $35,8 \%)$, odontomas (78 - 4,7\%) e mixomas odontogênicos (76-4,6\%).

No estudo de Jing et al. (2007) todos os tumores foram reavaliados e reclassificados segundo a última Classificação da OMS publicada em 2005 (BARNES et al., 2005), o que levou a uma modificação no panorama de prevalências de tumores, principalmente devido a inclusão do queratocisto odontogênico como um tumor.

Os estudos de Okada, Yamamoto e Tilakaratne (2007) e Sriram e Shetty (2007) também avaliaram a prevalência de TOs em países da Ásia e foram publicados em 2007. Entretanto, ambos basearam-se na Classificação de TOs publicada em 1992, não incluindo os tumores odontogênicos queratocísticos em suas amostras.

Okada, Yamamoto e Tilakaratne (2007) considerou a inclusão do queratocisto odontogênico no grupo de TOs uma medida precoce tomada pela OMS na sua terceira classificação. Assim, o autor encontrou em seu estudo 157 ameloblastomas (69,5\%), 21 tumores odontogênicos adenomatóides (9,3\%), 11 mixomas odontogênicos $(4,9 \%)$ e 10 odontomas (4,4\%). Para os autores eram necessárias 
maiores comprovações científicas que permitissem essa nova classificação do queratocisto odontogênico como um tumor.

Sriram e Shetty (2008) avaliaram a prevalência de TOs na Índia, a partir dos registros do Departamento de Patologia Bucal do Hospital Universitário de Nair, em Mumbai, referentes aos anos de 1971 a 2006. Os diagnósticos foram revisados e reclassificados, e os pesquisadores encontraram 250 tumores odontogênicos, sendo os mais freqüentes o ameloblastoma (154 - 61,6\%), seguido pelo tumor odontogênico adenomatóide (31 - 12,4\%), odontoma (15 - 6\%) e mixoma odontogênico (15-6\%).

Em 2009, Luo e Li apresentaram um estudo realizado na China no qual foram avaliados e reclassificados 1309 casos de TOs diagnosticados no período de 1985 a 2006 no Departamento de Patologia Bucal da Faculdade e Hospital de Estomatologia da Universidade de Pequin. Essas lesões representaram 8,99\% de todas as biópsias bucais enviadas para o Serviço. Assim como Jing et al., os autores encontraram alta prevalência de tumores odontogênicos queratocísticos (507 $38,7 \%)$, ameloblastomas (478 - 36,5\%), odontomas $(80-6,1 \%)$ e mixomas odontogênicos (34-2,6\%). Entretanto, a alta prevalência de TOs malignos (78- 6\%) foi um achado particular desse estudo, que difere daqueles anteriormente apresentados na literatura. Para os autores, o papel de fatores genéticos e ambientais no desenvolvimento dessas lesões necessita ser mais amplamente estudado.

\subsection{4 ÁFRICA}

Alguns estudos foram realizados na África a fim de avaliar a prevalência de tumores dos maxilares na população, gerando a idéia de que certos tumores odontogênicos seriam mais prevalentes nessa população do que em outros países no resto do mundo (DODGE, 1965; KOVI; LAING, 1966) e correlacionando essa maior prevalência a fatores raciais, uma vez que em países ocidentais como os 
Estados Unidos da América, Canadá, México, Chile e Brasil os odontomas seriam mais prevalentes (BUCHNER; MERRELL; CARPENTER, 2006b; DALEY; WYSOCKI; PRINGLE, 1994; MOSQUEDA-TAYLOR et al., 1997; OCHSENIUS et al., 2002; REGEZI; KERR; COURTNEY, 1978; SANTOS et al., 2001).

Dodge em 1965 realizou um estudo que falou em favor dessa teoria uma vez que diagnosticou 26 casos de tumores odontogênicos, dos quais 24 eram ameloblastomas e 2 fibromas ameloblásticos, através da análise da prevalência de tumores dos maxilares a partir dos arquivos do Centro de Registros de Câncer de Kampala (1952-1961) e dos casos do Laboratório de Patologia do Serviço Médico do Governo de Uganda (1947-1961). Da mesma forma, no ano seguinte, Kovi e Laing (1966) avaliaram os arquivos de Hospital Korle Bu de Acra, em Ghana e também encontraram um número significativo de ameloblastomas (20 casos). Em ambos os estudos, o objetivo principal era avaliar a prevalência de todos os tumores dos maxilares. Entretanto, os autores puderam constatar que os tumores odontogênicos, particularmente os ameloblastomas, representavam um número significante dessas lesões.

A maior parte dos estudos realizados na África que visavam avaliar especificamente a prevalência de TOs, foi desenvolvida na Nigéria, sendo que alguns deles basearam-se na mesma fonte de casos, o Hospital Escola Universitário de Lagos, cidade localizada na porção sudoeste do país. O que era diferente nesses estudos era o período de duração dos mesmos, como pode ser visto nos trabalhos de Mosadomi (1975) e Odukoya (1995).

Mosadomi (1975) analisou os casos de pacientes tratados no período de 1969 a 1974. Em seu estudo foram diagnosticados 19 ameloblastoma (65,5\%), 2 odontomas (6,9\%), 2 fibromas ameloblásticos (6,9\%), 2 tumores odontogênicos adenomatóides (6,9\%), 2 cementomas (6,9\%), 1 fibro-odontoma ameloblástico $(3,45 \%)$ e 1 cisto odontogênico calcificante (3,45\%). Para o autor, a prevalência dos tumores, particularmente do ameloblastoma, não podia ser realmente comparada a outros estudos, uma vez que os critérios de análise em cada um deles era muito diferente. Neste caso o autor havia se baseado na primeira Classificação da OMS (PINDBORG; KRAMER, 1972). Além disso, a idéia de que haveria uma maior incidência dos ameloblastomas em pacientes africanos não podia ser comprovada, devido a limitações encontradas na aquisição de dados epidemiológicos. 
Para Anand et al. (1967) a maior incidência aparente dos ameloblastomas na África seria na verdade resultado de um fenômeno conhecido como "Harvesting phenomenon", ou seja, tumores não tratados que têm crescimento lento e raramente ameaçam a vida, acabam por acumular-se durante anos por falta de doutores e centros de saúde, e criam um contingente de casos que se apresentam conjuntamente quando da criação de novos centros de tratamento, transmitindo uma falsa impressão de alta freqüência.

Vinte anos depois Odukoya (1995) realizou um estudo no mesmo Hospital Escola, a partir de uma amostra maior de casos, que foram acompanhados por um período mais longo de tempo, de 1971 a 1991. Odukoya avaliou todas as bióspsias do Departamento de Biologia e Patologia Bucal, das quais 289 eram TOs (19\%). O ameloblastoma, que correspondeu a $58,5 \%$ da amostra, foi o tumor mais prevalente seguido pelos mixomas odontogênicos (34 - 11,8\%) e tumores odontogênicos adenomatóides $(18$ - 6,2\%). Um achado importante foi a alta prevalência de carcinomas odontogênicos, compreendendo 5\% dos TOs. Neste trabalho e em todos os que se seguem, os critérios utilizados na classificação das lesões foram aqueles estabelecidos na segunda Classificação da OMS (KRAMER; PINDBORG; SHEAR, 1992).

Chidzonga, Lopez e Alverez (1996) avaliaram a prevalência dos TOs no Zimbábue, através da análise dos casos diagnosticados em um período de 10 anos, no Departamento de Cirurgia Bucal e Maxilofacial do Hospital Central de Harare. Os TOs, representaram 8,6\% das 1723 biópsias revisadas, prevalência muitas vezes maior do que aquela apresentada na maior parte dos outros estudos publicados na literatura.

No ano seguinte, a equipe de Arotiba (AROTIBA; OGUNBIYI; OBIECHINA, 1997) participou de um estudo sobre a incidência de TOs no Hospital Escola Universitário de Ibadan, região sudoeste da Nigéria. Foram revisados os arquivos do Departamento de Cirurgia Bucal e Maxilofacial e do Departamento de Patologia Bucal e os registros de câncer do Hospital de 1980 a 1994, contabilizando um total de 131 casos de TOs dos 423 tumores registrados. O ameloblastoma foi a lesão mais prevalente (76 casos), representando 59\% dos TOs, corroborando para os achados anteriormente relatados na literatura (DODGE, 1965; KOVI; LAING, 1966; MOSADOMI, 1975; ODUKOYA, 1995). 
Em 2004, baseados na mesma amostra dos estudos realizados por Mosadomi (1975) e por Odukoya (1995), Adebiyi, Odukoya e Taiwo avaliaram a prevalência dos tumores odontogênicos ectodermais. Mais uma vez o ameloblastoma foi a lesão mais prevalente contabilizando um total de 182 casos (92,3\%), o que segundo o autor poderia ser justificado pelas numerosas fontes de epitélio que dariam origem a essa lesão. Da mesma maneira, Ladeinde et al. (2005) encontraram uma maior prevalência de ameloblastomas, entre os TOs diagnosticados nos Departamentos de Cirurgia Bucal e Maxilofacial e de Biologia e Patologia Bucal do Hospital escola Universitário de Lagos.

Outro estudo realizado, agora por um grupo de pesquisadores (ADEBAYO; AJIKE; ADEKEYE, 2005) do Hospital Escola Universitário Ahmadu Bello, em Kaduna, no norte da Nigéria, baseou-se nos casos diagnosticados na Unidade Maxilofacial. Os autores encontraram uma alta prevalência de ameloblastomas (233 casos - 73,3\%) entre os TOs, maior do que aquela observada nos estudos realizados no sudeste do país. Para o autor, provavelmente estudos genéticos auxiliariam a elucidar o porquê das persistentes altas prevalências de ameloblastomas entre os africanos.

No único estudo prospectivo realizado na África (SIMON et al., 2005) o ameloblastoma foi mais uma vez a lesão mais prevalente entre os TOs. Entretanto, para os autores as aparentes altas freqüências dos ameloblastomas nos países de terceiro mundo poderiam indicar que os pacientes têm buscado auxilio quando as lesões causam sintomas incapacitantes, que haveria atraso no diagnóstico nos centros primário de atendimento por falta de capacitação dos profissionais e ainda, que haveria dificuldade na realização de pesquisas na área (SIMON et al., 2005).

Avaliando os estudos sobre prevalência de tumores odontogênicos alguns pontos falhos que podem interferir na pesquisa ficaram evidentes: (1) pacientes com tumores odontogênicos podem não ser encaminhados para os centros de tratamento de referência, (2) pacientes referidos a centros especializados de diagnóstico podem recusar-se a realizar os exames e por isso não serem submetidos a tratamento, (3) alguns pacientes podem não ter recursos para custear seu tratamento, (4) em alguns casos o diagnóstico pode não ter sido definido por falhas técnicas no processamento (SIMON et al., 2005). 
3 Proposicão 


\section{PROPOSIÇÃO}

A proposta deste estudo foi determinar a prevalência dos tumores odontogênicos diagnosticados nos Serviços de Anatomia Patológica das Faculdades de Odontologia de Bauru (USP) e de Araçatuba (UNESP) no Brasil, e das Faculdades de Odontologia da UNAM, da UAM-X e do Laboratório privado Peribact no México, compará-las e definir um perfil da ocorrência desses tumores nessas instituições e países seguindo a nova Classificação da Organização Mundial de Saúde (2005). 
4 Casuistica e Métodos 


\section{CASUÍSTICA E MÉTODOS}

\subsection{AMOSTRAGEM}

Os casos diagnosticados como tumores e cistos odontogênicos passíveis de reanálise diagnóstica foram selecionados dos arquivos dos Serviços de Anatomia Patológica Bucal de cinco centros de diagnóstico, dois no Brasil: Faculdade de Odontologia de Bauru - Universidade de São Paulo (FOB-USP), Faculdade de Odontologia de Araçatuba - Universidade Estadual Paulista (FOA-UNESP), e três no México: Faculdade de Odontologia da Universidade Nacional Autônoma do México (FO-UNAM), Faculdade de Odontologia da Universidade Autônoma Metropolitana Xochimilco (FO-UAMX) e Laboratório Peribact.

A amostragem obedeceu aos seguintes critérios de inclusão:

* Cortes microscópicos com coloração em HE (hematoxila e eosina) preservada, lamínulas e lâminas sem fraturas ou bolhas, assim como ausência de artefatos de técnica permitindo análise criteriosa.

* A inclusão seguiu à ordem cronológica retrospectiva de entrada nos registros até o ano de 2006, iniciando em diferentes anos em cada serviço como pode ser observado na Tabela 1.

Tabela 1 - Instituições envolvidas no estudo e período de estudo

\begin{tabular}{ccc}
\hline \hline Instituição & Período de estudo & Total \\
\hline FOB-USP & $1963-2006$ & 44 anos \\
FOA-UNESP & $1964-2006$ & 43 anos \\
FO-UNAM & $1959-2006$ & 48 anos \\
FO-UAMX & $1979-2006$ & 28 anos \\
Peribact & $1989-2006$ & 18 anos \\
\hline \hline
\end{tabular}

Casos que não apresentavam lâminas adequadas no momento da seleção, mas que possuíssem blocos de parafina com a superfície de corte preservada e livre de qualquer tipo de contaminação ou dano, além de material suficiente para 
novos cortes. Nestes casos, novos cortes foram realizados e novas lâminas foram confeccionadas e incluídas na amostra.

\subsection{DADOS DEMOGRÁFICOS E ASPECTO CLÍNICO}

Os dados demográficos como identificação do paciente, gênero e idade e os aspectos clínicos de cada lesão foram obtidos a partir dos laudos e das fichas de requisição de exame anatomopatológico. Todos os dados foram organizados em tabelas semelhantes ao modelo em anexo (Anexo A).

As lesões foram avaliadas quanto a sua localização, determinando o envolvimento mandibular ou maxilar. Os ossos maxilares foram divididos em região anterior, de canino a canino e posterior, de primeiro pré-molar a molar, considerando-se também ângulo e ramo mandibular.

\subsection{CRITÉRIOS MICROSCÓPICOS UTILIZADOS PARA O DIAGNÓSTICO}

Como critérios microscópicos utilizados para diagnosticar as lesões reanálisadas foram utilizados aqueles definidos pela nova Classificação de Tumores Odontogênicos publicada pela OMS no ano de 2005 (BARNES et al., 2005).

Todas as lesões foram microscopicamente analisadas por um examinador previamente calibrado e os casos que apresentaram diagnóstico divergente daquele emitido no laudo inicial foram examinados por um segundo patologista bucal, a fim de definir o correto diagnóstico.

Em todas as instituições foram utilizados microscópios de luz marcas e modelos citados na Tabela 2. 
Tabela 2 - Marcas e modelos de microscópios utilizados no trabalho

\begin{tabular}{cc}
\hline \hline Marcas & Modelos \\
\hline Leica & DMLS \\
Olympus & CHS-2 \\
Zeiss & Primo Star \\
\hline \hline
\end{tabular}

\subsection{COMITÊ DE ÉTICA EM PESQUISA (CEP)}

Este trabalho foi realizado após aprovação no Comitê de Ética em Pesquisa da Faculdade de Odontologia de Bauru - USP, em reunião realizada no dia 26 de fevereiro de 2008, sob o número 05/2008. Por tratar-se de um projeto de Cooperação Estrangeira, o mesmo foi encaminhado ao Comitê Nacional de Ética em Pesquisa - CONEP e recebeu parecer favorável (PARECER: 968/2007) - (Anexos B e C). 
5 Resultados 


\section{RESULTADOS}

Avaliando os registros dos casos diagnosticados como tumores e cistos odontogênicos selecionados dos arquivos dos Serviços de Anatomia Patológica Bucal dos cinco Centros de Diagnóstico envolvidos no estudo, dois no Brasil: Faculdade de Odontologia de Bauru - Universidade de São Paulo (FOB-USP), Faculdade de Odontologia de Araçatuba - Universidade Estadual Paulista (FOAUNESP), e três no México: Faculdade de Odontologia da Universidade Nacional Autônoma do México (FO-UNAM), Faculdade de Odontologia da Universidade Autônoma Metropolitana - Xochimilco (FO-UAMX) e Laboratório Peribact, um total de 2056 casos foram reclassificados.

Os anos e o número de casos avaliados em cada uma das instituições variaram de acordo com o tempo de existência do serviço como pode ser visto na Tabela 3.

Tabela 3 - Instituições, tempos de estudo e total de casos

\begin{tabular}{lllll}
\hline \hline Instituição & Tempo de estudo & Número de TOs & Total de biópsias & $\%$ \\
\hline FOB-USP & $1963-2006$ & 543 & 21.601 & 2,51 \\
FOA-UNESP & $1963-2006$ & 260 & 22.056 & 1,18 \\
FO-UNAM & $1959-2006$ & 500 & 16.816 & 2,97 \\
FO-UAMX & $1979-2006$ & 335 & 7.595 & 4,41 \\
Peribact & $1989-2006$ & 418 & 6.203 & 6,74 \\
\hline TOTAL & 2056 & 74.271 & 2,77 \\
\hline \hline
\end{tabular}

Desses 2.056 casos de TOs, 2.043 (99,37\%) eram benignos e 13 (0,63\%) malignos. Foi incluído no estudo um caso de queratoameloblastoma, três tumores odontogênicos não classificados, que apesar de serem nitidamente de origem odontogênica, não se enquadravam em nenhum dos tipos estabelecidos pela OMS e dois tumores odontogênicos combinados, que apresentavam aspectos de múltiplos tumores (Tabela 4). 
Tabela 4 - Casos estudados

\begin{tabular}{lll}
\hline \hline Tumores & Número de casos & $\%$ \\
\hline Tumores Benignos & 2.043 & $99,37 \%$ \\
Classificados & 2.037 & 99,71 \\
Tumores odontogênicos combinados & 2 & 0,09 \\
Queratoameloblastoma & 1 & 0,05 \\
Não classificados & 3 & 0,15 \\
Tumores malignos & 13 & 0,63 \\
\hline TOTAL & 2056 & 100 \\
\hline \hline
\end{tabular}

Para facilitar a compreensão e organização, os resultados foram separados de acordo com o país e as Instituições envolvidas. Além disso, em cada uma das Instituições, os dados foram separados de acordo com o tipo de tumor.

\subsection{BRASIL}

Dentre os 43.657 casos diagnosticados nos Serviços de Anatomia Patológica Bucal da FOB-USP e FOA - UNESP, 803 casos $(1,84 \%)$ foram classificados como TOs em nosso estudo. Desses, 800 eram benignos $(99,63 \%)$ e 3 eram malignos $(0,37 \%)$.

A lesão benigna mais freqüente foi tumor odontogênico queratocístico (TOQ 299 - 37,24\%), seguido pelos odontomas (OD 190 - 23,66\%), ameloblastomas (AME 132 - 16,43\%), mixomas (MIX $43-5,36 \%$ ) e tumores odontogênicos císticos calcificantes (TOCC 42 - 5,23\%). Ainda foram encontrados 24 fibromas odontogênicos periféricos (FOP - 2,99\%), 17 tumores odontogênicos adenomatóides (TOA - 2,12\%), 15 cementoblastomas (CEM - 1,87\%), 9 fibromas ameloblásticos (FA - 1,12\%), 8 fibromas odontogênicos centrais (FOC - 1\%), 6 tumores odontogênicos epiteliais calcificantes (TOEC - 0,75\%), 5 tumores dentinogênicos de células fantasmas (TDCF - 0,62\%), 4 fibro-odontomas ameloblásticos (FOA - 0,5\%), 4 fibrodentinomas ameloblásticos (FDA - 0,5\%), 1 tumor odontogênico escamoso (TOE - 0,12\%) e 1 tumor odontogênico não 
classificado (TONC - 0,12\%). Todos os tumores odontogênicos malignos eram carcinomas odontogênicos de células claras (COCC - 0,37\%) (Tabela 5).

\section{TUMORES BENIGNOS}

EPITÉLIO ODONTOGÊNICO COM ESTROMA FIBROSO MADURO, SEM ECTOMESÊNQUIMA ODONTOGÊNICO

\section{AMELOBLASTOMA}

Os ameloblastomas corresponderam a 16,43\% (132 casos) dos casos de TOs estudados. Quando consideramos todos os tipos, os ameloblastomas representaram o terceiro grupo mais prevalente de tumores. Cada um dos tipos apresentou características específicas como pode ser observado nos dados descritos abaixo.

\section{- AMELOBLASTOMA SÓLIDO - MULTICÍSTICO}

Os 89 casos de ameloblastomas sólidos representaram 11,08\% do total de casos de TOs e $67,42 \%$ de todos os ameloblastomas. A análise dos resultados revelou que $34,83 \%$ dos casos ocorreram em pacientes do gênero masculino (31 casos) e 64,04\% dos casos ocorreram em pacientes do gênero feminino (57 casos). Um caso $(1,13 \%)$ não apresentava os dados do paciente (mas:fem=1:1,84) (Tabela $6)$.

A idade mínima obtida na época do diagnóstico foi de 8 anos e a máxima de 78 anos (IM=33,14 e DP=16,96). Houve um pico de incidência de ameloblastomas sólidos nas segunda e terceira décadas de vida (44 casos - 49,44\%) (Tabela 7). 
Quanto à localização, 67 casos (75,28\%) ocorreram na mandíbula, 6 (6,74\%) na maxila e em 16 casos (17,98\%) a localização não foi especificada. Na mandíbula, 46 casos $(68,66 \%)$ acometeram a região posterior, 4 casos $(5,97 \%)$ acometeram a região anterior e 7 casos (10,45\%) se estenderam por mais de uma área. Em 10 casos $(14,92 \%)$ a área da mandíbula acometida não foi especificada. Na maxila cinco casos $(83,33 \%)$ ocorreram na região posterior e um caso $(16,67 \%)$ na região anterior. A razão maxila:mandíbula foi 1:11,17 (Tabela 8).

Quanto aos subtipos histológicos, 42 casos $(47,19 \%)$ eram tipo folicular, 17 casos $(19,10 \%)$ tipo plexiforme, 7 casos (7,86\%) tipo células granulares e 1 caso $(1,12 \%)$ tipo acantomatoso. Os demais casos apresentavam mais de um subtipo histológico, sendo 13 casos (14,61\%) folicular e acantomatoso, 7 (7,87\%) folicular e plexiforme e $2(2,25 \%)$ folicular, plexiforme e acantomatoso.

\section{- AMELOBLASTOMA UNICÍSTICO}

Os 43 casos de ameloblastomas unicísticos representaram 5,35\% do total de casos de TOs e $35,58 \%$ de todos os ameloblastomas. A análise dos resultados revelou que 39,53\% dos casos ocorreram em pacientes do gênero masculino (17 casos), 55,81\% dos casos ocorreram em pacientes do gênero feminino (24 casos) (mas:fem=1:1,41) e em 2 dos casos (4,65\%) o gênero não foi especificado como pode ser visto na Tabela 6.

A idade mínima obtida na época do diagnóstico foi de 8 anos e a máxima de 67 anos (IM=25,81 e DP=15,22). Assim como nos ameloblastomas do tipo sólido, houve um pico de incidência nas segunda e terceira décadas de vida (24 casos $55,81 \%$ ) (Tabela 7).

Quanto à localização, 33 casos (76,74\%) ocorreram na mandíbula, 5 $(11,63 \%)$ na maxila e em 5 casos $(11,63 \%)$ a localização não foi especificada. Na mandíbula, 25 casos $(75,76 \%)$ acometeram a região posterior, 2 casos $(6,06 \%)$ acometeram a região anterior e 6 casos $(18,18 \%)$ se estenderam por mais de uma área. Três casos (60\%) ocorreram na região posterior de maxila, um caso (20\%) ocorreu na região anterior e um caso (20\%) acometeu ambas as áreas. A razão maxila mandíbula foi 1:6,6 (Tabela 8). 
Quanto aos subtipos histológicos, 13 casos (30,23\%) eram tipo luminal, 10 casos $(23,26 \%)$ tipo intraluminal e 20 casos $(46,51 \%)$ tipo mural.

\section{$\checkmark$ TUMOR ODONTOGÊNICO ESCAMOSO}

Dentre todos os casos avaliados apenas um foi diagnosticado como tumor odontogênico escamoso e representou $0,12 \%$ de todos os TOs. Tratava-se de um paciente do gênero masculino (Tabela 6) com 68 anos de idade na época do diagnóstico (Tabela 7). A lesão localizava-se na mandíbula, mas a área exata não foi especificada (Tabela 8).

\section{$\checkmark$ TUMOR ODONTOGÊNICO EPITELIAL CALCIFICANTE}

Os tumores odontogênicos epiteliais calcificantes representaram 0,75\% (6 casos) dos casos de TOs estudados. A análise dos resultados revelou que 5 casos foram diagnosticados em pacientes do gênero masculino $(83,33 \%)$ e 1 caso em paciente do gênero feminino (16,67\%) (mas:fem=5:1) (Tabela 6).

Houve um pico de incidência na quarta década de vida, sendo que a idade mínima na época do diagnóstico foi de 30 anos e a máxima de 36 anos (IM=32,40 e DP=2,30) (Tabela 7).

Quanto à localização, todos os casos (100\%) ocorreram na mandíbula, sendo que 4 acometeram a região posterior (66,67\%), um a região anterior $(16,67 \%)$ e um se estendeu pelas duas áreas (16,67\%) (Tabela 8). 


\section{$\checkmark$ TUMOR ODONTOGENNICO ADENOMATÓIDE}

Os tumores odontogênicos adenomatóides corresponderam a 2,12\% dos casos de TOs diagnosticados (17 casos), dos quais 8 casos (47,06\%) foram diagnosticados em pacientes do gênero masculino e 9 casos $(52,94 \%)$ em pacientes do gênero feminino (mas:fem=1:1,12) (Tabela 6).

A idade mínima obtida na época do diagnóstico foi de 7 anos e a máxima de 52 anos $(\mathrm{IM}=18,17$ e $\mathrm{DP}=11,81)$. Tinta e cinco por cento dos casos ocorreram na segunda década de vida (Tabela 7).

Quanto à localização, 3 caso $(17,65 \%)$ ocorreu na mandíbula, 11 casos $(64,70 \%)$ ocorreram na maxila e em 3 casos (17,65\%) a localização não foi especificada. Na mandíbula em um dos casos $(33,33 \%)$ a lesão acometeu a região posterior e nos outros dois $(66,67 \%)$ a lesão se estendia pelas regiões anterior e posterior. Na maxila seis casos $(54,55 \%)$ ocorreram na região anterior, um caso ocorreu na região posterior $(9,09)$ e em 2 casos $(18,18 \%)$ a lesão acometeu ambas as áreas, anterior e posterior. Em dois casos (18,18\%) a área acometida da maxila não foi especificada. A razão maxila:mandíbula foi 3,67:1 (Tabela 8).

\section{$\checkmark$ TUMORES ODONTOGENNICOS QUERATOCÍSTICOS}

Os tumores odontogênicos queratocísticos representaram 37,24\% (299 casos) dos TOs diagnosticados. Dezesete casos apresentavam lesões múltiplas nos maxilares, sendo todos diagnosticados como portadores da síndrome do carcinoma nevóide basocelular. Desses pacientes, 9 eram do gênero masculino $(52,94 \%)$ e 8 do gênero feminino (52,94\%), Treze pacientes $(76,47 \%)$ apresentavam idade inferior a 31 anos quando foram diagnosticados. Foram encontradas ainda, lesões císticas que se apresentaram delimitadas por epitélio ortoqueratinizado e que, de acordo com a OMS, não são incluídas entre os TOQs e por isso não foram consideradas no estudo.

Cento e sessenta e um casos eram do gênero masculino (53,85\%) e 137 do gênero feminino (45,82\%) (mas:fem=1,17:1), como podemos notar na Tabela 6 . 
A idade mínima obtida na época do diagnóstico foi de 8 anos e a máxima de 79 anos (IM=34,27 e DP=17,45). O número de pacientes que se apresentavam nas segunda, terceira, quarta e quinta décadas de vida foi muito semelhante (Tabela 7).

Quanto à localização, 158 casos (52,84\%) ocorreram na mandíbula, 95 $(31,77 \%)$ na maxila, 17 (5,69\%) ocorreram em mais de uma localização e em 29 casos $(9,70 \%)$ a localização não foi especificada. Na mandíbula, 108 casos $(68,35 \%)$ acometeram a região posterior, 23 casos (14,56\%) acometeram a região anterior e 20 (12,66\%) se estenderam por mais de uma área. Em 7 casos $(4,43 \%)$ a área da mandíbula acometida não foi especificada. Na maxila, a região mais acometida foi a anterior com 41 casos (43,16\%). Dezenove casos $(20 \%)$ estenderam-se a partir região anterior até a posterior, 27 casos $(28,42 \%)$ acometeram a área posterior e em casos $(8,42 \%)$ a área exata de acometimento não foi especificada. A razão maxila:mandíbula foi 1:1,66 (Tabela 8).

\section{EPITÉLIO ODONTOGÊNICO COM ECTOMESÊNQUIMA ODONTOGÊNICO, COM OU SEM FORMAÇÃO DE TECIDO DURO}

\section{$\checkmark$ FIBROMA AMELOBLÁSTICO}

Os tumores fibromas ameloblásticos corresponderam a 1,12\% dos casos de TOs diagnosticados (9 casos), dos quais 6 casos $(66,67 \%)$ foram diagnosticados em pacientes do gênero masculino e 3 (33,33\%) em pacientes do gênero feminino (mas:fem=2:1) (Tabela 6).

A idade mínima obtida na época do diagnóstico foi de 3 anos e a máxima de 28 anos (IM=14,89 e DP=8,27). Todos os casos ocorreram em pacientes com idade inferior a 30 anos (Tabela 7).

Quanto à localização, 8 casos (88,89\%) ocorreram na mandíbula e 1 caso $(11,11 \%)$ ocorreu na região anterior da maxila. Na mandíbula 5 casos $(62,50 \%)$ ocorreram na região posterior e em 3 casos (37,50\%) a área acometida não foi especificada (maxila:mandíbula=1:8) (Tabela 8). 


\section{$\checkmark$ FIBRODENTINOMA AMELOBLÁSTICO}

Os fibrodentinomas ameloblásticos corresponderam a 0,5\% dos casos de TOs diagnosticados (4 casos), dos quais 2 casos (50\%) foram diagnosticados em pacientes do gênero masculino e 2 (50\%) em pacientes do gênero feminino (mas:fem=1;1) (Tabela 6).

A idade mínima obtida na época do diagnóstico foi de 3 anos e a máxima de 15 anos $(\mathrm{IM}=10,50$ e $\mathrm{DP}=5,47)$. Todos os tumores aconteceram em pacientes com idade inferior a 20 anos (Tabela 7).

Quanto à localização, 2 casos (50\%) ocorreram na mandíbula, 1 caso (25\%) ocorreu na maxila e em 1 caso (25\%) a localização não foi especificada. Todas as lesões ocorreram na região posterior, tanto na mandíbula quanto na maxila (maxila:mandíbula=1:2) (Tabela 8).

\section{$\checkmark$ FIBRO-ODONTOMA AMELOBLÁSTICO}

Os fibro-odontomas ameloblásticos corresponderam a 0,5\% dos casos de TOs diagnosticados (4 casos), dos quais 3 casos (75\%) foram diagnosticados em pacientes do gênero feminino e em 1 caso (25\%) esse dado não foi informado (Tabela 6).

A idade mínima obtida na época do diagnóstico foi de 13 anos e a máxima de 22 anos $(\mathrm{IM}=21,67$ e $\mathrm{DP}=8,50)$. Todos os casos foram diagnosticados em pacientes na segunda ou terceira décadas de vida (Tabela 7).

Quanto à localização, 2 casos (50\%) ocorreram na região posterior de mandíbula e em 2 casos (50\%) a localização não foi especificada (Tabela 8). 


\section{$\checkmark$ ODONTOMAS}

Os odontomas corresponderam a $23,66 \%$ (190 casos) dos casos de TOs diagnosticados. Quando consideramos os dois tipos, os odontomas representaram o segundo grupo mais prevalente de tumores. Cada um dos tipos apresentou características específicas como pode ser observado nos dados descritos abaixo.

\section{- ODONTOMA COMPLEXO}

Os 59 casos de odontomas complexos representaram $7,35 \%$ do total de casos de TOs e $31,05 \%$ de todos os odontomas. A análise dos resultados revelou que 29 pacientes eram do gênero masculino $(49,15 \%)$ e 30 do gênero feminino (50,85\%) (mas:fem=1:1,03), segundo a Tabela 6.

A idade mínima obtida na época do diagnóstico foi de 2 anos e a máxima de 63 anos (IM=17,70 e DP=11,02). Quarenta casos (67,80\%) ocorreram em pacientes na primeira ou segunda décadas de vida (Tabela 7 ).

Quanto à localização, 25 casos (42,37\%) ocorreram na mandíbula, 25 $(42,37 \%)$ na maxila e em 9 casos $(15,26 \%)$ a localização não foi especificada. $\mathrm{Na}$ mandíbula, 17 casos (68\%) acometeram a região posterior, 4 caso (16\%) acometeu a região anterior e 3 (12\%) se estenderam por mais de uma área. Em 1 caso (4\%) a área da mandíbula acometida não foi especificada. Na maxila, 13 casos (52\%) ocorreram na região anterior, 10 casos (40\%) na região posterior e em 2 casos (8\%) a área acometida não foi especificada (maxila:mandíbula=1:1) (Tabela 8).

\section{- ODONTOMA COMPOSTO}

Os odontomas compostos representaram $16,31 \%$ (131 casos) do total de casos de TOs e $68,95 \%$ de todos os odontomas. A análise dos resultados revelou 
que 69 pacientes eram do gênero masculino $(52,67 \%)$ e 60 do gênero feminino $(45,80 \%)$ (mas:fem=1,15:1). Dois casos (1,53\%) não apresentavam informações mínimas em sua ficha (Tabela 6).

A idade mínima obtida na época do diagnóstico foi de 3 anos e a máxima de 64 anos (IM=17,79 e DP=11,86). Oitenta e cinco casos (64,89\%) ocorreram em pacientes na primeira ou segunda décadas de vida (Tabela 7 ).

Quanto à localização, 43 casos (32,82\%) ocorreram na mandíbula, 71 $(54,20 \%)$ na maxila e em 17 casos (12,98\%) a localização não foi especificada. Na mandíbula, 13 casos $(30,23 \%)$ acometeram a região posterior, 25 casos $(58,14 \%)$ acometeram a região anterior, 4 casos $(9,30 \%)$ se estenderam por mais de uma área e em 1 caso $(2,33)$ área acometida não foi especificada. Na maxila, 52 casos $(73,24 \%)$ ocorreram na região anterior, 9 casos (12,68\%) na região posterior, 7 casos $(9,86 \%)$ se estenderam por mais de uma área e em 3 casos $(4,22 \%)$ não foi especificada a área acometida (maxila:mandíbula=1,65:1) (Tabela 8).

\section{$\checkmark$ TUMOR ODONTOGÊNICO CÍSTICO CALCIFICANTE}

Os tumores odontogênicos císticos calcificantes corresponderam a 5,23\% dos casos de TOs diagnosticados (42 casos). Desses, 22 casos (52,38\%) foram diagnosticados em pacientes do gênero masculino e 20 (47,62\%) em pacientes do gênero feminino (mas:fem=1,1:1) (Tabela 6).

A idade mínima obtida na época do diagnóstico foi de 7 anos e a máxima de 91 anos (IM=33,59 e DP=23,33). Vinte e oito por cento dos casos ocorreram na segunda década de vida (Tabela 7).

Quanto à localização, 22 casos (52,38\%) ocorreram na mandíbula, 18 $(42,86 \%)$ na maxila e em 2 casos (4,76\%) a localização não foi especificada. Na mandíbula, 10 casos $(45,46 \%)$ acometeram a região posterior, 9 casos $(40,90 \%)$ acometeram a região anterior e 3 casos (13,64\%) se estenderam por mais de uma área. Um caso $(5,56 \%)$ ocorreu na região posterior da maxila, 10 casos $(55,55 \%)$ ocorreram na região anterior, 5 casos (27,78\%) acometeram ambas as áreas e em 2 casos $(11,11 \%)$ a região acometida não foi especificada (maxila:mandíbula=1:1,22) (Tabela 8). 


\section{$\checkmark$ TUMOR DENTINOGÊNICO DE CÉLULAS FANTASMAS}

Os tumores dentinogêncios de células fantasmas corresponderam a 0,62\% dos casos de TOs diagnosticados (5 casos), dos quais 4 casos (80\%) foram diagnosticados em pacientes do gênero masculino e 1 caso (20\%) em um paciente do gênero feminino (mas:fem=4:1) (Tabela 6).

A idade mínima obtida na época do diagnóstico foi de 12 anos e a máxima de 41 anos (IM=27,25 e DP=11,90). Sessenta por cento dos casos ocorreram entre a segunda e terceira décadas de vida (Tabela 7).

Quanto à localização, 2 casos (40\%) ocorreram na mandíbula, 2 casos (40\%) ocorreram na maxila e em 1 caso (20\%) a localização não foi especificada. $\mathrm{Na}$ mandíbula, uma lesão (50\%) se estendia pelas regiões anterior e posterior e a outra (50\%) ocorreu na região anterior. Na maxila, 1 caso (50\%) ocorreu na região anterior e o outro (50\%) na região posterior (maxila:mandíbula=1:1) (Tabela 8).

\section{* MESÊNQUima ou ECTOMESÊNQUima odontogêNiCo COM OU SEM EPITÉLIO ODONTOGENNICO}

\section{$\checkmark$ FIBROMA ODONTOGENNICO}

Na última Classificação de Tumores Odontogênicos publicada pela OMS, os fibromas odontogênicos periféricos não foram incluídos. Entretanto, trata-se de uma lesão que pode ser diagnosticada em um número significante de pacientes e que até hoje tem suas características e origem amplamente discutidas. Sendo assim, decidimos incluir essas lesões em nosso estudo. 


\section{- FIBROMA ODONTOGENAICO CENTRAL}

Os fibromas odontogênicos centrais corresponderam a 1\% dos casos de TOs diagnosticados (8 casos), sendo que 2 casos (25\%) ocorreram em pacientes do gênero masculino e 6 casos (75\%) em pacientes do gênero feminino (mas:fem=1:3) (Tabela 6).

A idade mínima obtida na época do diagnóstico foi de 16 anos e a máxima de 47 anos $(\mathrm{IM}=25,14$ e $\mathrm{DP}=11,10)$. Cinquenta por cento dos casos ocorreram na segunda década de vida (Tabela 7).

Quanto à localização, 5 casos (62,50\%) ocorreram na mandíbula, 2 casos ocorreram na maxila (25\%) e em 1 caso (12,50\%) a localização não foi especificada. Dentre os casos que ocorreram na mandíbula, 3 (60\%) acometeram a região posterior, 1 (20\%) se estendeu da região anterior até a posterior e em 1 caso (20\%) a área acometida não foi especificada. Na maxila 1 caso (50\%) ococrreu na região anterior e o outro (50\%) se estendeu da região anterior até a posterior (maxila:mandíbula=1:2,5) (Tabela 8).

\section{- FIBROMA ODONTOGÊNICO PERIFÉRICO}

Os fibromas odontogênicos periféricos corresponderam a 2,99\% dos casos de TOs diagnosticados (24 casos). Nove casos (37,50\%) foram diagnosticados em pacientes do gênero masculino, 14 (58,33\%) em pacientes do gênero feminino (mas:fem=1:1,55) e em um caso $(4,17 \%)$ esse dado não foi informado (Tabela 6).

A idade mínima obtida na época do diagnóstico foi de 4 anos e a máxima de 54 anos (IM=25,88 e $D P=14,03)$. Houve um pico de incidência na segunda década de vida (7casos - 29\%), como pode notar na Tabela 7 .

Quanto à localização, 12 casos (50\%) ocorreram na mandíbula, 6 (25\%) na maxila e em 6 casos (25\%) a localização não foi especificada. Na mandíbula, 2 casos (16,67\%) acometeram a região posterior, 6 casos (50\%) acometeram a região anterior, 3 casos (25\%) se estenderam por mais de uma área e em um caso 8,33\%) esse dado não foi informado. Na maxila, 4 casos $(66,67 \%)$ ocorreram na região 
anterior de maxila, 1 caso (16,67\%) envolveu as duas áreas e em 1 caso (16,67\%) a localização não foi especificada (maxila:mandíbula=1:2) (Tabela 8).

\section{$\checkmark$ MIXOMA ODONTOGÊNICO}

Os mixomas odontogênicos corresponderam a 5,36\% dos casos de TOs diagnosticados (43 casos). Quatorze casos (32,56\%) foram diagnosticados em pacientes do gênero masculino e 29 (67,44\%) em pacientes do gênero feminino (mas:fem=1:2,07) (Tabela 6).

A idade mínima obtida na época do diagnóstico foi de 5 anos e a máxima de 73 anos (IM=28,26 e DP=15,68). Quarenta e seis por cento dos casos ocorreram entre a segunda e terceira décadas de vida (Tabela 7).

Quanto à localização, 24 casos (55,81\%) ocorreram na mandíbula, 15 $(34,88 \%)$ na maxila e em 4 casos $(9,31 \%)$ a localização não foi especificada. $\mathrm{Na}$ mandíbula, 12 casos (50\%) acometeram a região posterior, 6 casos (25\%) acometeram a região anterior, 4 casos $(16,67 \%)$ se estenderam por mais de uma área e em 2 casos (8,33\%) a área afetada não foi especificada. Seis casos (40\%) ocorreram na região posterior de maxila, 4 casos $(26,67 \%)$ ocorreram na região anterior, 4 casos $(26,67 \%)$ acometeram ambas as áreas e em 1 caso a área afetada não foi especificada (6,66\%) (maxila:mandíbula=1:1,6) (Tabela 8).

\section{$\checkmark$ CEMENTOBLASTOMA}

Os cementoblastomas corresponderam a 1,87\% dos casos de TOs diagnosticados (15 casos), dos quais 7 casos $(46,67 \%)$ foram diagnosticados em pacientes do gênero masculino e 8 (53,33\%) em pacientes do gênero feminino (mas:fem=1:1,14) (Tabela 6). 
A idade mínima obtida na época do diagnóstico foi de 10 anos e a máxima de 58 anos (IM=28,78 e DP=14). Cinqüenta e três por cento dos casos ocorreram entre a segunda e terceira décadas de vida (Tabela 7).

Quanto à localização, 10 casos $(66,67 \%)$ ocorreram na mandíbula, 3 casos (20\%) ocorreram na maxila e em 2 casos (13,33\%) a localização não foi especificada. Na mandíbula, 90\% dos casos (9) ocorreram na região posterior e 10\% dos casos (1) ocorreu na região anterior. Na maxila duas lesões $(66,67 \%)$ ocorreram na região posterior e uma lesão (33,33\%) se estendeu da região anterior até a posterior (maxila:mandíbula=1:3,33) (Tabela 8).

\section{$\checkmark$ TUMOR ODONTOGÊNICO NÃO CLASSIFICADO}

O tumor odontogênico não classificado era uma lesão sabidamente de origem odontogênica benigna, mas que não se enquadravam em nenhum dos tipos estabelecidos pela OMS. Representou $0,12 \%$ dos tumores odontogênicos diagnosticados. Tratava-se de um paciente do gênero feminino (Tabela 6) e com 47 anos de idade na época do diagnóstico (Tabela 7). O tumor se estendia pelas regiões anterior e posterior da mandíbula (Tabela 8).

\section{TUMORES MALIGNOS}

CARCINOMA ODONTOGÊNICO

$\checkmark$ CARCINOMA ODONTOGÊNICO DE CÉLULAS CLARAS

Os carcinomas odontogênicos de células claras corresponderam a 0,37\% dos casos de TOs diagnosticados (3 casos), todos diagnosticados em pacientes do gênero feminino (Tabela 6). 
A idade mínima obtida na época do diagnóstico foi de 36 anos e a máxima de 69 anos $(\mathrm{IM}=50,67$ e $\mathrm{DP}=16,80)$. Todos os casos foram diagnosticados em pacientes com idade acima dos 31 anos (Tabela 7).

Quanto à localização, 2 casos $(66,67 \%)$ ocorreram na mandíbula e 1 caso $(33,33 \%)$ ocorreu na maxila. Na mandíbula, um caso ocorreu na região posterior (50\%) e o outro se estendeu pelas regiões anterior e posterior (50\%). A localização exata da lesão em maxila não foi especificada (maxila:mandíbula=1:2) (Tabela 8).

A partir dos dados adquiridos nas duas instituições brasileiras foi possível definir um perfil de prevalência para os TOs como pode ser visto nas Tabelas 6, 7, 8 e 9. No Gráfico 1 é possível visualizarmos a diferença na prevalência dos tumores mais comumente encontrados nessas instituições brasileiras.

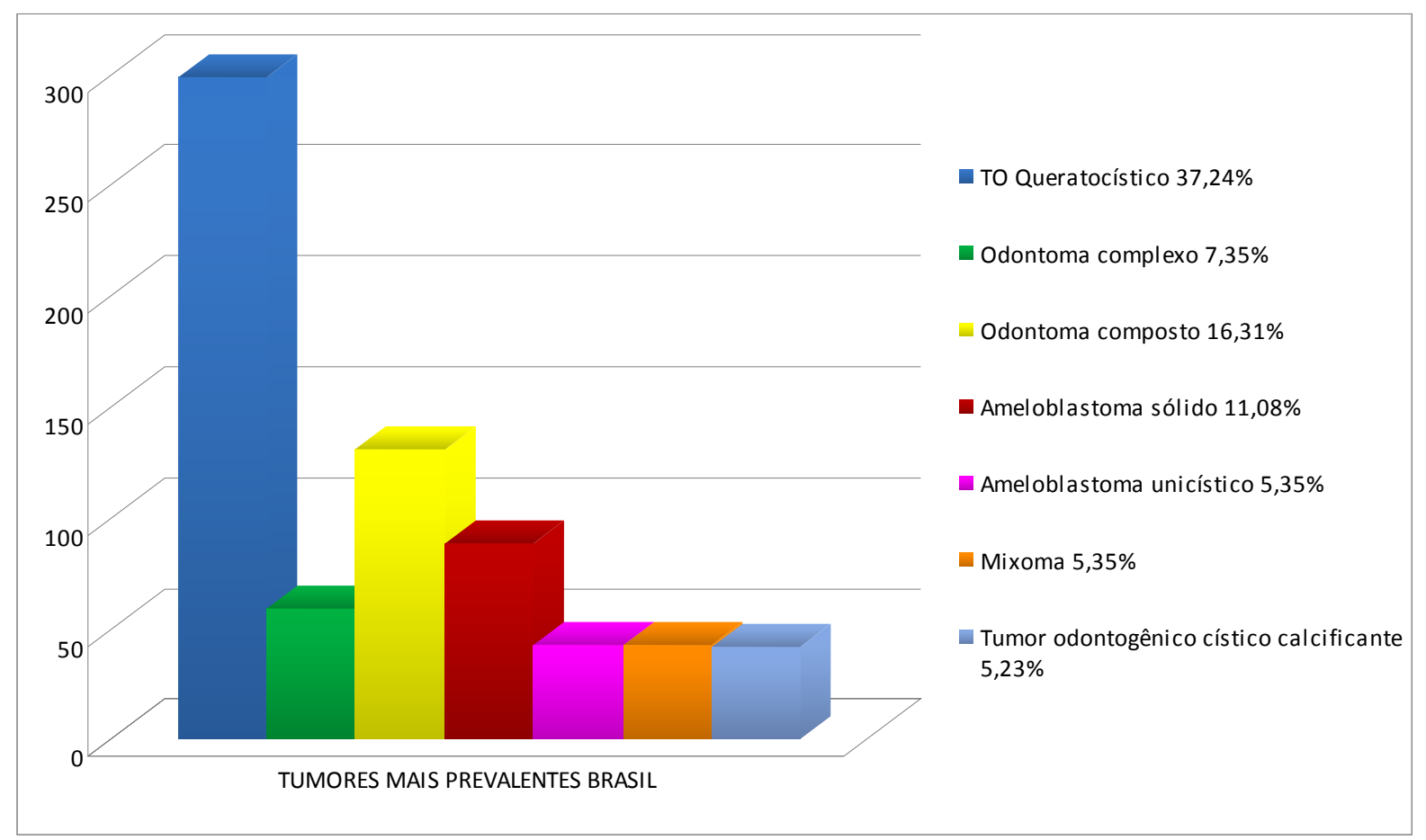

Gráfico 1 - Tumores mais prevalentes nas instituições brasileiras 
Tabela 5 - Freqüência relativa dos tumores odontogênicos nas instituições brasileiras

\begin{tabular}{|c|c|c|c|}
\hline Diagnóstico & Abreviação & Número de casos & Porcentagem \\
\hline \multicolumn{4}{|c|}{ Tumores Benignos } \\
\hline \multicolumn{4}{|c|}{ Epitélio odontogênico com estroma fibroso maduro, sem ectomesênquima odontogênico } \\
\hline Ameloblastoma sólido multicístico & AS-M & 89 & 11,08 \\
\hline Ameloblastoma unicístico & A-U & 43 & 5,35 \\
\hline Tumor odontogênico escamoso & TOE & 1 & 0,12 \\
\hline Tumor odontogênico epitelial calcificante & TOEC & 6 & 0,75 \\
\hline Tumor odontogênico adenomatóide & TOA & 17 & 2,12 \\
\hline Tumor odontogênico queratocístico & TOQ & 299 & 37,24 \\
\hline \multicolumn{4}{|c|}{ Epitélio odontogênico com ectomesênquima odontogênico, com ou sem formação de tecido duro } \\
\hline Fibroma ameloblástico & FA & 9 & 1,12 \\
\hline Fibrodentinoma ameloblástico & FDA & 4 & 0,5 \\
\hline Fibro-odontoma ameloblástico & FOA & 4 & 0,5 \\
\hline Odontoma complexo & OC & 59 & 7,35 \\
\hline Odontoma composto & OCp & 131 & 16,31 \\
\hline Tumor odontogênico cístico calcificante & TOCC & 42 & 5,23 \\
\hline Tumor dentinogênico de células fantasmas & TDCF & 5 & 0,62 \\
\hline \multicolumn{4}{|c|}{ Mesênquima ou ectomesênquima odontogênico com ou sem epitélio odontogênico } \\
\hline Fibroma odontogênico central & FOC & 8 & 1 \\
\hline Fibroma odontogênico periférico & FOP & 24 & 2,99 \\
\hline Mixoma odontogênico - Mixofibroma & MO & 43 & 5,36 \\
\hline Cementoblastoma & $\mathrm{CB}$ & 15 & 1,87 \\
\hline Tumor odontogênico não classificado & TONC & 1 & 0,12 \\
\hline \multicolumn{4}{|l|}{ Tumores Malignos } \\
\hline \multicolumn{4}{|l|}{ Carcinoma odontogênico } \\
\hline Carcinoma odontogênico de células claras & cocc & 3 & 0,37 \\
\hline TOTAL & & 803 & 100 \\
\hline
\end{tabular}


Tabela 6 - Distribuição por gênero dos tumores odontogênicos nas instituições brasileiras

\begin{tabular}{|c|c|c|c|c|c|c|c|c|}
\hline \multirow[t]{2}{*}{ Tumores Odontogênicos } & \multicolumn{6}{|c|}{ Gênero } & \multicolumn{2}{|c|}{ Total } \\
\hline & Masculino & $\%$ & Feminino & $\%$ & NE & $\%$ & Total & $\%$ \\
\hline \multicolumn{9}{|l|}{ Tumores Benignos } \\
\hline \multicolumn{9}{|l|}{$1^{\circ}$ Grupo } \\
\hline AS-M & 31 & 34,83 & 57 & 64,04 & 1 & 1,13 & 89 & 11,08 \\
\hline$A-U$ & 17 & 39,53 & 24 & 55,81 & 2 & 4,65 & 43 & 5,35 \\
\hline TOE & 1 & 100 & - & - & - & - & 1 & 0,12 \\
\hline TOEC & 5 & 83,33 & 1 & 16,67 & - & - & 6 & 0,75 \\
\hline TOA & 8 & 47,06 & 9 & 52,94 & - & - & 17 & 2,12 \\
\hline TOQ & 161 & 53,85 & 137 & 45,82 & 1 & 0,33 & 299 & 37,24 \\
\hline \multicolumn{9}{|l|}{$2^{\circ}$ Grupo } \\
\hline AS-M & 6 & 66,67 & 3 & 33,33 & - & - & 9 & 1,12 \\
\hline$A-U$ & 2 & 50 & 2 & 50 & - & - & 4 & 0,5 \\
\hline TOE & - & - & 3 & 75 & 1 & 25 & 4 & 0,5 \\
\hline TOEC & 29 & 49,15 & 30 & 50,85 & - & - & 59 & 7,35 \\
\hline TOA & 69 & 52,67 & 60 & 45,80 & 2 & 1,53 & 131 & 16,31 \\
\hline TOQ & 22 & 52,38 & 20 & 47,62 & - & - & 42 & 5,23 \\
\hline AS-M & 4 & 80 & 1 & 20 & - & - & 5 & 0,62 \\
\hline \multicolumn{9}{|l|}{$3^{\circ}$ Grupo } \\
\hline FOC & 2 & 25 & 6 & 75 & - & - & 8 & 1 \\
\hline FOP & 9 & 37,5 & 14 & 58,33 & 1 & 4,17 & 24 & 2,99 \\
\hline MO & 14 & 32,56 & 29 & 67,44 & - & - & 43 & 5,36 \\
\hline CB & 7 & 46,67 & 8 & 53,33 & - & - & 15 & 1,87 \\
\hline TONC & - & - & 1 & 100 & - & - & 1 & 0,12 \\
\hline \multicolumn{9}{|l|}{ Tumores Malignos } \\
\hline \multicolumn{9}{|l|}{$\mathrm{CO}$} \\
\hline COCC & - & - & 3 & 100 & - & - & 3 & 0,37 \\
\hline TOTAL & 387 & 48,19 & 408 & 50,81 & 8 & 1 & 803 & 100 \\
\hline
\end{tabular}


Tabela 7 - Distribuição por faixa etária dos tumores odontogênicos nas instituições brasileiras

\begin{tabular}{|c|c|c|c|c|c|c|c|c|c|c|c|c|c|c|c|}
\hline \multirow[t]{3}{*}{ Tumor } & \multirow[t]{3}{*}{ Total } & \multicolumn{14}{|c|}{ Idade na época do diagnóstico } \\
\hline & & \multicolumn{11}{|c|}{ Faixa etária } & \multirow{2}{*}{$\begin{array}{l}\text { Variação } \\
\text { da Idade }\end{array}$} & \multirow{2}{*}{ Med } & \multirow{2}{*}{ Idade Média \pm DF } \\
\hline & & $0-10$ & $11-20$ & $21-30$ & $31-40$ & $41-50$ & $51-60$ & $61-70$ & $71-80$ & $81-90$ & $91-100$ & NE & & & \\
\hline \multicolumn{16}{|c|}{ Benignos } \\
\hline \multicolumn{16}{|c|}{$1^{\circ} \mathrm{Grupo}$} \\
\hline AS-M & 89 & 1 & 17 & 27 & 9 & 11 & 8 & 4 & 1 & 1 & - & 10 & $8-78$ & 28 & $33,14 \pm 16,96$ \\
\hline$A-U$ & 43 & 2 & 16 & 8 & 3 & 4 & 2 & 1 & - & - & - & 7 & $8-67$ & 20 & $25,81 \pm 15,22$ \\
\hline TOE & 1 & - & - & - & - & - & - & 1 & - & - & - & - & 68 & 68 & 68 \\
\hline TOEC & 6 & - & - & - & 5 & - & - & - & - & - & - & 1 & $30-36$ & 32 & $32,40 \pm 2,30$ \\
\hline TOA & 17 & 2 & 6 & 3 & - & - & 1 & - & - & - & - & 5 & $7-52$ & 14,5 & $18,17 \pm 11,81$ \\
\hline TOQ & 299 & 11 & 51 & 59 & 42 & 42 & 16 & 16 & 7 & 1 & 1 & 53 & $8-79$ & 31 & $34,27 \pm 17,45$ \\
\hline \multicolumn{16}{|c|}{$2^{\circ}$ Grupo } \\
\hline FA & 9 & 2 & 4 & 3 & - & - & - & - & - & - & - & - & $3-28$ & 13 & $14,89 \pm 8,27$ \\
\hline FDA & 4 & 2 & 2 & - & - & - & - & - & - & - & - & - & $3-15$ & 12 & $10,5 \pm 5,47$ \\
\hline FOA & 4 & - & 1 & 2 & - & - & - & - & - & - & - & 1 & $13-22$ & 22 & $21,67 \pm 8,50$ \\
\hline OC & 59 & 13 & 27 & 7 & 5 & 1 & - & 1 & - & - & - & 5 & $2-63$ & 14,5 & $17,70 \pm 11,02$ \\
\hline OCp & 131 & 33 & 52 & 15 & 10 & 3 & 1 & 2 & - & - & - & 15 & $3-64$ & 14 & $17,79 \pm 11,86$ \\
\hline TOCC & 42 & 2 & 12 & 4 & 2 & 6 & 1 & 2 & 2 & - & 1 & 10 & $7-91$ & 22,5 & $33,59 \pm 23,33$ \\
\hline TDCF & 5 & - & 1 & 2 & - & 1 & - & - & - & - & - & 1 & $12-41$ & 28 & $27,25 \pm 11,90$ \\
\hline \multicolumn{16}{|c|}{$3^{\circ}$ Grupo } \\
\hline FOC & 8 & - & 4 & 1 & 1 & 1 & - & - & - & - & - & 1 & $16-47$ & 20 & $25,14 \pm 11,10$ \\
\hline FOP & 24 & 1 & 7 & 3 & 2 & 3 & 1 & - & - & - & - & 7 & $4-54$ & 23 & $25,88 \pm 14,03$ \\
\hline MO & 43 & 4 & 9 & 11 & 6 & 6 & 1 & 1 & 1 & - & - & 4 & $5-73$ & 24 & $28,26 \pm 15,68$ \\
\hline CB & 15 & 1 & 4 & 4 & 2 & 2 & 1 & - & - & - & - & 1 & $10-58$ & 23 & $27,78 \pm 14,00$ \\
\hline TONC & 1 & - & - & - & - & 1 & - & - & - & - & - & - & 47 & 47 & 47 \\
\hline \multicolumn{16}{|c|}{ Malignos } \\
\hline \multicolumn{16}{|c|}{$\mathrm{CO}$} \\
\hline $\mathrm{COCC}$ & 3 & - & - & - & 1 & 1 & - & 1 & - & - & - & - & $36-69$ & 47 & $50,67 \pm 16,80$ \\
\hline TOTAL & 803 & 74 & 213 & 149 & 88 & 82 & 32 & 29 & 11 & 2 & 2 & 121 & - & - & - \\
\hline
\end{tabular}


Tabela 8 - Distribuição por localização dos tumores odontogênicos nas instituições brasileiras

\begin{tabular}{|c|c|c|c|c|c|c|c|c|c|c|c|c|c|c|}
\hline \multirow{3}{*}{ Tumor } & \multirow[t]{3}{*}{ Total } & \multicolumn{12}{|l|}{ Localização } & \multirow{3}{*}{$\begin{array}{c}\text { Razão } \\
\text { Max: Manc }\end{array}$} \\
\hline & & \multicolumn{5}{|c|}{ Mandíbula } & \multicolumn{5}{|c|}{ Maxila } & \multirow[t]{2}{*}{$\mathrm{NE}$} & \multirow[t]{2}{*}{ Ambas } & \\
\hline & & Anterior & Ambas & Posterior & NE & Total & Anterior & Ambas & Posterior & NE & Total & & & \\
\hline \multicolumn{15}{|c|}{ Benignos } \\
\hline \multicolumn{15}{|c|}{$1^{\circ}$ Grupo } \\
\hline AS-M & 89 & 4 & 7 & 46 & 10 & 67 & 1 & - & 5 & - & 6 & 16 & - & 1:11,17 \\
\hline$A-U$ & 43 & 2 & 6 & 25 & - & 33 & 1 & 1 & 3 & - & 5 & 5 & - & $1: 6,6$ \\
\hline TOE & 1 & - & - & - & 1 & 1 & - & - & - & - & - & - & - & - \\
\hline TOEC & 6 & 1 & 1 & 4 & - & 6 & - & - & - & - & - & - & - & - \\
\hline TOA & 17 & 0 & 2 & 1 & 0 & 3 & 6 & 2 & 1 & 2 & 11 & 3 & - & $3,67: 1$ \\
\hline TOQ & 299 & 23 & 20 & 108 & 7 & 158 & 41 & 19 & 27 & 8 & 95 & 29 & 17 & $1: 1,66$ \\
\hline \multicolumn{15}{|l|}{$2^{\circ}$ Grupo } \\
\hline FA & 9 & - & - & 5 & 3 & 8 & 1 & - & - & - & 1 & - & - & $1: 8$ \\
\hline FDA & 4 & - & - & 2 & - & 2 & - & - & 1 & - & 1 & 1 & - & $1: 2$ \\
\hline FOA & 4 & - & - & 2 & - & 2 & - & - & - & - & - & 2 & - & - \\
\hline OC & 59 & 4 & 3 & 17 & 1 & 25 & 13 & - & 10 & 2 & 25 & 9 & - & 1:1 \\
\hline OCp & 131 & 25 & 4 & 13 & 1 & 43 & 52 & 7 & 9 & 3 & 71 & 17 & - & $1,65: 1$ \\
\hline TOCC & 42 & 9 & 3 & 10 & - & 22 & 10 & 5 & 1 & 2 & 18 & 2 & - & $1: 1,22$ \\
\hline TDCF & 5 & 1 & 1 & - & - & 2 & 1 & - & 1 & - & 2 & 1 & - & 1:1 \\
\hline \multicolumn{15}{|l|}{$3^{\circ}$ Grupo } \\
\hline FOC & 8 & - & 1 & 3 & 1 & 5 & 1 & 1 & - & - & 2 & 1 & - & $1: 2,5$ \\
\hline FOP & 24 & 6 & 3 & 2 & 1 & 12 & 4 & 1 & - & 1 & 6 & 6 & - & $1: 2$ \\
\hline MO & 43 & 6 & 4 & 12 & 2 & 24 & 4 & 4 & 6 & 1 & 15 & 4 & - & $1: 1,6$ \\
\hline $\mathrm{CB}$ & 15 & 1 & - & 9 & - & 10 & - & 1 & 2 & - & 3 & 2 & - & $1: 3,33$ \\
\hline TONC & 1 & - & 1 & - & - & 1 & - & - & - & - & - & - & - & \\
\hline \multicolumn{15}{|c|}{ Malignos } \\
\hline \multicolumn{15}{|c|}{$\mathrm{CO}$} \\
\hline cocc & 3 & - & 1 & 1 & - & 2 & - & - & - & 1 & 1 & - & - & $1: 2$ \\
\hline TOTAL & 803 & 82 & 57 & 260 & 27 & 426 & 135 & 41 & 66 & 20 & 262 & 98 & 17 & $1: 1,62$ \\
\hline
\end{tabular}




\subsection{MÉXICO}

Dentre os 30.614 casos diagnosticados nos Serviços de Anatomia Patológica Bucal da Faculdade de Odontologia da Universidade Nacional Autônoma do México - UNAM, da Faculdade de odontologia da Universidade Autônoma Metropolitana Xochilmico e no Laboratório Peribact, 1253 casos (4,09\%) foram classificados como TOs em nosso estudo, dos quais 1243 eram benignos $(99,2 \%)$ e 10 eram malignos $(0,8 \%)$.

A lesão mais freqüente foi o tumor odontogênico queratocístico (TOQ 443 35,35\%), seguido pelo odontoma (OD $305-24,34 \%$ ), ameloblastoma (AME 213 17\%), mixoma (MIX 120 -9,58\%) e tumores odontogênicos adenomatóides (TOA 45 - 3,59\%). Foram encontrados também 44 tumores odontogênicos císticos calcificantes (TOCC - 4,40\%), 19 fibromas odontogênicos periféricos (FOP 1,52\%), 13 cementoblastomas (CEM - 1,04\%), 10 fibromas odontogênicos centrais (FOC - 0,80\%), 8 fibromas ameloblásticos (FA - 0,64\%), 8 fibro-odontomas ameloblásticos (FOA - 0,64\%), 6 tumores odontogênicos epiteliais calcificantes (TOEC - 0,48\%), 2 tumores dentinogênicos de células fantasmas (TDCF - 0,16), 1 fibrodentinoma ameloblástico (0,08\%) e 1 odontoameloblastoma (ODA - 0,08\%). (Tabela 17). Outras lesões sabidamente benignas mais que não se enquadravam na classificação foram contabilizadas, sendo 2 tumores odontogênicos combinados (TOC - 0,16), 2 tumores odontogênicos não classificados (TONC - 0,16) e um queratoameloblastoma (QAM - 0,08\%).

Dentre os tumores malignos foram diagnosticados 3 carcinomas ameloblásticos primários (CAP - 0,24\%), 1 carcinoma ameloblástico secundário (CAS - 0,08\%), 1 carcinoma epidermóide intra-ósseo primário (CEIOP - 0,08), 3 carcinomas epidermóides intra-ósseo primários derivados de tumores odontogênicos queratocísticos (CEIOPTOQ - 0,24\%) e dois fibrossarcomas ameloblásticos (FSA 0,16\%) (Tabela 9). 


\section{TUMORES BENIGNOS}

EPITÉLIO ODONTOGÊNICO COM ESTROMA FIBROSO MADURO, SEM ECTOMESÊNQUIMA ODONTOGENNICO

\section{$\checkmark$ AMELOBLASTOMA}

Os ameloblastomas corresponderam a 17\% (213 casos) dos casos de TOs estudados. Quando consideramos todos os tipos, os ameloblastomas representaram o terceiro grupo mais prevalente de tumores. Cada um dos tipos apresentou características específicas como pode ser observado nos dados descritos abaixo.

- AMELOBLASTOMA SÓLIDO - MULTICÍSTICO

Os 72 casos de ameloblastomas sólidos representaram 5,75\% do total de casos de TOs e $33,80 \%$ de todos os ameloblastomas. A análise dos resultados revelou que 37 casos foram diagnosticados em pacientes do gênero masculino $(51,39 \%)$ e 35 casos em pacientes do gênero feminino $(48,61 \%)$ (mas:fem=1,06:1), como pode ser visto na Tabela 10.

A idade mínima obtida na época do diagnóstico foi de 10 anos e a máxima de 76 anos (IM=37,14 e DP=17,47). Houve um pico de incidência de ameloblastomas sólidos entre a terceira e quinta décadas de vida (43 casos - 59,72\%) (Tabela 11).

Quanto à localização, 57 casos $(79,17 \%)$ ocorreram na mandíbula, 5 (6,94\%) na maxila e em 10 casos (13,89\%) a localização não foi especificada. Na mandíbula, 32 casos $(56,14 \%)$ acometeram a região posterior, 2 casos $(3,51 \%)$ acometeram a região anterior, 4 casos $(7,02 \%)$ se estenderam por mais de uma área e em 19 casos 9 (33,33\%) a localização precisa não foi especificada. Na maxila, um caso (20\%) ocorreu na região posterior, 2 casos (40\%) ocorreram na região anterior, e em 
2 casos (40\%) a localização exata não foi especificada. (maxila:mandíbula=1:11,4) (Tabela 12).

Quanto aos subtipos histológicos, 19 casos $(26,39 \%)$ eram tipo folicular, 41 casos $(56,94 \%)$ tipo plexiforme e 1 caso $(1,39 \%)$ tipo células granulares. Os demais casos apresentavam mais de um subtipo histológico, sendo 9 casos $(12,5 \%)$ folicular e acantomatoso e 2 casos (2,78\%) tipo plexiforme e acantomatoso.

\section{- AMELOBLASTOMA UNICÍSTICO}

Os 137 casos de ameloblastomas unicísticos representaram 10,93\% do total de casos de TOs e $64,32 \%$ de todos os ameloblastomas. A análise dos resultados revelou que $51,10 \%$ dos casos ocorreram em pacientes do gênero masculino (70 casos), 48,17\% dos casos ocorreram em pacientes do gênero feminino (66 casos) (mas;fem=1,06:1) e em 1 caso $(0,73 \%)$ os dados do paciente não foram recuperados (Tabela 10).

A idade mínima obtida na época do diagnóstico foi de 5 anos e a máxima de 67 anos (IM=27,23 e DP=13,96). Houve um pico de incidência entre a segunda e terceira décadas de vida (89 casos - 64,96\%) (Tabela 11 ).

Quanto à localização, 111 casos (81,02\%) ocorreram na mandíbula, 11 $(8,03 \%)$ na maxila e em 15 casos (10,95\%) a localização não foi especificada. Na mandíbula, 67 casos $(60,36 \%)$ acometeram a região posterior, 1 caso $(0,9 \%)$ acometeu a região anterior e 4 casos (3,60\%) se estenderam por mais de uma área. Em 39 casos $(35,14 \%)$ a área acometida da mandíbula não foi especificada. Quatro casos (36,37\%) ocorreram na região posterior de maxila, 3 casos $(27,27 \%)$ ocorreram na região anterior, 2 casos (18,18\%) acometeram ambas as áreas e em 2 casos $(18,18 \%)$ a área acometida não foi especificada (maxila:mandíbula=1:10,09) (Tabela 12).

Quanto aos subtipos histológicos, 46 casos (33,58\%) eram tipo luminal, 50 casos (36,50\%) tipo intraluminal e 41 casos $(29,92 \%)$ tipo mural. 


\section{- AMELOBLASTOMA PERIFÉRICO}

Os 4 casos de ameloblastomas periférico representaram $0,32 \%$ do total de casos de TOs e $1,88 \%$ de todos os ameloblastomas. Três casos eram do gênero masculino (75\%) e um do gênero masculino (25\%) (mas:fem=3:1) (Tabela 10).

A idade mínima obtida na época do diagnóstico foi de 40 anos e a máxima de 66 anos (IM=55,25 e DP=11,12). Todos os pacientes eram adultos com idade acima dos 40 anos (Tabela 11).

Quanto à localização, 2 casos (50\%)ocorreram na mandíbula, um na região posterior e no outro a região acometida não foi informada. Uma caso (25\%) ocorreu na maxila em área não especificada e em um dos casos (255) o dado localização não pode ser recuperado (Tabela 12).

\section{$\checkmark$ TUMOR ODONTOGENNICO EPITELIAL CALCIFICANTE}

Os tumores odontogênicos epiteliais calcificantes representaram 0,48\% (6 casos) dos casos de TOs estudados. A análise dos resultados revelou que 2 casos foram diagnosticados em pacientes do gênero masculino (33,33\%) e 4 casos em um paciente do gênero feminino $(66,67 \%)$ (mas:fem=1:2) (Tabela 10).

A idade mínima obtida na época do diagnóstico foi de 19 anos e a máxima de 55 anos (IM=39,33 e DP=13,70). Não foi possível definir uma faixa etária em que os casos ocorressem com maior freqüência (Tabela 11).

Quanto à localização, 3 casos (50\%) ocorreram na mandíbula e 3 (50\%) na maxila. Na mandíbula, os 2 casos $(66,67 \%)$ ocorreram na região posterior e em um dos casos a área acometida não foi especificada. Dois casos $(66,67 \%)$ ocorreram na região anterior de maxila e um caso $(33,33 \%)$ ocorreu na região posterior (maxila:mandíbula=1:1) (Tabela 12). 


\section{$\checkmark$ TUMOR ODONTOGENNICO ADENOMATÓIDE}

Os tumores odontogênicos adenomatóides corresponderam a 3,59\% dos casos de TOs diagnosticados (45 casos), dos quais 19 casos (42,22\%) foram diagnosticados em pacientes do gênero masculino e 26 (57,78\%) em pacientes do gênero masculino (mas:fem=1:1,37) (Tabela 10).

A idade mínima obtida na época do diagnóstico foi de 10 anos e a máxima de 69 anos $(\mathrm{IM}=17,71$ e $\mathrm{DP}=9,16)$. Setenta e cinco por cento dos casos ocorreram na segunda década de vida (Tabela 11).

Quanto à localização, 15 casos (33,33\%) ocorreram na mandíbula, 22 casos (48,89\%) ocorreram na maxila e em 8 casos (17,78\%) a localização não foi especificada. Na mandíbula, 2 casos (13,33\%) acometeram a área posterior, 6 casos (40\%) a área anterior, em 3 casos (20\%) a lesão se estendia por ambas regiões e em 4 casos $(26,67 \%)$ a área a cometida não foi especificada. Na maxila 9 casos $(40,90 \%)$ ocorreram na região anterior, 1 caso (4,56\%) ocorreu na região posterior, 5 casos $(22,73 \%)$ se estendiam por ambas as regiões e em 7 casos $(31,81 \%)$ a área acometida não foi especificada (maxila:mandíbula=1,16:1) (Tabela 22).

\section{$\checkmark$ TUMORES ODONTOGÊNICOS QUERATOCÍSTICOS}

Os tumores odontogênicos queratocísticos representaram 35,35\% (443 casos) dos TOs diagnosticados, sendo o grupo mais prevalente de tumores. Vinte e dois casos apresentavam lesões múltiplas nos maxilares, e foram diagnosticados como portadores da síndrome do carcinoma nevóide basocelular. Desses pacientes sindrômicos, 9 eram do gênero feminino $(40,91 \%)$ e treze do gênero masculino (59,09\%). Dezessete pacientes $(77,27 \%$, encontravam-se entre a primeira e a terceira décadas de vida. Foram encontradas ainda, lesões císticas que se apresentaram delimitadas por epitélio ortoqueratinizado, e que de acordo com a OMS não são incluídas entre os TOQs e por isso não foram consideradas no estudo. 
A análise dos resultados revelou que 245 casos eram do gênero masculino (55,30\%) e 196 pacientes eram do gênero feminino (44,24\%) (mas:fem=1,25:1). Em dois dos casos $(0,45 \%)$ não foi possível recuperar os dados do paciente como, pode ser visto na Tabela 10.

A idade mínima obtida na época do diagnóstico foi de 3 anos e a máxima de 81 anos (IM=31,49 e $\mathrm{DP}=17,93)$. Quarenta e nove por cento dos pacientes se encontravam entre a segunda e terceira décadas de vida (Tabela 11).

Quanto à localização, 262 casos (59,14\%) ocorreram na mandíbula, 106 (23,93\%) na maxila, 22 (4,97\%) ocorreram em mais de uma localização e em 53 casos $(11,96 \%)$ a localização não foi especificada. Na mandíbula, 150 casos $(57,25 \%)$ acometeram a região posterior, 25 casos (9,54\%) acometeram a região anterior e 13 (4,96\%) se estenderam por mais de uma área. Em 74 casos (28,25\%) a área da mandíbula acometida não foi especificada. Na maxila, a região mais acometida foi a anterior com 42 casos (39,62\%). Quatro casos (3,77\%) estenderamse a partir região anterior até a posterior, 20 casos (18,87\%) acometeram a área posterior e em 40 casos (37,74\%) a área exata de acometimento não foi especificada (maxila:mandíbula=1:2,47) (Tabela 12).

\section{- EPITÉLIO ODONTOGÊNICO COM ECTOMESÊNQUIMA ODONTOGÊNICO, COM OU SEM FORMAÇÃO DE TECIDO DURO}

\section{$\checkmark$ FIBROMA AMELOBLÁSTICO}

Os fibromas ameloblásticos corresponderam a $0,64 \%$ dos casos de TOs diagnosticados ( 8 casos), dos quais três $(37,50 \%)$ foram diagnosticado em pacientes do gênero masculino e cinco (62,50\%) em pacientes do gênero feminino (mas:fem=1:1,67) (Tabela 10).

A idade mínima obtida na época do diagnóstico foi de 2 anos e a máxima de 15 anos $(\mathrm{IM}=10$ e $\mathrm{DP}=4)$. Todos os pacientes se encontravam entre a primeira e a segunda décadas de vida (Tabela 11). 
Quanto à localização, 6 casos (75\%) ocorreram na mandíbula e 2 casos (25\%) ocorreram na maxila. Na mandíbula 1 caso $(16,67 \%)$ ocorreu na região porterior, 1 caso $(16,67 \%)$ na região anterior, 2 casos $(33,33 \%)$ se estendiam por ambas as regiões e em 2 casos (33,33\%) a região acometida não foi especificada. Na maxila, 1 caso (50\%) acometeu a área anterior e o outro (50\%) se estendia por ambas as áreas (maxila:mandíbula=1:3) (Tabela 12).

\section{$\checkmark$ FIBRODENTINOMA AMELOBLÁSTICO}

O único fibrodentinoma ameloblástico diagnosticado correspondeu a 0,08\% dos casos de TOs diagnosticados. O paciente era do gênero feminino (Tabela 10) e na época do diagnóstico apresentava-se com 10 anos de idade (Tabela 11). A lesão localizava-se na região posterior da mandíbula (Tabela 12).

\section{$\checkmark$ FIBRO-ODONTOMA AMELOBLÁSTICO}

Os fibro-odontomas ameloblásticos corresponderam a 0,64\% dos casos de TOs diagnosticados (8 casos), dos quais 5 casos (62,50\%) foram diagnosticado em pacientes do gênero masculino e $3(37,50 \%)$ em pacientes do gênero feminino (mas:fem=1,67:1) (Tabela 10).

A idade mínima na época do diagnóstico foi de 2 anos e a máxima de 25 $(\mathrm{IM}=9,88$ e $\mathrm{DP}=6,71)$. Sete pacientes $(87,5 \%)$ se apresentavam na primeira década de vida, o que configurou um pico de incidência.

Quanto à localização, 6 casos (75\%) ocorreram na mandíbula, sendo cinco $(83,33 \%)$ na região posterior e um não revelava a área exata acometida $(16,67 \%)$. Os dois casos que ocorreram na maxila encontravam-se na área anterior (maxila:mandíbula=1:3) (Tabela 12). 


\section{$\checkmark$ ODONTOMAS}

Os odontomas corresponderam a $24,34 \%$ (305 casos) dos casos de TOs diagnosticados. Quando consideramos os dois tipos, os odontomas representaram o segundo grupo mais prevalente de tumores. Cada um dos tipos apresentou características específicas como pode ser observado nos dados descritos abaixo.

\section{- ODONTOMA COMPLEXO}

Os 123 casos de odontomas complexos representaram $9,82 \%$ do total de casos de TOs e $40,33 \%$ de todos os odontomas. A análise dos resultados revelou que 57 casos eram do gênero masculino $(46,34 \%)$ e que 66 casos $(53,66 \%)$ pertenciam ao gênero feminino (mas:fem=1:1,16) (Tabela 10).

A idade mínima obtida na época do diagnóstico foi de 3 anos e a máxima de 75 anos (IM=23,50 e $D P=15,68)$. Sessenta e oito por cento dos casos foram diagnosticados em pacientes na primeira, segunda ou terceira décadas de vida (Tabela 11).

Quanto à localização, 59 casos $(47,97 \%)$ ocorreram na mandíbula, 44 $(35,77 \%)$ na maxila, em 19 casos (15,45\%) a localização não foi especificada e um caso apresentava lesões em ambos os ossos maxilares (0,81\%). Na mandíbula, 41 casos (69,49\%) acometeram a região posterior, 5 casos (8,47\%) acometeram a região anterior e 1 caso (1,70\%) se estendeu por mais de uma área. Em 12 casos $(20,34 \%)$ a área da mandíbula acometida não foi especificada. Na maxila, 22 casos (50\%) ocorreram na região anterior, 11 casos (25\%) na região posterior, 6 casos $(13,64 \%)$ se estenderam por mais de uma área e em 5 caso $(11,36 \%)$ a área acometida não foi especificada (maxila:mandíbula=1:1,34) (Tabela 12). 


\section{- ODONTOMA COMPOSTO}

Os odontomas compostos representaram $14,52 \%$ (182 casos) do total de casos de TOs e $59,67 \%$ de todos os odontomas. A análise dos resultados revelou que 81 casos eram do gênero masculino (44,51\%) e 100 casos $(54,94 \%)$ do gênero feminino (mas:fem=1:1,23). Um paciente $(0,55 \%)$ não trazia esse dado (Tabela 10).

A idade mínima obtida na época do diagnóstico foi de 3 anos e a máxima de 76 anos (IM=18,68 e DP=12,34). Em sessenta e nove por cento dos casos (126) os pacientes estavam na primeira ou segunda décadas de vida (Tabela 11).

Quanto à localização, 55 casos (30,22\%) ocorreram na mandíbula, 104 $(57,14 \%)$ na maxila, em 22 casos (12,09\%) a localização não foi especificada e em 1 caso $(0,55 \%)$ o paciente apresentava lesões múltiplas. Na mandíbula, 17 casos $(30,91 \%)$ acometeram a região posterior, 20 casos $(36,36 \%)$ acometeram a região anterior, 5 casos $(9,09 \%)$ se estenderam por mais de uma área e em 13 casos $(23,64 \%)$ a área afetada não foi especificada. Na maxila, 69 casos $(66,35 \%)$ ocorreram na região anterior, 10 casos $(9,61 \%)$ na região posterior, 6 casos $(5,77 \%)$ se estenderam por mais de uma área e em 19 casos $(18,27 \%)$ a área afetada não foi especificada (maxila:mandíbula=1,68:1) (Tabela 12).

\section{$\checkmark$ ODONTOAMELOBLASTOMA}

O único odontoameloblastoma diagnosticado correspondeu a $0,08 \%$ dos casos de TOs avaliados. A paciente era do gênero feminino (Tabela 10) e na época do diagnóstico apresentava-se com 25 anos de idade (Tabela 11). A lesão ocorreu na região posterior da maxila (Tabela 12). 


\section{$\checkmark$ TUMOR ODONTOGENNICO CÍSTICO CALCIFICANTE}

Os tumores odontogênicos císticos calcificantes corresponderam a 3,51\% dos casos de TOs diagnosticados (44 casos). Desses, 16 casos (36,36\%) foram diagnosticados em pacientes do gênero masculino e $28(63,64 \%)$ em pacientes do gênero feminino (mas:fem=1:1,75) (Tabela 10).

A idade mínima obtida na época do diagnóstico foi de 7 anos e a máxima de 62 anos (IM=23,74 e DP=15,03). Quarenta e cinco por cento dos casos ocorreram na segunda década de vida (Tabela 11).

Quanto à localização, 14 casos (31,82\%) ocorreram na mandíbula, 21 $(47,73 \%)$ na maxila e em 9 casos $(20,45 \%)$ a localização não foi especificada. $\mathrm{Na}$ mandíbula, 4 casos $(28,57 \%)$ ocorreram na região posterior, 1 caso $(7,14 \%)$ na região anterior, 2 casos $(14,29 \%)$ se estenderam por mais de uma área e em 7 casos (50) a área afetada não foi especificada. Doze casos $(57,14 \%)$ ocorreram na região anterior da maxila, 2 casos (9,52\%) ocorreram na região posterior, 4 casos (19,05\%) acometeram ambas as áreas e em 3 casos (14,29\%) a área afetada não foi informada (maxila:mandíbula=1,5:1) (Tabela 12).

\section{$\checkmark$ TUMOR DENTINOGÊNICO DE CÉLULAS FANTASMAS}

Dois casos de tumor dentinogênico de célula fantasmas foram diagnosticados e corresponderam a $0,16 \%$ dos casos de TOs diagnosticados. Os pacientes eram do gênero feminino (Tabela 10) e ambos tinham 41 anos na época do diagnóstico. (Tabela 11). Em um dos casos a lesão ocorreu em uma área não especificada da mandíbula e no outro na região anterior da maxila (Tabela 12). 
MESÊNQUIMA OU ECTOMESÊNQUIMA ODONTOGÊNICO COM OU SEM EPITÉLIO ODONTOGÊNICO

\section{$\checkmark$ FIBROMA ODONTOGÊNICO}

\section{- FIBROMA ODONTOGÊNICO CENTRAL}

Os fibromas odontogênicos centrais corresponderam a 0,80\% dos casos de TOs diagnosticados (10 casos). Seis casos (60\%) foram diagnosticados em pacientes do gênero masculino e 4 casos (40\%) em pacientes do gênero feminino (mas:fem=1,5:1) (Tabela 10).

A análise dos resultados revelou que a idade mínima obtida na época do diagnóstico foi de 14 anos e a máxima de 49 anos ( $\mathrm{IM}=28,55$ e $\mathrm{DP}=14,17)$. Houve um pico de incidência na segunda década de vida (40\% dos casos) (Tabela 11 ).

Quanto à localização, 4 casos (40\%) ocorreram na mandíbula, 3 deles (75\%) na região posterior e um em área não determinada, e 6 tumores (60\%) ocorreram na maxila, sendo um $(16,67 \%)$ na região anterior, um $(16,67 \%)$ na região posterior e um $(16,67 \%)$ se estendendo por ambas as regiões. Em 3 casos (50\%) a área afetada da maxila não foi especificada (maxila:mandíbula:1,5:1) (Tabela 12).

\section{- FIBROMA ODONTOGÊNICO PERIFÉRICO}

Os fibromas odontogênicos periféricos corresponderam a 1,52\% dos casos de TOs diagnosticados (19 casos). Quatro casos (21,05\%) foram diagnosticados em pacientes do gênero masculino e 15 (78,95\%) em pacientes do gênero feminino (mas:fem=1:3,75) (Tabela 10).

A idade mínima obtida na época do diagnóstico foi de 8 anos e a máxima de 52 anos $(I M=29,72$ e $D P=13,61)$. Houve um pico de incidência na terceira década de vida (8 casos $-42,11 \%)$ (Tabela 11$)$. 
Quanto à localização, 5 casos (26,31\%) ocorreram na mandíbula, 9 (47,38\%) na maxila e em 5 casos (26,31\%) a localização não foi especificada. Na mandíbula, 3 casos (60\%) ocorreram na região posterior, 1 caso (20\%) ocorreu na região anterior e 1 caso (20\%) se estendeu por ambas as áreas. Na maxila, 4 casos $(44,44 \%)$ ocorreram na região anterior de maxila, 3 casos (33,33\%) na região posterior, 1 caso $(11,11 \%)$ envolveu as duas regiões e em 1 caso $(11,11 \%)$ a área afetada não foi informada (maxila:mandíbula=1,8:1) (Tabela 12).

\section{$\checkmark \quad$ MIXOMA ODONTOGÊNICO}

Os mixomas odontogênicos corresponderam a 9,58\% dos casos de TOs diagnosticados (120 casos). Quarenta e um casos (34,17\%) foram diagnosticados em pacientes do gênero masculino e 79 (65,83\%) em pacientes do gênero masculino (mas:fem=1:1,93) (Tabela 10).

A idade mínima obtida na época do diagnóstico foi de 4 anos e a máxima de 84 anos (IM=29,44 e DP=16,44). Cinqüenta e quatro por cento dos casos (65 casos) ocorreram entre a segunda e terceira décadas de vida (Tabela 11).

Quanto à localização, 60 casos (50\%) ocorreram na mandíbula, 46 (38,33\%) na maxila e em 14 casos (11,67\%) a localização não foi especificada. Na mandíbula, 28 casos $(46,66 \%)$ acometeram a região posterior, 7 casos $(11,67 \%)$ acometeram a região anterior, 7 casos $(11,67 \%)$ se estenderam por mais de uma área e em 18 casos (30\%) a área acometida não foi especificada. Quatorze casos $(30,43 \%)$ ocorreram na região posterior de maxila, 4 casos $(8,70 \%)$ ocorreram na região anterior, 11 casos $(23,91 \%)$ acometeram ambas as áreas e em 17 casos $(36,96 \%)$ a área afetada não foi informada (maxila:mandíbula=1:1,3) (Tabela 12). 


\section{$\checkmark$ CEMENTOBLASTOMA}

Os cementoblastomas corresponderam a 1,04\% dos casos de TOs diagnosticados (13 casos), dos quais 2 casos (15,38\%) foram diagnosticados em pacientes do gênero masculino e 11 (84,62\%) em pacientes do gênero feminino (mas:fem=1:5,5) (Tabela 10).

A idade mínima obtida na época do diagnóstico foi de 6 anos e a máxima de 77 anos (IM=31,83 e $D P=20,36)$. Quarenta e seis por cento dos casos ocorreram entre a segunda e terceira décadas de vida (Tabela 11).

Quanto à localização, 9 casos $(69,24 \%)$ ocorreram na mandíbula, 2 casos $(15,38 \%)$ ocorreram na maxila e em 2 casos (15,38\%)a localização não foi indicada. Todos os casos que ocorreram na mandíbula e na maxila afetaram a região posterior (maxila:mandíbula=1:4,5) (Tabela 12).

\section{$\checkmark$ TUMOR ODONTOGÊNICO COMBINADO}

Dois casos de tumor odontogênico combinado foram diagnosticados e corresponderam a $0,16 \%$ dos casos de TOs avaliados. Ambos ocorreram em pacientes do gênero feminino (Tabela 10) e os pacientes apresentavam 14 e 25 anos de idade na época do diagnóstico (IM=19,5 e DP=7,78) (Tabela 11). As lesões ocorreram na mandíbula, uma na região anterior e a outra na região posterior (Tabela 12). Uma das lesões era composta em parte por um tumor odontogênico cístico calcificante e em parte por um fibroma ameloblástico, enquanto a outra era composta em parte por um tumor odontogênico adenomatóide e em parte por um tumor odontogênico epitelial calcificante. 


\section{$\checkmark$ TUMOR ODONTOGENNICO NÃO CLASSIFICADO}

Dois casos de tumor odontogênico não classificado foram diagnosticados e corresponderam a 0,16\% dos casos de TOs avaliados. Um paciente era do gênero masculino e o outro do gênero feminino (mas:fem=1:1) (Tabela 10) e os pacientes apresentavam 10 e 18 anos de idade na época do diagnóstico (IM=14 e DP=5,66) (Tabela 11). As lesões ocorreram na mandíbula, uma na região posterior e na outra a área afetada não foi informada (Tabela 12). Ambas eram sabidamente lesões de origem odontogênica e com características de benignidade.

$\checkmark$ QUERATOAMELOBLASTOMA

O único odontoameloblastoma diagnosticado correspondeu a 0,08\% dos casos de TOs avaliados. O paciente era do gênero masculino (Tabela 26) e na época do diagnóstico apresentava-se com 29 anos de idade (Tabela 27). A lesão ocorreu em uma área não especificada da mandíbula (Tabela 28).

\section{TUMORES MALIGNOS}

\section{CARCINOMA ODONTOGENNICO}

\section{$\checkmark$ CARCINOMA AMELOBLÁSTICO PRIMÁRIO}

Os carcinomas ameloblásticos primários corresponderam a 0,24\% dos casos de TOs (3 casos) e a 30\% dos casos de tumores odontogênicos malignos diagnosticados. Dois casos (66,67\%) foram diagnosticados em pacientes do gênero 
masculino e 1 caso (33,33\%) em um paciente do gênero feminino (mas:fem=2:1) (Tabela 10).

A idade mínima obtida na época do diagnóstico foi de 22 anos e a máxima de 72 anos $(I M=40,67$ e $D P=27,30)$. Sessenta e sete por cento dos casos foi diagnosticado na terceira década de vida, como pode ser visto na Tabela 11.

Quanto à localização, 2 casos $(66,67 \%)$ ocorreram na mandíbula e 1 caso $(33,33 \%)$ na região anterior maxila. Na mandíbula, 1 caso (50\%) ocorreu na região posterior e em 1 caso (50\%) a área acometida não foi especificada (maxila:mandíbula=1:2) (Tabela 12).

\section{$\checkmark$ CARCINOMA AMELOBLÁSTICO SECUNDÁRIO}

O único carcinoma ameloblástico secundário diagnosticado correspondeu a 0,08\% dos casos de TOs e a 10\% dos casos de tumores odontogênicos malignos. 0 paciente era do gênero feminino (Tabela 10) e na época do diagnóstico apresentava-se com 25 anos de idade (Tabela 11). A lesão ocorreu na mandíbula, região posterior (Tabela 12 ).

\section{$\checkmark$ CARCINOMA EPIDERMÓIDE INTRA-ÓSSEO PRIMÁRIO}

O único carcinoma epidermóide intra-ósseo primário diagnosticado correspondeu a 0,08\% dos casos de TOs e a 10\% dos casos de tumores odontogênicos malignos. O paciente era do gênero masculino (Tabela 10) e na época do diagnóstico apresentava-se com 32 anos de idade (Tabela 11). A lesão ocorreu na mandíbula, região anterior (Tabela 12). 


\section{$\checkmark$ CARCINOMA EPIDERMÓIDE INTRA-ÓSSEO PRIMÁRIO DERIVADO DE TUMOR ODONTOGÊNICO QUERATOCÍSTICO}

O carcinoma epidermóide intra-ósseo primário derivado de tumore odontogênico queratocístico correspondeu a $0,24 \%$ dos casos de TOs (3 casos) e a $30 \%$ dos casos de tumores odontogênicos malignos diagnosticados. Os três casos (100\%) foram diagnosticados em pacientes do gênero (Tabela 10).

A idade mínima obtida na época do diagnóstico foi de 59 anos e a máxima de 72 anos (IM=65,33 e DP=6,03). Todos os casos foram diagnosticados em pacientes com idade acima da quinta década de vida (Tabela 11).

Quanto à localização, todos os 3 casos ocorreram na mandíbula, 2 casos $(66,67 \%)$ na região posterior e em 1 caso $(33,33 \%)$ a área acometida não foi especificada (Tabela 12).

\section{SARCOMA ODONTOGENNICO}

\section{FIBROSSARCOMA AMELOBLÁSTICO}

O fibrossarcoma ameloblástico correspondeu a $0,16 \%$ dos casos de TOs e a $20 \%$ dos casos de tumores odontogênicos malignos. Os pacientes eram um do gênero feminino e o outro do gênero masculino (mas:fem=1:1) (Tabela 10) e na época do diagnóstico apresentavam-se com 24 anos de idade (Tabela 11). As lesões ocorreram na mandíbula, uma na região posterior e a outra a localização não foi especificada (Tabela 12).

A partir dos dados adquiridos nas três instituições mexicanas foi possível definir um perfil de prevalência para os TOs como pode ser visto nas Tabelas 10, 11, 12 e 13. No Gráfico 2 é possível visualizarmos a diferença na prevalência dos tumores mais comumente encontrados nessas instituições mexicanas. 


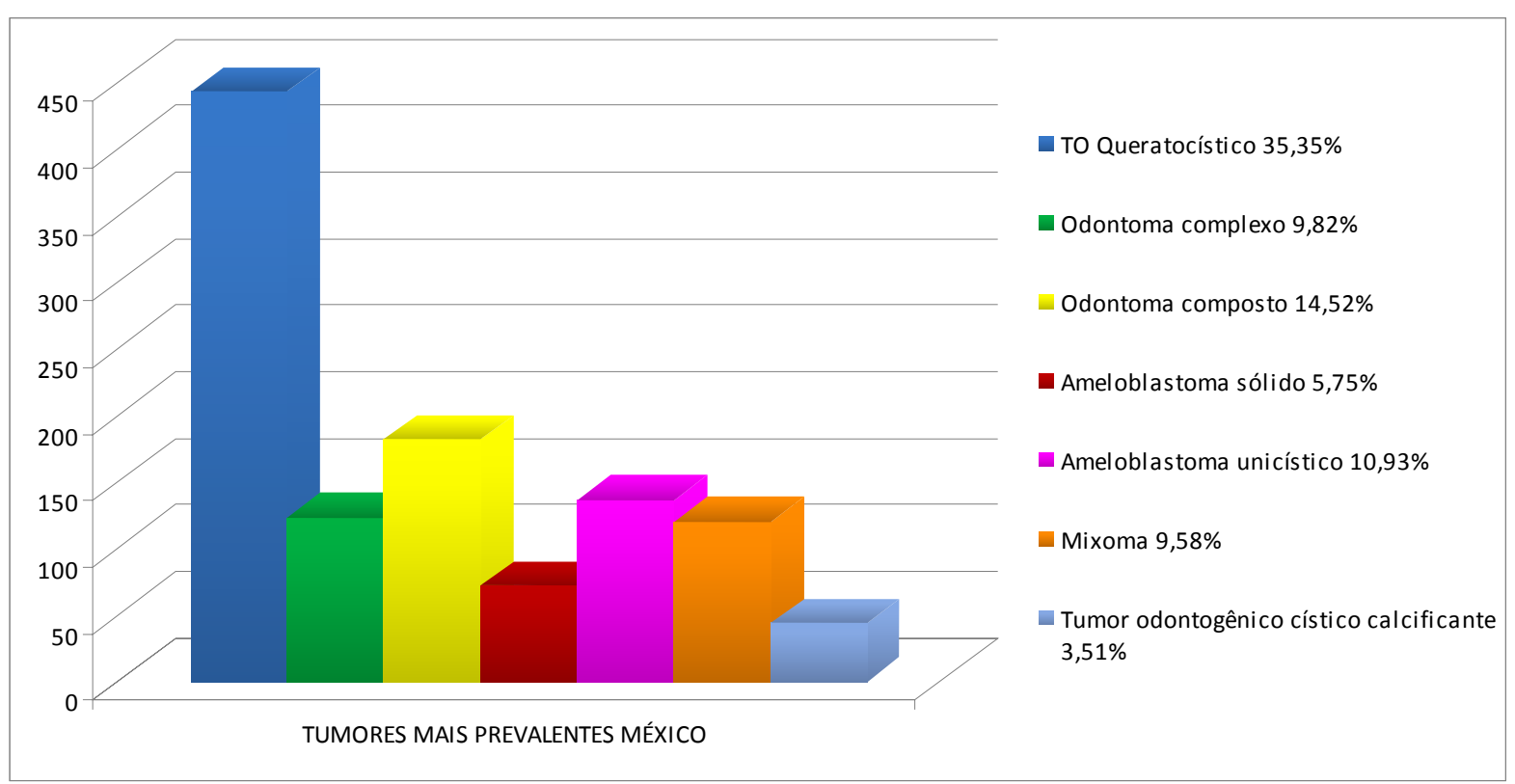

Gráfico 2 - Tumores mais prevalentes nas instituições mexicanas 
Tabela 9- Freqüência relativa dos tumores odontogênicos nas instituições mexicanas

\begin{tabular}{|c|c|c|c|}
\hline Diaqnóstico & Abreviação & Número de casos & Porcentaqem \\
\hline \multicolumn{4}{|c|}{ Tumores Benignos } \\
\hline \multicolumn{4}{|c|}{ Epitélio odontogênico com estroma fibroso maduro, sem ectomesênquima odontogênico } \\
\hline Ameloblastoma sólido multicístico & AS-M & 72 & 5,75 \\
\hline Ameloblastoma unicístico & $A-U$ & 137 & 10,93 \\
\hline Ameloblastoma periférico & AP & 4 & 0,32 \\
\hline Tumor odontogênico epitelial calcificante & TOEC & 6 & 0,48 \\
\hline Tumor odontogênico adenomatóide & TOA & 45 & 3,59 \\
\hline Tumor odontogênico queratocístico & TOQ & 443 & 35,35 \\
\hline \multicolumn{4}{|c|}{ Epitélio odontogênico com ectomesênquima odontogênico, com ou sem formação de tecido duro } \\
\hline Fibroma ameloblástico & FA & 8 & 0,64 \\
\hline Fibrodentinoma ameloblástico & FDA & 1 & 0,08 \\
\hline Fibro-odontoma ameloblástico & FOA & 8 & 0,64 \\
\hline Odontoma complexo & OC & 123 & 9,82 \\
\hline Odontoma composto & OCp & 182 & 14,52 \\
\hline Odontoameloblastoma & ODA & 1 & 0,08 \\
\hline Tumor odontogênico cístico calcificante & TOCC & 44 & 3,51 \\
\hline Tumor dentinogênico de células fantasmas & TDCF & 2 & 0,16 \\
\hline \multicolumn{4}{|c|}{ Mesênquima ou ectomesênquima odontogênico com ou sem epitélio odontogênico } \\
\hline Fibroma odontogênico central & FOC & 10 & 0,80 \\
\hline Fibroma odontogênico periférico & FOP & 19 & 1,52 \\
\hline Mixoma odontogênico - Mixofibroma & $\mathrm{MO}$ & 120 & 9,58 \\
\hline Cementoblastoma & $\mathrm{CB}$ & 13 & 1,04 \\
\hline Tumor odontogênico combinado & TOC & 2 & 0,16 \\
\hline Tumor odontogênico não classificado & TONC & 2 & 0,16 \\
\hline Queratoameloblastoma & QAM & 1 & 0,08 \\
\hline \multicolumn{4}{|l|}{ Tumores Malignos } \\
\hline \multicolumn{4}{|l|}{ Carcinoma odontogênico } \\
\hline Carcinoma ameloblástico primário & CAP & 3 & 0,24 \\
\hline Carcinoma ameloblástico secundário & CAS & 1 & 0,08 \\
\hline Carcinoma de células escamosas intra-ósseo primário & CEIOP & 1 & 0,08 \\
\hline $\begin{array}{l}\text { Carcinoma de células escamosas intra-ósseo primário derivado de TOQ } \\
\text { Sarcomas odontogênicos }\end{array}$ & CEIOPTOQ & 3 & 0,24 \\
\hline Fibrossarcoma ameloblástico & FSA & 2 & 0,16 \\
\hline TOTAL & & 1253 & 100 \\
\hline
\end{tabular}


Tabela 10 - Distribuição por gênero dos tumores odontogênicos nas instituições mexicanas

\begin{tabular}{|c|c|c|c|c|c|c|c|c|}
\hline \multirow[t]{2}{*}{ Tumores Odontoqênicos } & \multicolumn{6}{|c|}{ Gênero } & \multicolumn{2}{|c|}{ Total } \\
\hline & Masculino & $\%$ & Feminino & $\%$ & NE & $\%$ & Total & $\%$ \\
\hline \multicolumn{9}{|l|}{ Tumores Benignos } \\
\hline AS-M & 37 & 51,39 & 35 & 48,61 & - & - & 72 & 5,75 \\
\hline $\mathrm{A}-\mathrm{U}$ & 70 & 51,10 & 66 & 48,17 & 1 & 0,73 & 137 & 10,93 \\
\hline$A P$ & 3 & 75 & 1 & 25 & - & - & 4 & 0,32 \\
\hline TOEC & 2 & 33,33 & 4 & 67,77 & - & - & 6 & 0,48 \\
\hline TOA & 19 & 42,22 & 26 & 57,78 & - & - & 45 & 3,59 \\
\hline TOQ & 245 & 55,30 & 196 & 44,24 & 2 & 0,45 & 443 & 35,35 \\
\hline \multicolumn{9}{|l|}{$2^{\circ}$ Grupo } \\
\hline FA & 3 & 37,50 & 5 & 62,50 & - & - & 8 & 0,64 \\
\hline FDA & - & - & 1 & 100 & - & - & 1 & 0,08 \\
\hline FOA & 5 & 62,50 & 3 & 37,50 & - & - & 8 & 0,64 \\
\hline OC & 57 & 46,34 & 66 & 53,66 & - & - & 123 & 9,82 \\
\hline OCp & 81 & 44,51 & 100 & 54,94 & 1 & 0,55 & 182 & 14,52 \\
\hline ODA & - & - & 1 & 100 & - & - & 1 & 0,08 \\
\hline TOCC & 16 & 36,36 & 28 & 63,64 & - & - & 44 & 3,51 \\
\hline TDCF & - & - & 2 & 100 & - & - & 2 & 0,16 \\
\hline \multicolumn{9}{|l|}{$3^{\circ}$ Grupo } \\
\hline FOC & 6 & 60 & 4 & 40 & - & - & 10 & 0,80 \\
\hline FOP & 4 & 21,05 & 15 & 78,95 & - & - & 19 & 1,52 \\
\hline MO & 41 & 34,17 & 79 & 65,83 & - & - & 120 & 9,58 \\
\hline $\mathrm{CB}$ & 2 & 15,38 & 11 & 84,62 & - & - & 13 & 1,04 \\
\hline TOC & - & - & 2 & 100 & - & - & 2 & 0,16 \\
\hline TONC & 1 & 50 & 1 & 50 & - & - & 2 & 0,16 \\
\hline QAM & 1 & 100 & - & - & - & - & 1 & 0,08 \\
\hline \multicolumn{9}{|l|}{ Tumores Malignos } \\
\hline \multicolumn{9}{|l|}{$\mathrm{CO}$} \\
\hline CAP & 2 & 66,7 & 1 & 33,3 & - & - & 3 & 0,24 \\
\hline CAS & - & - & 1 & 100 & - & - & 1 & 0,08 \\
\hline CEIOP & 1 & 100 & - & - & - & - & 1 & 0,08 \\
\hline CEIOPTOQ & 3 & 100 & - & - & - & - & 3 & 0,24 \\
\hline \multicolumn{9}{|l|}{ so } \\
\hline FSA & 1 & 50 & 1 & 50 & - & - & 2 & 0,16 \\
\hline IOIAL & 600 & 47,89 & 649 & 51,79 & 4 & 0,32 & 1253 & 100 \\
\hline
\end{tabular}


Tabela 11 - Distribuicão por faixa etária dos tumores odontoqênicos nas instituicões mexicanas

\begin{tabular}{|c|c|c|c|c|c|c|c|c|c|c|c|c|c|c|c|}
\hline \multirow{3}{*}{ Tumor } & \multirow{3}{*}{ Total } & \multirow{2}{*}{\multicolumn{11}{|c|}{$\begin{array}{l}\text { Jdade na época do diaanóstico } \\
\text { Faixa etária }\end{array}$}} & \multirow{3}{*}{$\begin{array}{l}\text { Variação } \\
\text { da Idade }\end{array}$} & \multirow{3}{*}{ Med } & \multirow{3}{*}{ Idade Média \pm DP } \\
\hline & & & & & & & & & & & & & & & \\
\hline \multirow{2}{*}{\multicolumn{16}{|c|}{$\begin{array}{l}\text { Benignos } \\
1^{\circ} \mathrm{Grupo}\end{array}$}} \\
\hline & & & & & & & & & & & & & & & \\
\hline AS-M & 72 & 1 & 10 & 20 & 13 & 6 & 11 & 4 & 4 & - & - & 3 & $1-76$ & 32 & $37,14 \pm 17,47$ \\
\hline$A-U$ & 137 & 3 & 48 & 41 & 20 & 8 & 6 & 7 & - & - & - & 4 & $5-67$ & 23 & $27,23 \pm 13,96$ \\
\hline AP & 4 & - & - & - & 1 & - & 2 & 1 & - & - & - & - & $40-66$ & 57,5 & $55,25 \pm 11,12$ \\
\hline TOEC & 6 & - & 1 & 1 & 1 & 2 & 1 & - & - & - & - & - & $19-55$ & 41 & $39,33 \pm 13,70$ \\
\hline TOA & 45 & 2 & 34 & 7 & 1 & - & - & 1 & - & - & - & - & $10-69$ & 15 & $17,71 \pm 9,16$ \\
\hline \multicolumn{16}{|l|}{$2^{\circ} \mathrm{Grupo}$} \\
\hline FA & 8 & 4 & 4 & - & - & - & - & - & - & - & - & - & $2-15$ & 11,5 & $10 \pm 4$ \\
\hline FDA & 1 & 1 & - & - & - & - & - & - & - & - & - & - & 10 & 10 & 10 \\
\hline FOA & 8 & 7 & - & 1 & - & - & - & - & - & - & - & - & $2-25$ & 9,5 & $9,88 \pm 6,71$ \\
\hline OC & 123 & 18 & 46 & 20 & 14 & 7 & 3 & 3 & 2 & - & - & 10 & $3-75$ & 19 & $23,50 \pm 15,68$ \\
\hline OCp & 182 & 42 & 84 & 29 & 10 & 6 & 2 & 3 & 1 & - & - & 5 & $3-76$ & 15 & $18,68 \pm 12,34$ \\
\hline ODA & 1 & - & 1 & - & - & - & - & - & - & - & - & - & 25 & 25 & 25 \\
\hline TOCC & 44 & 4 & 20 & 10 & - & 4 & 3 & 1 & - & - & - & 2 & $7-62$ & 17 & $23,74 \pm 15,03$ \\
\hline TDCF & 2 & - & - & - & - & 2 & - & - & - & - & - & - & 41 & 41 & 41 \\
\hline \multicolumn{16}{|l|}{$3^{\circ}$ Grupo } \\
\hline FOC & 10 & - & 4 & 1 & 2 & 2 & - & - & - & - & - & 1 & $14-49$ & 25 & $28,55 \pm 14,17$ \\
\hline FOP & 19 & 1 & 3 & 8 & 1 & 4 & 1 & - & - & - & - & 1 & $8-52$ & 27 & $29,72 \pm 13,61$ \\
\hline MO & 120 & 8 & 30 & 35 & 17 & 12 & 6 & 1 & 2 & 2 & - & 7 & 4_84 & 27 & $29,44 \pm 16,44$ \\
\hline CB & 13 & 1 & 3 & 3 & 2 & 1 & 1 & - & 1 & - & - & 1 & $6-77$ & 26 & $31,83 \pm 20,36$ \\
\hline TOC & 2 & - & 1 & 1 & - & - & - & - & - & - & - & - & $14-25$ & 19,5 & $19,5 \pm 7,78$ \\
\hline TONC & 2 & 1 & 1 & - & - & - & - & - & - & - & - & - & $10-18$ & 14 & $14 \pm 5,66$ \\
\hline QAM & 1 & - & - & 1 & - & - & - & - & - & - & - & - & 29 & 29 & 29 \\
\hline \multirow{2}{*}{\multicolumn{16}{|c|}{$\begin{array}{l}\text { Malignos } \\
\mathrm{CO}\end{array}$}} \\
\hline & & & & & & & & & & & & & & & \\
\hline CAP & 3 & - & - & 2 & - & - & - & - & 1 & - & - & - & $22-72$ & 28 & $40,67 \pm 27,30$ \\
\hline CAS & 1 & - & - & 1 & - & - & - & - & - & - & - & - & 25 & 25 & 25 \\
\hline CEIOP & 1 & - & - & - & 1 & - & - & - & - & - & - & - & 32 & 32 & 32 \\
\hline $\begin{array}{l}\text { CEIOPTOQ } \\
\text { SO }\end{array}$ & 3 & - & - & - & - & - & 1 & 1 & 1 & - & - & - & $59-71$ & 66 & $65,33 \pm 6,03$ \\
\hline FSA & 2 & - & - & 2 & - & - & - & - & - & - & - & - & 24 & 24 & 24 \\
\hline TOTAL & 1253 & 119 & 407 & 284 & 140 & 99 & 66 & 48 & 27 & 3 & - & 60 & - & - & - \\
\hline
\end{tabular}


Tabela 12 - Distribuicão por localizacão dos tumores odontogênicos nas instituicões mexicanas

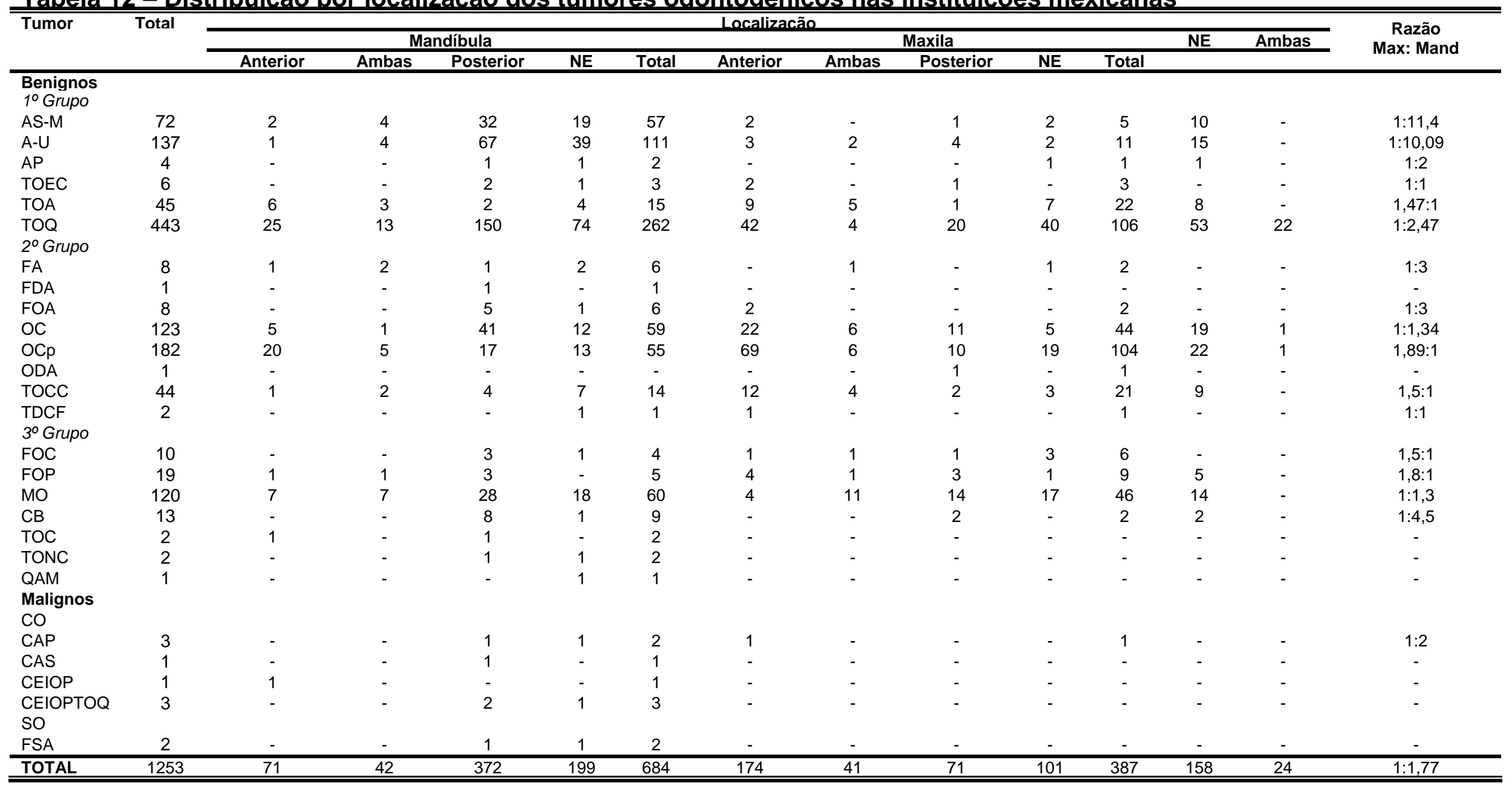


6 Discussão 


\section{DISCUSSÃO}

\subsection{CLASSIFICAÇÕES DOS TUMORES ODONTOGÊNICOS}

Os tumores odontogênicos são lesões de grande importância para patologistas e cirurgiões bucais que vem estudando essas lesões há décadas buscando entender seus mecanismos de formação e desenvolvimento, bem como desenvolver técnicas cada vez mais adequadas de tratamento.

Esses tumores compõem um grupo de lesões incomuns, porém interessantes, que se forma a partir dos tecidos que dão origem aos dentes. Até certo ponto, essas lesões são imagens de uma odontogênese incontrolada que refletem diferentes graus de interação intertecidual e variados padrões de crescimento, e variam de proliferações hamartomatosas não neoplásicas até neoplasias malignas com capacidade metastática (PHILIPSEN; REICHART, 2002).

Inúmeras foram as tentativas realizadas até hoje para classificar esses tumores, tentativas essas que se basearam em diferentes critérios como estágio de desenvolvimento do órgão dental envolvido (BROCA, 1868), origem dos tecidos odontogênicos (GABELL et al., 1914), evidência embriológica de indução recíproca entre esses tecidos (GORLIN; CHAUDHRY; PINDBORG, 1961; PINDBORG; CLAUSEN, 1958; ROBINSON, 1952; THOMA; GOLDMAN, 1946), grau de diferenciação do epitélio odontogênico de origem (SHEAR, 1965) e diferenciação de tumores odontogênicos de lesões "neoplastic-like" (BADEN, 1971).

Entretanto, somente em 1971 com a criação da primeira classificação de tumores odontogênicos publicada pela OMS (PINDBORG; KRAMER, 1971) se estabeleceram critérios mundialmente aceitos e usados como um padrão de classificação para os tumores odontogênicos até então reconhecidos. O conhecimento mais aprofundado sobre o comportamento biológico dessas lesões e a melhor compreensão sobre a interação indutiva entre os tecidos que as originavam foram pontos chaves para a fragmentação dessa classificação nos diversos tipos tumorais.

Após 20 anos de descobertas, com a possibilidade de desvendar constituintes específicos dos tumores odontogênicos e os mecanismos de desenvolvimento dos 
mesmos tornou-se necessário ampliar essa primeira classificação e foi então publicada a segunda classificação de tumores odontogênicos da OMS (KRAMER; PINDBORG; SHEAR, 1992), mais completa e atualizada. Entretanto, a ênfase do texto foi dada aos critérios clínicos diagnósticos e às técnicas convencionais de histopatologia de rotina (KRAMER; PINDBORG; SHEAR, 1992), métodos disponíveis e confiáveis até o momento.

Desde então, o desenvolvimento de novas tecnologias em diagnóstico imunoistoquímico, biologia molecular e genética, assim como o acúmulo de conhecimento a respeito de características clínicas e epidemiológicas dos tumores incluídos nas classificações anteriores, revelaram a necessidade de atualização da segunda classificação da OMS. Assim em 2005, uma terceira edição da Classificação de tumores odontogênicos foi publicada pela OMS (BARNES et al., 2005).

Um número importante de modificações foi incluído na terceira edição da classificação, demonstrando um aprimoramento no conhecimento da definição, epidemiologia, etiologia, localização, achados clínicos, imaginológicos, microscópicos, além de alterações genéticas, e do prognóstico dos tumores odontogênicos (REICHART; PHILIPSEN; SCIUBBA, 2006).

O esclarecimento sobre o comportamento dos tumores odontogênicos malignos foi uma importante mudança observada na terceira edição da classificação da OMS, que pode ser vista com a separação do ameloblastoma metastatizante, do carcinoma ameloblástico tipo primário e do carcinoma ameloblástico tipo secundário; do carcinoma epidermóide intra-ósseo primário em tipos sólido, derivado de tumor odontogênico queratocístico e derivado do epitélio de outros cistos; além da inclusão do antigo tumor odontogênico de células claras e do carcinoma odontogênico de células fantasmas no grupo de tumores malignos. Apesar disso, devido a raridade dessas lesões há muito que se estudar e descobrir sobre esses tumores malignos, o que torna a publicação de casos e a discussão dos mesmos uma prática recomendada.

No grupo de tumores benignos, a separação do tumor odontogênico cístico calcificante e do tumor dentinogênico de células fantasmas ficou muito clara. Entretanto, restam ainda algumas dúvidas no que diz respeito à relevância clínica e terapêutica da separação ou não das diversas variantes císticas (REICHART; PHILIPSEN; SCIUBBA, 2006). 
Outras pequenas modificações foram realizadas no grupo de tumores de mesênquima ou ectomesênquima odontogênico com ou sem epitélio odontogênico, como a modificação da nomenclatura das variantes de fibroma odontogênico central em "pobre em epitélio" ou "rica em epitélio" e cementoblastoma, alterações essas baseadas nos achados histológicos (REICHART; PHILIPSEN; SCIUBBA, 2006) e que não alteraram em nada a compreensão dos mesmos.

Mas as maiores modificações observadas na nova classificação, ocorreram no grupo dos tumores odontogênicos de epitélio odontogênico com estroma maduro e sem ectomesênquima. Uma das mais importantes foi o reconhecimento das diferentes variantes do ameloblastoma, uma vez que reflete o maior entendimento sobre os diferentes perfis biológicos desses tumores, sua incidência variada quanto a idade, distribuição, localização, achados imaginológicos, prognóstico e terapêuticas (REICHART; PHILIPSEN; SCIUBBA, 2006).

Outra modificação relevante foi a introdução do tumor odontogênico adenomatóide neste grupo de tumores, demonstrando um aperfeiçoamento nos conhecimentos microscópicos dessas lesões, facilitando a compreensão do mesmo (REICHART; PHILIPSEN; SCIUBBA, 2006). Somado a isso, um melhor conhecimento genético dessas lesões levou a mais revolucionária e controversa modificação da classificação, que foi a inclusão do antigo queratocisto odontogênico nesse mesmo grupo de tumores, recebendo a denominação de tumor odontogênico queratocístico (REICHART; PHILIPSEN; SCIUBBA, 2006).

Essa modificação vem sendo amplamente discutida na literatura e baseou-se no comportamento neoplásico do queratocisto odontogênico, sua alta taxa de recorrência, e também em alterações cromossomais e genéticas detectadas em casos esporádicos do tumor odontogênico queratocístico e de queratocistos odontogênicos observados em pacientes portadores da síndrome do carcinoma nevóide basocelular, também denominada síndrome de Gorlin (REICHART; PHILIPSEN; SCIUBBA, 2006).

Apesar das muitas descobertas descritas na literatura que permitiram a criação da nova classificação da OMS, a falta de marcadores específicos que confirmem a origem odontogênica dessas lesões e a falta de achados relacionados a alterações genéticas que possam levar ao desenvolvimento das mesmas, faz com que os diagnósticos ainda sejam baseados principalmente nas considerações anatômicas, na relação com os dentes e/ou nas similaridades histomorfológicas 
entre os tumores odontogênicos com os órgãos que dão origem aos dentes (MOSQUEDA-TAYLOR, 2008).

Além disso, sabe-se que as classificações têm uma vida curta, dependendo principalmente da persistência dos conceitos básicos que suportam a existência das lesões. Sendo assim, pode-se esperar que algumas das lesões menos conhecidas ou mesmo aquelas não classificadas atualmente, possam ser adequadamente definidas em edições futuras (MOSQUEDA-TAYLOR, 2008). De qualquer maneira a criação dessas classificações é indispensável, pois elas permitem o estudo organizado e esclarecedor sobre os tumores, sua patogênese, a possível relação entre as lesões e seu comportamento biológico.

Para Baden (1971) teoricamente, as deficiências das classificações podem não ser muito importantes, mas na prática clínica, classificações e terminologias auxiliam o clínico a tomar decisões terapêuticas que são primariamente baseadas no comportamento biológico da lesão. Sendo assim, é desejável usar uma linguagem uniforme compreendida por patologistas e cirurgiões a fim dê assegurar uma conduta adequada e o bem estar do paciente.

Por tudo isso, baseados nas diversas classificações já publicadas, inúmeros autores vêm realizando estudos epidemiológicos sobre tumores odontogênicos em todo o mundo (ADEBAYO; AJIKE; ADEKEYE, 2005; AVELAR et al., 2008; BUCHNER; MERRELL; CARPENTER, 2006; FERNANDES et al., 2005; LUO; LI, 2009; MOSQUEDA-TAYLOR et al., 1997; PIPPI, 2006; SIMON et al., 2005; SRIRAM; SHETTY, 2008; TOMAS, 2007). Esses estudos são muito importantes porque permitem saber mais a respeito da ocorrência dessas lesões em populações diversas e definir a importância relativa das várias neoplasias em relação ao bem estar dessas populações. Além disso, auxiliam a identificar populações de risco e possíveis causas e fatores associados ao desenvolvimento desses tumores (DALEY; WYSOCKI; PRINGLE, 1994; MOSQUEDA-TAYLOR, 2008).

Partindo da premissa de que as modificações apresentadas pela terceira edição da Classificação de Tumores Odontogênicos da OMS (BARNES et al., 2005) poderiam levar a uma mudança na freqüência relativa dos tumores odontogênicos no Brasil e no México, avaliamos a prevalência desses tumores em duas instituições no Brasil, a Faculdade de Odontologia de Bauru - USP e a Faculdade de Odontologia de Araçatuba - UNESP, e três instituições no México, a Faculdade de 
Odontologia da UNAM, a Faculdade de Odontologia da UAMX e o laboratório privado Peribact.

Como pode ser visto através da revisão de literatura vários trabalhos foram realizados em todo o mundo a respeito da prevalência dos TOs. Entretanto, o principal problema que dificulta a comparação entre os diferentes estudos epidemiológicos é que a maior parte deles não empregou critérios semelhantes para a classificação dos tumores estudados, uma vez que, em diferentes épocas foram utilizadas diferentes classificações ou diferentes conceitos que incluíam, por exemplo, mais de uma lesão em uma única designação (MOSQUEDA-TAYLOR, 2008).

Somando-se a isso existem outros fatores como o número muito variado de lesões descritas nos diferentes estudos, sendo algumas vezes muito limitado o que impediria uma comparação real, e a época em que esses estudos foram realizados, visto que estudos muito antigos não permitem traçar uma comparação válida devido à descoberta de novas lesões assim como a mudança na interpretação de outras (DALEY; WYSOCKI; PRINGLE, 1994; TAY, 1999).

Outros fatores importantes a serem considerados nesse tipo de estudo são a experiência e a especialidade dos cirurgiões-dentistas que enviam as peças, sendo muito variado o tipo de lesão enviado por diferentes profissionais como endodontista, periodontista ou cirurgião bucomaxilofacial; a inclusão de peças enviadas de diversas regiões de um mesmo país, não representando adequadamente o estudo de uma determinada população; e a exclusão de peças que possam ter sido enviadas para outros serviços de anatomia patológica, deixando de fazer parte da amostra da região estudada (DALEY; WYSOCKI; PRINGLE, 1994).

Sendo assim, o número de trabalhos que poderiam ser comparados adequadamente com o atual fica restrito e se limitaria aos estudos de Jing et al. (2007), Tomas (2007), Avelar et al. (2008) e Luo e Li (2009). Em 2007, Tomas descreve os tumores, suas características clínicas e alguns dados epidemiológicos. Além disso, o autor cita quais seriam as lesões mais freqüentes, mas não revela o número exato de casos, o que impede uma comparação direta com nosso estudo.

No estudo de Jing et al. (2007) não é informado o percentual de TOs em relação ao total de biópsias diagnosticadas no serviço. Além disso, o autor descreve seus achados a respeito do tumor odontogênico queratocístico, mas o exclui quando 
compara seu estudo com os demais estudos de série de casos, assim como fizeram Luo e Li em 2009. Sendo assim, a comparação de nossos achados tornasse parcialmente limitada.

Por tudo isso, e também devido à alta freqüência relativa do tumor odontogênico queratocístico encontrada tanto no Brasil $(37,25 \%$ dos casos) quanto no México (35,35\%), decidimos realizar uma discussão inicial a respeito do tumor odontogênico queratocístico descrevendo nossos achados e comparando-os com outros trabalhos que enfocam apenas essa lesão e com os estudos de Jing et al. (2007), Avelar et al. (2008) e Luo e Li (2009).

É importante frisar que a introdução do queratocisto odontogênico no grupo de tumores odontogênicos foi a alteração mais significante realizada na nova classificação, uma vez que modificou numérica e significantemente a prevalência dessas lesões (MOSQUEDA-TAYLOR, 2008), o que pode ser visto quando avaliamos a prevalência dos TOs entre as lesões tanto no Brasil quanto no México considerando o TOQs como tumor (1,84\% e 4,09\%) ou não (1,15\% e 2,65\%).

\subsection{TUMOR ODONTOGÊNICO QUERATOCÍSTICO}

Também chamado queratocisto odontogênico, queratocistoma odontogênico e cisto primordial, o tumor odontogênico queratocístico foi recentemente incluído no grupo de tumores de epitélio odontogênico com estroma maduro e sem ectomesênquima e recebeu essa denominação a fim de demonstrar sua natureza neoplásica ainda que benigna (BARNES et al., 2005).

Toller (1967) foi o primeiro a sugerir a natureza neoplásica benigna dos queratocistos odontogênicos. Mais tarde em 1984, Ahlfors, Larsson e Sjogren propuseram que os queratocistos odontogênicos deveriam ser vistos como neoplasias císticas benignas. Desde então, evidências como o comportamento localmente destrutivo e as altas taxas de recorrência da lesão; o brotamento do epitélio a partir de células da camada basal do TOQ no tecido conjuntivo capsular subjacente; a formação de cistos satélites; sua tendência à multiplicidade, muitas vezes aparecendo em mais de uma área na cavidade bucal; a presença de figuras mitóticas na camada suprabasal do epitélio cístico e a detecção de alterações 
cromossomais e genéticas têm sido acumuladas e corroboram para o entendimento dessa teoria (SHEAR, 2002a; SHEAR, 2002b; SHEAR, 2002c).

Evidências de que a patogênese tanto dos tumores odontogênicos queratoçísticos esporádicos quanto daqueles que fazem parte da síndrome dos carcinomas nevóides basocelulares envolve um mecanismo de dois eventos, com perda de um alelo no cromossomo 9q22, têm sido demonstradas (LEVANAT et al., 1996; LO MUZIO et al., 1999). Esse mecanismo de dois eventos refere-se ao processo através do qual um tumor supressor tumoral é inativado (KNUDSON, 1971), sendo o primeiro evento a mutação em um alelo, que embora possa ser herdado de maneira dominante, não apresenta efeito fenotípico. O segundo evento se refere a perda de outro alelo e é conhecida como perda de heterozigose. Nos TOQs, essa perda de heterozigose leva à perda de regulação de oncoproteínas ciclin D1 e p53, genes supressores tumorais que se apresentam alterados nos carcinomas epidermóides (LO MUZIO et al., 1999).

Entretanto, a comprovação dessa teoria não foi mundialmente aceita e vem sendo motivo de controvérsia. Alguns autores acreditam que são necessárias maiores comprovações da natureza neoplásica dessa lesão (OKADA; YAMAMOTO; TILAKARATNE, 2007). Por isso e pelo pouco tempo de existência da terceira classificação da OMS, alguns estudos a respeito das prevalências de TOs, não incluem o TOQ no grupo de tumores odontogênicos (OKADA; YAMAMOTO; TILAKARATNE, 2007; SRIRAM; SHETTY, 2008).

Em nosso estudo os TOQ foram considerados como tumores odontogênicos e sua prevalência foi avaliada em ambas as populações, brasileira e mexicana. Tanto nas instituições brasileiras quanto nas mexicanas o TOQ foi a lesão mais prevalente (37,24\% e 35,35\% respectivamente). O mesmo foi observado nos estudos de Avelar et al. (2008 - 28,99\%) e Luo e Li (2009 - 38,73\%), que utilizaram como referência a última classificação da OMS. No estudo de Jing et al. (2007 - 35,8\%), o TOQ representou o segundo grupo mais prevalente de TOs, mesmo apresentando um percentual muito semelhante ao descrito em nosso estudo.

Os dados clínicos e demográficos da casuística do Brasil e do México revelaram um padrão já conhecido do tumor odontogênico queratocístico no mundo, ou seja, a maior parte dos casos foi diagnosticada em pacientes do gênero masculino e com idade variando entre a segunda e terceira décadas de vida. Este perfil assemelha-se ao perfil descrito em outros trabalhos publicados na literatura 
(AVELAR et al., 2008; JING et al., 2007; LUO; LI, 2009; MYOUNG et al., 2001). Alguns estudos avaliaram a variável raça (RACHANIS; SHEAR, 1978), entretanto no Brasil devido à grande miscigenação da população, a determinação da raça seria um dado subjetivo, o que nos levou a excluir essa variável do estudo.

Os tumores odontogênico queratocísticos ocorrem em uma ampla faixa etária e casos têm sido descritos tanto nos primeiros anos de vida quanto acima dos 90 anos de idade (MEARA et al., 1996), assim como pôde ser visto nos casos diagnosticados em nosso estudo (Tabelas 7 e 11), apesar do pronunciado pico de freqüência na segunda e terceira décadas de vida, descrito como achado variando de 40 a 60\% dos casos (AVELAR et al., 2008; CHIRAPATHOMSAKUL; SASTRAVAHA; JANSISYANONT, 2006; JING et al., 2007; LUO; LI, 2009; SHEAR; SPEITGHT, 2007).

Alguns autores têm demonstrado também uma distribuição etária bimodal, com um segundo pico de incidência na quinta década de vida ou mais tarde (; AHLFORDS et al., 1984; JONES et al., 2006; RACHANIS; SHEAR, 1971), enquanto em outros estudos (AVELAR et al., 2008; JING et al., 2007; LUO; LI, 2009) foi observada uma distribuição mais regular das lesões na quarta e quinta décadas de vida, assim como podemos ver em nossos casos (Tabelas 7 e 11).

Inúmeros estudos têm mostrado que os TOQs podem ocorrer em qualquer região dos ossos maxilares. Contudo, a mandíbula é apontada como a localização mais prevalente na maior parte desses trabalhos, sendo a região posterior a mais afetada (AHLFORDS et al., 1984; AVELAR et al., 2008; JING et al., 2007; JONES et al., 2006;. LUO; LI, 2009; MORGAN et al., 2005; RACHANIS; SHEAR, 1971; Pudemos observar que tanto no Brasil $(52,84 \%)$ como no México $(59,14 \%)$ a região mais afetada foi a posterior de mandíbula, corroborando com os achados da literatura. Entretanto, nossos achados percentuais foram os menores observados, o que pode ser explicado pelo grande número de casos em que a localização da lesão não foi informada.

No Brasil, dentre os 17 casos que apresentaram múltiplos TOQs, somente 13 foram diagnosticados como portadores da síndrome de carcinoma nevóide basocelular. Já no México 22 casos apresentaram TOQs múltiplos e todos foram diagnosticados como portadores da síndrome.

No grupo de pacientes sindrômicos, tanto no Brasil como no México, houve uma maior prevalência de pacientes do gênero masculino, assim como demonstrado 
por Jones et al. (2006) em seu estudo. Vedtofte e Prætorius (1979) observaram uma distribuição igual entre os gêneros, enquanto Brannon (1976) e Woolgar, Rippin e Browne (1987 a e b) observaram uma maior prevalência de pacientes do gênero feminino.

Segundo alguns autores (WOOLGAR JA; RIPPIN JW; BROWNE RM, 1987a; WOOLGAR JA; RIPPIN JW; BROWNE RM, 1987b; MEARA et al., 1996) os pacientes com a SCNB apresentam pico de incidência até a terceira década de vida como observado em nossos casos. Além disso, Woolgar, Rippin e Browne (1987) compararam em seu estudo a faixa de idade em que se encontravam os pacientes com lesões esporádicas de TOQs com aqueles que eram portadores da síndrome na época da remoção dos primeiros TOQs. Os autores puderam verificar que os pacientes com tumores esporádicos contribuíram com um maior número de casos de pacientes acima dos 50 anos de idade, reforçando nossos achados.

\subsection{DEMAIS TUMORES ODONTOGENICOS}

Como já explicitado anteriormente o número de trabalhos que consideram a nova classificação dos TOs da OMS é muito pequeno. Sendo assim, uma comparação limitada a esses estudos pode não traduzir a realidade quanto a prevalência dos TOs. Por isso, decidimos comparar nosso achados aos trabalhos que usaram como critérios de classificação de TOs a segunda classificação da OMS. Entretanto, não podemos deixar de salientar que se excluirmos os tumores odontogênicos queratocísticos do nosso grupo de estudo, a prevalência dos TOs observadas no Brasil e no México diminuem em 0,69\% e 1,44\%, respectivamente, valores considerados percentualmente significantes visto a raridade dessas lesões.

\section{EPITÉLIO ODONTOGÊNICO COM ESTROMA FIBROSO MADURO, SEM ECTOMESÊNQUIMA ODONTOGÊEICO}




\section{AMELOBLASTOMA}

Em nosso estudo o ameloblastoma representou o terceiro grupo de lesões mais prevalentes no Brasil (16,53\%)n e no México (17\%) (Tabelas 5 e 9) quando consideramos todos os tipos conjuntamente. Nos trabalhos que seguiram os critérios da nova classificação da OMS, Jing et al. (2007) descreveram o ameloblastoma como a lesão mais prevalente enquanto para Avelar et al. (2008) e Luo e Li (2009) esse foi o segundo grupo de lesões mais prevalentes.

Comparando com os demais trabalhos em que os critérios de classificação utilizados foram aqueles da segunda classificação da OMS, fica evidente uma maior concordância com nossos achados. Inúmeros trabalhos realizados tanto na América (BUCHNER; MERRELL; CARPENTER, 2006; DALEY; WYSOCKI; PRINGLE, 1994; MOSQUEDA-TAYLOR et al., 1997; OCHSENIUS et al., 2002; SANTOS et al., 2001) como na Europa (TAMME et al., 2004) apresentaram o ameloblastoma como a segunda lesão mais prevalente, sendo superada apenas pelos odontomas. Entretanto, esses achados não são uma constante em todos os estudos realizados nesses continentes (AVELAR et al., 2008; FERNANDES et al., 2005; OGUNSALU, 2003; OLGAC; KOSEOGLU; AKSAKALLI, 2006; STYPULKOWSKA, 1998).

$\mathrm{Na}$ Ásia e na África, contudo, os ameloblastomas foram a lesão mais prevalente na maior parte dos estudos (ADEBAYO; AJIKE; ADEKEYE, 2005; AROTIBA; OGUNBIYI; OBIECHINA, 1997; CHIDZONGA; LOPEZ; ALVEREZ, 1996; LADEINDE et al., 2005; LU et al., 1998; ODUKOYA, 1995; OKADA; YAMAMOTO; TILAKARATNE, 2007; SIMON et al., 2005; SRIRAM; SHETTY, 2008). Esses achados vêm sendo interpretados há muitos anos como uma predisposição étnica ou como diferenças geográficas influenciadas pelo meio (AROTIBA; OGUNBIYI; OBIECHINA, 1997; DALEY; WYSOCKI; PRINGLE, 1994; GARDNER, 1999; LU et al., 1998; SANTOS et al., 2001).

Entretanto, segundo Fregnani et al. (2002), fica fácil perceber que essas justificativas não são válidas uma vez que, na maior parte dos trabalhos em que observa-se uma maior prevalência de ameloblastomas, os casos foram recuperados de serviços hospitalares ou centros de referência (ADEBAYO; AJIKE; ADEKEYE, 2005; AROTIBA; OGUNBIYI; OBIECHINA, 1997; CHIDZONGA; LOPEZ; ALVEREZ, 1996; LADEINDE et al., 2005; LU et al., 1998; LUO; LI, 2009; ODUKOYA, 1995; 
OLGAC; KOSEOGLU; AKSAKALLI, 2006; SIMON et al., 2005; SRIRAM; SHETTY, 2008), uma vez que essas lesões requerem uma biópsia para sua confirmação diagnóstica e a cirurgia geralmente envolve grandes ressecções ósseas.

Além disso, os odontomas são lesões encontradas em radiografias de rotina realizadas por cirurgiões-dentistas em seus consultórios. Na maior parte dos casos os tratamentos são realizados nos próprios consultórios ou em faculdades de odontologia sem biópsia prévia, o que pode ser confirmado pela alta prevalência dessas lesões em estudos realizados em laboratórios e departamentos de faculdades de estudo (BUCHNER; MERRELL; CARPENTER, 2006; DALEY; WYSOCKI; PRINGLE, 1994; MOSQUEDA-TAYLOR et al., 1997; OCHSENIUS et al., 2002; SANTOS et al., 2001). Em particular, no estudo retrospectivo de MosquedaTaylor et al. (1997) que incluiu duas universidades e um hospital, fica evidente essa diferença uma vez que não foi diagnosticado sequer um odontoma no grupo de tumores pesquisados no Hospital, o que corrobora com os achados anteriores.

Dentre as instituições estudadas em nosso trabalho, quatro eram faculdades de odontologia e em todas o que encontramos foi uma maior prevalência de odontomas do que de ameloblastomas. Somente no laboratório privado Peribact o número de ameloblastoma se sobrepôs ao de odontomas. Essa inversão de valores observada no laboratório deve-se, provavelmente, ao fato de tratar-se de um laboratório de referência na cidade do México.

Alguns trabalhos destacavam ainda, uma maior incidência de ameloblastomas em indivíduos negros do que em Caucasianos (AROTIBA; OGUNBIYI; OBIECHINA, 1997; GUNHAN et al., 1990; MOSQUEDA-TAYLOR et al., 1997; SAWYER et al., 1985; SHEAR; SINGH, 1978). Entretanto, para alguns autores (ANAND; DAVEY; COHEN, 1967; SIMON et al., 2005) a maior prevalência dessas lesões em indíviduos negros na África seria aparente e resultaria do fenômeno conhecido como "Harvesting phenomenon", ou seja, em que tumores que têm crescimento lento e raramente ameaçam a vida, não são tratados e acabam por acumular-se durante anos, criando um contingente de casos que se apresentam conjuntamente quando da criação de centros de tratamento. Somado a isso, deve-se considerar que em muitos países em desenvolvimento os odontomas não são registrados, tratados ou enviados para confirmação diagnóstica, criando com isso uma estimativa subestimada de casos (BUCHNER; MERRELL; CARPENTER, 2006; FREGNANI et al., 2002; MOSQUEDA-TAYLOR et al., 1997). 
Para Koury et al. (1993), muitas variações podem ocorrer em cada grupo racial, dependendo de variáveis como localização geográfica, padrões de imigração, reprodução isolada ou reprodução entre grupos. Além disso, variações raciais e étnicas são geralmente associadas a considerações do meio em que as pessoas vivem como diferenças socioeconômicas, incluindo acesso a cuidados à saúde, variações no estilo de vida e fatores culturais.

\section{- AMELOBLASTOMA SÓLIDO - MULTICÍSTICO}

Considerando separadamente os diversos tipos de ameloblastomas foi possível definirmos padrões específicos em cada um deles que justificam a sua separação, como determinando pela terceira classificação a OMS (BARNES et al., 2005).

No Brasil houve uma maior prevalência de ameloblastomas sólidos em relação aos unicísticos como observado por Buchner et al. (2006), Luo e Li (2009) e Tamme et al. (2004). Entretanto, o mesmo não foi observado no México.

O acometimento de pacientes de ambos os sexos em quantidade semelhantes vem sendo descrito na literatura (LUO; LI, 2009; REICHART; PHILIPSEN; SONNER, 1995; TAMME et al., 2004) e pode ser observado por nós no grupo de pacientes mexicanos. Entretanto, no Brasil houve uma maior prevalência entre os pacientes do gênero feminino (64,04\%). Já Buchner et al. (2006a) detectaram um maior número de pacientes homens, o que nos leva a crer que a determinação de um gênero mais prevalente seria inadequada.

Segundo Barnes et al. (2005), a maior parte dos casos de ameloblastomas sólidos é diagnosticada entre 30 e 60 anos de idade. Tanto no Brasil quanto no México mais de 68\% dos casos foram diagnosticados acima dos 30 anos de idade, com idades médias de 33,14 e 37,14, respectivamente, valores que se aproximam aquele apresentado por Luo e Li (2009). Entretanto, no Brasil 19\% dos casos foram diagnosticados na segunda década de vida, porcentagem relativamente alta quando comparada aos estudos de Buchner et al. (2006a) e Luo e Li (2009); e que chama atenção uma vez que essas lesões são consideradas raras em pacientes com idade inferior a 20 anos (BARNES et al., 2005; KIM; JANG; KWANG-JU, 2001). 
Os ameloblastomas sólidos ocorrem predominantemente em mandíbula com marcada predileção pela região posterior (BARNES et al., 2005; BUCHNER; MERRELL; CARPENTER, 2006; LUO; LI, 2009; TAMME et al., 2004). Em nosso estudo, essa característica também pôde ser verificada nos casos diagnosticados tanto na Brasil quanto no México.

Quanto aos subtipos microscópicos do ameloblastoma sólido observamos uma maior prevalência do tipo folicular no Brasil enquanto no México a prevalência do tipo plexiforme foi maior. Mais de $25 \%$ dos casos que apresentaram mais de um padrão microscópico nos dois países.

Sabe-se hoje que a maior parte dos ameloblastomas apresenta mais de um padrão microscópico na mesma lesão e que a distinção desses padrões não apresenta significado clínico (BARNES et al., 2005; REICHART; PHILIPSEN, 2004). Além disso, o aspecto microscópico descrito pode não representar a realidade de toda a lesão, uma vez que, grande parte dos casos avaliados em nosso estudo foi diagnosticada em biópsias incisionais que são fragmentadas e podem corresponder a pequenas porções da lesão (LI et al., 2000).

\section{- AMELOBLASTOMA UNICÍSTICO}

A freqüência relativa do ameloblastoma unicístico tem sido relatada como sendo entre 5 a $46 \%$ de todos os tipos de ameloblastomas (BUCHNER; MERRELL; CARPENTER, 2006; LUO; LI, 2009; REICHART; PHILIPSEN, 2004; REICHART; PHILIPSEN; SONNER, 1995; TAMME et al., 2004) e Li et al (2000). No Brasil, os ameloblastomas unicísticos representaram 35,58\% dos ameloblastoma, entretanto, no México os valores encontrados foram muito superiores aos descritos na literatura (64,32\%). Essas diferenças provavelmente ocorrem devido à falta de compreensão do conceito de ameloblastoma unicístico, que pode apresentar três subtipos microscópicos, luminal, intraluminal e mural (BUCHNER; MERRELL; CARPENTER, 2006), e da dificuldade que pode haver em diagnosticar cada um deles em biópsias incisionais quando não correlacionando com dados clínicos e radiográficos.

Alguns estudos descrevem uma maior prevalência de ameloblastoma unicístico entre pacientes do gênero masculino (LI et al., 2000) assim como 
encontramos nos pacientes diagnosticados no México. No Brasil, contudo encontramos uma maior prevalência entre pacientes do gênero feminino, achado também descrito por Buchner et al. (2006). Importante salientar que Luo e Li (2009) descreveram uma distribuição semelhante entre os gêneros, o que demonstra que, assim como no ameloblastoma sólido, a determinação de um gênero mais prevalente talvez seja inadequada.

Quando comparamos a distribuição etária dos pacientes dos dois tipos de ameloblastomas, pudemos observar um contraste entre os dados encontrados, uma vez que a idade média dos pacientes com ameloblastomas unicísticos (Brasil=25,81 e México=27,33) foi muito mais baixa do que aquela apresentada pelos pacientes diagnosticados com ameloblastoma sólido (Brasil=33,14 e México=37,14). Nossos dados corroboram com aqueles descritos na literatura (BUCHNER; MERRELL; CARPENTER, 2006; LI et al., 2000; LUO; LI, 2009; TAMME et al., 2004).

Os ameloblastomas unicísticos apresentam quanto a localização uma marcante predominância pela mandíbula (Brasil=76,74\%, México=81,02\%), sendo a razão maxila:mandíbula 1:6,6 no Brasil e 1:10,09 no México, principalmente é a região posterior (BUCHNER; MERRELL; CARPENTER, 2006; LI et al., 2000; LUO; LI, 2009; TAMME et al., 2004).

Quanto aos subtipos microscópicos, pudemos verificar uma maior prevalência do tipo intraluminal $(36,50 \%)$ no México, enquanto o tipo mural foi o mais comumente diagnosticado no Brasil (46,51\%), assim como observado por Li et al (2000). Para esses autores a presença de uma hialinização subepitelial é um aspecto microscópico que pode auxiliar no diagnóstico dos ameloblastomas unicísticos uma vez que, grande parte dos casos é diagnosticada em biópsias incisionais que são fragmentadas e podem corresponder a pequenas porções da lesão, contudo esse não foi um dado avaliado em nosso trabalho.

\section{- AMELOBLASTOMA PERIFÉRICO}

Os ameloblastomas periféricos representaram apenas 1,88\% de todos os ameloblastomas diagnosticados no México, enquanto no Brasil nenhum caso foi diagnosticado. Na literatura essas lesões são descritas como extremamente raras, 
correspondendo de $0,6 \%$ a $10 \%$ de todos os ameloblastomas diagnosticados em estudos de séries (GUROL; BURKES, 1995; LUO; LI, 2009; OKADA; TILAKARATNE, 2007; PHILIPSEN et al., 2001; REICHART; PHILIPSEN; SONNER, 1995; UENO et al., 1986; WALDRON; EL-MOFTY, 1987) Quando comparados a todos os TOs representaram $0,32 \%$ das lesões diagnosticadas no México, valor que se aproxima aqueles descritos por Luo e Li (2009) e Okada et al. (2007).

Nos estudos relatados na literatura assim como em nossos resultados foi possível verificar uma concordância quanto a uma maior prevalência de pacientes do gênero masculino (mas:fem=3:1), com idade média $(55,25)$ maior do que nos outros tipos de ameloblastoma e uma localização preferencial em mandíbula (maxila:mandíbula=1:2) (PHILIPSEN et al., 2001).

\section{$\checkmark$ TUMOR ODONTOGÊNICO ESCAMOSO}

O tumor odontogênico escamoso é uma lesão extremamente rara com menos de 50 casos descritos na literatura. Somente um caso foi diagnosticado em nossa amostra o que limita nossa discussão sobre essa lesão. Contudo, foi possível verificar que nosso caso apresentava algumas características semelhantes aquelas descritas na literatura como baixa freqüência relativa $(0,12 \%-0,20 \%)$, predileção pelo gênero masculino e pela mandíbula (BARNES et al., 2005; PHILIPSEN; REICHART, 1996; REICHART; PHILIPSEN, 2004). O paciente apresentava-se com 68 anos de idade e encontrava-se dentro da ampla faixa etária citada em inúmeros trabalhos (8-74 anos de idade), mas acima da idade média de 38,7 anos (Tabela 7).

Por tratar-se de uma lesão rara e nem sempre bem reconhecida pelos patologistas o diagnóstico errôneo de ameloblastoma, especialmente dos tipos acantomatoso e desmoplásico, ou de carcinomas epidermóide bem diferenciado pode estar ocorrendo (BATSAKIS; CLEARY, 1993; BUCHNER et al., 2006). Em nosso caso, não houve erro diagnóstico. 


\section{$\checkmark$ TUMOR ODONTOGENNICO EPITELIAL CALCIFICANTE}

O tumor odontogênico epitelial calcificante é uma lesão rara que representa entre 0,35\% a 3\% dos casos de TOs descritos nos estudos de prevalência de TOs. Geralmente, não apresenta predileção por gênero, ocorrem em paciente nas mais variadas faixas etárias, com uma idade média variando entre 36,9 a 40 anos, e atinge a mandíbula mais freqüentemente do que a maxila (maxila:mandíbula=1:2), sendo a região de pré-molares e molares a mais atingida (BARNES et al., 2005; REICHART; PHILIPSEN, 2004).

Em nosso estudo, encontramos dados variados nos diferentes países. No Brasil, pudemos observar uma baixa freqüência relativa $(0,75 \%)$, predileção por pacientes do gênero masculino, idade média de 32,40 anos e maior acometimento da mandíbula (100\% dos casos). No México a freqüência relativa também foi baixa (0,48\%), houve predileção pelo gênero feminino, idade média de 39,33 anos e distribuição semelhante entre os ossos maxilares.

Visto que nossa amostra é muito pequena, e nossos dados não mantiveram um padrão, torna-se difícil confrontá-los com os dados da literatura e tirar conclusões precisas.

\section{$\checkmark$ TUMOR ODONTOGÊNICO ADENOMATÓIDE}

O tumor odontogênico adenomatóide foi a quinta lesão mais prevalente no grupo de TOs diagnosticados no Brasil e a sétima no México. Excluindo o TOQ, essa lesão passa a quarta e sexta posição em prevalência o que lhe confere uma condição de lesão não tão rara quando comparada com outras tantas que compõem o grupo de tumores odontogênicos (PHILIPSEN et al., 1991). Segundo MosquedaTaylor et al. (2008), essa lesão assim como o tumor odontogênico cístico calcificante, o fibroma ameloblástico, o fibro-odontoma ameloblástico, o fibroma odontogênico periférico e o cementoblastoma, seriam lesões que apesar de raras em termos de patologia geral, apresentariam uma freqüência relativa intermediária 
em relação aos TOs, dado que deve ser considerado importante para a definição dos diagnósticos diferenciais dos tumores de cabeça e pescoço.

Nos estudos realizados sobre os TOs pode-se verificar uma vasta distribuição do tumor odontogênico adenomatóide em todo o mundo e também variações amplas nas prevalências apresentadas em todos os continentes, indo de 3 a $9 \%$ na América, de 1 e 2\% na Europa, de 3 e 12\% na Ásia e de 0,9\% a 13\% na África. Em 2007, Philipsen et al. atribuíram essa maior freqüência relativa dos TOAs ao "Harvesting phenomenon" descrito por Anand (1965). Nossos achados se assemelham àqueles descritos em vários países, não refletindo um padrão específico (DALEY; WYSOCKI; PRINGLE, 1994; LUO; LI, 2009; OLGAC; KOSEOGLU; AKSAKALLI, 2006; SANTOS et al., 2001; STYPULKOWSKA, 1998).

A característica mais marcante do tumor odontogênico adenomatóide é sua grande freqüência entre pacientes diagnosticados na segunda e terceira décadas de vida (Brasil=53\% e México=91\%). Marcada predileção por pacientes do gênero feminino foi observada em inúmeros estudos (Brasil=52,94\% e México=57,78\%), assim como um predominante acometimento da maxila, particularmente a região anterior (Brasil=35,29\% e México=20\%), chegando a razões maxila:mandíbula de até 3,5:1 (ADEBAYO; AJIKE; ADEKEYE, 2005; BUCHNER, MERRELL, CARPENTER, 2006; FERNANDES et al., 2005; LEON et al., 2005; LU et al., 1998; LUO; LI, 2009; MOSQUEDA-TAYLOR et al., 1997; OCHSENIUS ET AL., 2002; ODUKOYA, 1995; OLGAC, KOSEOGLU E AKSAKALLI, 2005; OKADA, YAMAMOTO, TILAKARATNE, 2007; PHILIPSEN et al., 1991; PHILIPSEN; REICHART, 1999; SRIRAM E SHETTY, 2008).

\section{EPITÉLIO ODONTOGÊNICO COM ECTOMESÊNQUIMA ODONTOGÊNICO, COM OU SEM FORMAÇÃO DE TECIDO DURO}

Os tumores odontogênicos que constituem esse grupo apresentam comportamento biológico variável indo desde verdadeiras neoplasias até hamartomas. São chamados tumores odontogênicos mistos por serem constituídos por tecidos derivados tanto de epitélio quanto mesênquima odontogênico. Como um grupo, essas lesões representam os diversos estágios da odontogênese, desde os 
mais primitivos (fibroma ameloblástico) até aqueles que mostram um alto grau de morfodiferenciação (odontoma complexo) (TOMICH, 1999).

Existe uma discussão freqüente na literatura sobre quando e como os tumores mistos podem ser inter-relacionados. Cahn e Blum (1952) propuseram o conceito de continuidade, assumindo que o fibroma ameloblástico poderia amadurecer com o tempo levando a formação de um odontoma, entretanto, esse conceito não foi amplamente aceito por algumas razões como a detecção de fibromas ameloblásticos residuais e recidivantes que não apresentavam qualquer aspecto de maior diferenciação ou maturação e o fato de algumas dessas lesões ocorrerem mais freqüentemente acima dos 20 anos de idade, ou seja, após o período de odontogênese ter se encerrado (PHILIPSEN; REICHART; PRÆETORIUS, 1997).

Contudo, Philipsen, Reichart e Prætorius (1997) propuseram a existência de dois tipos biológicos de fibromas ameloblásticos. O primeiro tipo seria constituído por verdadeiras neoplasias, ou seja, por aquelas lesões que se formam após o fim da odontogênese (acima dos 20 anos de idade), sendo elas o fibroma ameloblástico e o fibrodentinoma ameloblástico, lesões que apresentam uma distribuição semelhante quanto à faixa etária e localização.

O segundo grupo seria constituído por lesões que se formam durante o período de odontogênese (infância e adolescência) e representariam lesões hamartomatosas que incluiriam uma variedade de estágios de desenvolvimento do odontoma complexo. Essas lesões poderiam se desenvolver passando do estágio primitivo de fibroma ameloblástico, por um estágio de fibro-odontoma ameloblástico e se transformariam com o tempo e finalmente, em odontomas complexos. Lembrando que, essa teoria só é plausível uma vez que tanto o fibro-odontoma ameloblástico como o odontoma são lesões que passam por um estágio de mineralização e calcificação, nenhum deles surge como lesões calcificadas de novo.

Essa teoria suporta a visão de Hansen e Ficarra que, em 1988, afirmaram que alguns dos fibromas ameloblásticos representavam estágios iniciais e mais primitivos do desenvolvimento dos odontomas complexos. Entretanto, não existem meios que permitam distinguir esses dois tipos de fibroma ameloblástico e que comprovem essa teoria, de modo que todas essas lesões permanecem classificadas como tumores odontogênicos e representam entidades distintas. 
Quanto aos odontomas, a separação realizada na última classificação da OMS entre os dois tipos, complexo e composto, refletiu a hipótese de que a patogênese de cada um deles é distinta. Para Philipsen, Reichart e Prætorius (1997), o odontoma composto se formaria como resultado de uma hiperatividade da lâmina dental e seria, na verdade, uma malformação ou hamartoma. A predominante localização em áreas também acometidas por dentes supranumerários justificaria essa hipótese (REICHART; PHILIPSEN, 2004).

Além dessas lesões, ainda encontram-se nesse grupo de TOs, o odontoameloblastoma, o tumor odontogênico cístico calcificante e o tumor dentinogênico de células fantasmas que serão abordados separadamente em outro ponto da discussão.

\section{$\checkmark$ FIBROMA AMELOBLÁSTICO}

Segundo a OMS (BARNES et al., 2005) o fibroma ameloblástico apresenta-se formado por dois componentes o ectomesênquima odontogênico, que se assemelha à papila dentária, e cordões e ilhas de epitélio odontogênico, que se assemelham à lâmina dental ou ao órgão do esmalte, ambos neoplásicos. Não apresenta tecido duro, mas quando se observa a formação de dentina displásica essa lesão deve ser denominada fibrodentinoma ameloblástico.

Quando avaliamos os estudos sobre prevalência de TOs, a distinção entre o fibroma ameloblástico, o fibrodentinoma ameloblástico e o fibro-odontoma ameloblástico nem sempre é realizada. Algumas vezes o fibrodentinoma ameloblástico é incluído no grupo dos fibromas ameloblásticos (JING et al., 2007) e outras vezes no grupo de fibro-odontomas ameloblástico (BUCHNER; MERRELL; CARPENTER, 2006); o que dificulta sobremaneira uma comparação válida entre os estudos.

Estudos têm demonstrado que os fibromas ameloblásticos são lesões raras, que apresentam freqüências relativas variáveis, na maioria das vezes não ultrapassando 4,5\% dos casos, assim como observado em nosso estudo. Entretanto, na Estônia foi observada freqüência relativa de 16\%, achado que não 
pode ser comparado a nenhum outro da literatura e nem ser justificado pelo próprio autor.

Quando avaliamos o gênero mais acometido nossos dados foram diferentes entre os dois países, havendo uma maior prevalência para o gênero masculino no Brasil e uma menor prevalência no México. A OMS não faz menção a predileção por gênero, mas Philipsen e Reichart (1997) demonstraram através da revisão de inúmeros casos um maior prevalência em pacientes do gênero masculino. Quando avaliamos os estudos sobre prevalência de TOs, pudemos observar uma desigualdade de resultados (BUCHNER; MERRELL; CARPENTER, 2006; JING et al.,2007; OCHSENIUS et al., 2002; OLGAC; KOSEOGLU; AKSAKALLI, 2006).

O padrão de localização dos fibromas ameloblásticos é muito bem definido, ocorrendo predominantemente na região posterior de mandíbula, como observado por nós no Brasil $(55,55 \%)$ e por inúmeros trabalhos da literatura. No México a mandíbula foi mais acometida, contudo houve uma maior distribuição nas demais regiões (AVELAR et al., 2008; BARNES et al., 2005; BUCHNER; MERRELL; CARPENTER, 2006; CHIDZONGA; LOPEZ; ALVEREZ, 1996; LADEINDE et al., 2005; LU et al., 1998, LUO; LI, 2009; OLGAC; KOSEOGLU; AKSAKALLI, 2006; PHILIPSEN; REICHART, 1997).

Outro aspecto característico dos fibromas ameloblástico é que são lesões freqüentemente diagnosticadas em pacientes nas duas primeiras décadas de vida (BARNES et al., 2005; BUCHNER; MERRELL; CARPENTER, 2006; CHIDZONGA; LOPEZ; ALVEREZ, 1996; LADEINDE et al., 2005; PHILIPSEN; REICHART, 1997), assim como detectado em nosso estudo (Brasil=66,67\% e México=100\%). Contudo, foi possível perceber em outros trabalhos uma ampla distribuição de casos em outras faixas etárias (AVELAR et al., 2008; LU et al., 1998; LUO; LI, 2009; OLGAC; KOSEOGLU; AKSAKALLI, 2006), o que vai contra a teoria de Philipsen, Reichart e Prætorius (1997).

\section{$\checkmark$ FIBRODENTINOMA AMELOBLÁSTICO}

Na nova classificação da OMS (BARNES et al., 2005) o fibrodentinoma ameloblástico está incluído no grupo dos fibromas ameloblásticos. Em nosso 
encontramos apensa 4 casos no Brasil e 1 caso no México. Os casos diagnosticados no Brasil e no México apresentaram predileção pela mandíbula e todos os pacientes se encontravam ou na primeira ou na segunda década de vida, achados que corroboram com a literatura. Entretanto, quanto ao gênero, não foi possível verificarmos maior prevalência para o gênero masculino como verificado na maior parte dos estudos (BARNES et al., 2005; OCHSENIUS et al., 2002; OLGAC; KOSEOGLU; AKSAKALLI, 2006; REICHART; PHILIPSEN, 2004; SRIRAM; RAVINDRA, 2008). Devido à pequena amostra tornasse difícil traçarmos um padrão de comportamento dessa lesão.

\section{$\checkmark$ FIBRO-ODONTOMA AMELOBLÁSTICO}

O fibro-odontoma ameloblástico apresenta uma freqüência relativa variando entre 0,2\% A 1,91\% (ADEBAYO; AJIKE; ADEKEYE, 2005; AVELAR et al., 2008; CHIDZONGA; LOPEZ; ALVEREZ, 1996; FERNANDES et al., 2005; JING et al., 2007; LU et al., 1998; LUO; LI, 2009; OCHSENIUS et al., 2002; OKADA; YAMAMOTO; TILAKARATNE, 2007; SANTOS et al., 2001; SRIRAM; SHETTY, 2008). Em nosso estudo encontramos 4 casos no Brasil e 8 caso no México, que representaram $0,5 \%$ e $0,64 \%$ de todos os TOs diagnosticados nos diferentes países, respectivamente.

Quando avaliamos as características relacionadas ao gênero e à faixa etária os casos diagnosticados no México seguem o padrão descrito na literatura, ou seja, maior predileção pelo gênero masculino e pela primeira década de vida (BARNES et al., 2005; PHILIPSEN; REICHART; PRAETORIUS, 1997). Contudo, os casos diagnosticados no Brasil não apresentaram esse padrão, uma vez que todos os casos foram diagnosticados em pacientes do gênero feminino, na segunda ou terceira décadas de vida.

Para a OMS (BARNES et al., 2005) não há uma área mais afetada, entretanto Reichart e Philipsen (2004) descrevem a região posterior da mandíbula como a área mais comumente acometida, como pudemos verificar em nosso estudo. Como a nossa amostra é muito pequena, nos achado apenas corroboram com 
aqueles já descritos na literatura, não nos permitindo traçarmos um padrão de comportamento para essa lesão.

\section{$\checkmark$ ODONTOMAS}

Os odontomas corresponderam a $23,66 \%$ e a $24,34 \%$ dos casos de TOs diagnosticados respectivamente, no Brasil e no México. Quando consideramos os dois tipos, os odontomas representaram o segundo grupo mais prevalente de tumores em ambos os países. Quando excluímos os TOQs, essas lesões passam a corresponder ao grupo mais prevalente em ambos os países, achado que se assemelha ao de inúmeros trabalhos realizados na América e na Europa (BUCHNER; MERRELL; CARPENTER, 2006; DALEY; WYSOCKI; PRINGLE, 1994; MOSQUEDA-TAYLOR et al., 1997; OCHSENIUS et al., 2002; SANTOS et al., 2001).

A distinção entre os dois tipos de odontomas é arbitrária, sendo baseada na organização tecidual, sendo o tipo complexo representado por uma massa de tecidos dentários desordenada contendo esmalte, dentina e cemento aglomerados enquanto, o tipo composto apresenta-se constituído por inúmeras estruturas bem organizadas que se assemelham a dentículos (BARNES et al., 2005; REICHART; PHILIPSEN, 2004).

Segundo Reichart e Philipsen (2004), essas lesões parecem apresentar um déficit na organização estrutural apesar de serem constituídas tanto por epitélio como ectomesênquima odontogênico com a morfologia normal sendo, por isso, consideradas hamartomas ou más-formações e não verdadeiras neoplasias.

\section{- ODONTOMA COMPLEXO}

Os odontomas complexos apresentam freqüência relativa que varia entre $3,5 \%$ a 30\%, o que mostra que essa lesão é uma das mais prevalentes entre todos os TOs (BARNES et al., 2005; OLGAC; KOSEAGLU; AKSAKALLI, 2006; JING et al., 2007; LU et al., 1998; LUO; LI, 2009; PHILIPSEN; REICHART; PRAETORIUS, 
1997). O mesmo pode ser observado por nós nos casos diagnosticados tanto no Brasil (7,35\%) como no México (9,82\%).

Foi possível observarmos em nosso estudo uma distribuição muito semelhante entre os gêneros, tanto no Brasil quanto no México, como descrito pela OMS (BARNES et al., 2005). Entretanto, Philipsen, Reichart e Prætorius (1997), descreveram uma predileção por pacientes do gênero masculino. Quando avaliamos os estudos de prevalência de TOs em que os tipos de odontomas foram avaliados separadamente, pudemos observar variadas razões entre os gêneros, o que demonstra que o acometimento dos diferentes gêneros é um achado aleatório (FERNADES et al., 2005; LU et al., 1998; LUO; LI, 2009; OCHSENIUS et al., 2002; OKADA; YAMAMOTO; TILAKARATNE, 2007; OLGAC; KOSEAGLU; AKSAKALLI, 2006; TAMME et al., 2004).

Tanto no Brasil quanto no México mais de sessenta e oito por cento dos casos ocorreram antes dos 30 anos de idade, com um pico de incidência na segunda década de vida, dados semelhantes aqueles descritos na literatura (BARNES et al., 2005; FERNADES et al., 2005; LUO; LI, 2009; PHILIPSEN; REICHART; PRAETORIUS, 1997).

Ao avaliarmos a teoria de Philipsen e Reichart (1997) e Hansen e Ficarra (1988) de que o odontoma complexo seria o estágio final de desenvolvimento dos fibromas ameloblástico hamartomastosos, passando pelo estágio de fibro-odontoma ameloblástico, tornasse difícil aceita-lá uma vez que, todas as lesões apresentaram um pico de incidência na mesma faixa etária.

Embora algumas diferenças possam existir na literatura, a maior parte dos autores encontrou uma maior prevalência de odontomas complexos na região posterior da mandíbula, seguida pela região anterior da maxila (BARNES et al., 2005; LU et al., 1998; LUO; LI, 2009; OLGAC; KOSEAGLU; AKSAKALLI, 2006; PHILIPSEN; REICHART; PRAETORIUS, 1997; TAMME et al., 2004), assim como foi observado nos casos desse estudo. 


\section{- ODONTOMA COMPOSTO}

Os odontomas compostos apresentam freqüência relativa que varia entre 8 a $37 \%$, o que mostra que essa lesão é uma das mais prevalentes entre os TOs, como observado por nós nos casos diagnosticados tanto no Brasil (16,31\%) como no México (14,52\%). Em alguns estudos realizados na Ásia a prevalência dessa lesão se apresentou muito menor chegando a 1,8\%, o que parece ser explicado por trataram-se de estudos realizados em Hospitais (BARNES et al., 2005; JING et al., 2007; LU et al., 1998; LUO; LI, 2009; OKADA; YAMAMOTO; TILAKARATNE, 2007; OLGAC; KOSEAGLU; AKSAKALLI, 2006; PHILIPSEN; REICHART; PRAETORIUS, 1997).

Quanto aos gêneros, foi possível observarmos uma distribuição muito semelhante tanto no Brasil quanto no México, como pode ser visto nas Tabelas 6 e 10. Na literatura, quando avaliamos os estudos de prevalência de TOs e de revisão de casos, pudemos observar variadas razões entre os gêneros, o que demonstra que o acometimento dos diferentes gêneros é um achado aleatório (BARNES et al., 2005; FERNADES et al., 2005; LU et al., 1998; LUO; LI, 2009; OCHSENIUS et al., 2002; OKADA; YAMAMOTO; TILAKARATNE, 2007; OLGAC; KOSEAGLU; AKSAKALLI, 2006; PHILIPSEN; REICHART; PRÆTORIUS, 1997; TAMME et al., 2004).

Tanto no Brasil quanto no México mais de sessenta e quatro por cento dos casos ocorreram antes dos 20 anos de idade, com um pico de incidência na segunda década de vida, dados semelhantes aqueles descritos na literatura (BARNES et al., 2005; FERNADES et al., 2005; LU et al., 1998; LUO; LI, 2009; OKADA; YAMAMOTO; TILAKARATNE, 2007; OLGAC; KOSEAGLU; AKSAKALLI, 2006; PHILIPSEN; REICHART; PRAETORIUS, 1997; TAMME et al., 2004).

Os odontomas compostos podem ocorrer em qualquer região dos ossos maxilares, mas na maior parte dos estudos avaliados essas lesões apresentaram-se na região anterior de maxila, assim como observamos em nossos casos (BARNES et al., 2005; LUO; LI, 2009; OLGAC; KOSEAGLU; AKSAKALLI, 2006; PHILIPSEN; REICHART; PRAETORIUS, 1997; TAMME et al., 2004). Em particular na Ásia observamos uma alta prevalência dessas lesões na mandíbula (JING et al., 2007; LU et al., 1998; OKADA; YAMAMOTO; TILAKARATNE, 2007). 
Em dois casos de odontomas diagnosticados no México, foi possível verificar que os pacientes apresentavam lesões múltiplas. Nesses casos, não foram diagnosticados outros comprometimentos nos pacientes, mas é importante lembrar que múltiplos odontomas podem ser um dos componentes de algumas síndromes, como a Síndrome de Gardner. Além disso, podem ser as manifestações iniciais dessas alterações genéticas e sua identificação precoce favorecerá um melhor prognóstico da doença (SCHMIDSEDER; HAUSAMEN, 1975; WIJN et al., 2007; MOSQUEDA-TAYLOR, 2008).

\section{$\checkmark$ ODONTOAMELOBLASTOMA}

O odontoameloblastoma é uma lesão extremamente rara, composta por ectomesênquima odontogênico e epitélio odontogênico que se assemelha ao ameloblastoma tanto em estrutura como em comportamento (BARNES et al., 2005), com poucos casos descritos na literatura. Segundo Reichart e Philipsen (2004) e Mosqueda-Taylor et al. (2002) dentre os quase cinqüenta casos descritos na literatura, cerca de 15 representariam os critérios adequados para esse diagnóstico. Analisando os trabalhos de revisão de casos e de prevalência dos odontoameloblastomas foi possível perceber uma maior prevalência entre pcientes do gênero masculino, com idade média de variando entre 18,8 e 20,2 anos e uma distribuição semelhante entre mandíbula e maxila, geralmente em região posterior aos caninos (MOSQUEDA-TAYLOR et al., 2002; REICHART; PHILIPSEN, 2004).

Nossa paciente era do gênero feminino e apresentava-se com 25 anos na época do diagnóstico. A lesão estava localizada em maxila, região posterior. Apesar de não apresentar as características descritas na literatura, por tratar-se de um único caso fica difícil inferirmos quaisquer conclusões. 


\section{$\checkmark$ TUMOR ODONTOGÊNICO CÍSTICO CALCIFICANTE}

O tumor odontogênico cístico calcificante também chamado cisto odontogênico calcificante ou queratinizante, cisto de Gorlin ou simplesmente cisto odontogênico calcificante apresenta-se como uma neoplasia cística de origem odontogênica (BARNES et al., 2005).

Apesar de ser uma entidade distinta, essa lesão pode apresentar uma grande diversidade nos seus aspectos clínicos e histopatológicos, assim como no seu comportamento biológico (REICHART; PHILIPSEN, 2004). Em função disso, inúmeras foram as tentativas de classificar os diferentes padrões de apresentação dessa lesão (BUCHNER, 1991; HONG; ELLIS; HARTMAN; 1991; PRAETORIUS et al., 1981; REICHART; PHILIPSEN; REICHART, 2004; TOIDA, 1998). Contudo, segundo a nova classificação da OMS, todos os padrões de apresentação dessa lesão seguem agrupados como tumor odontogênico cístico calcificante, com exceção da sua variante sólida que passou a ser classificada como tumor dentinogênico de células fantasmas (BARNES et al., 2005).

O tumor odontogênico cístico calcificante pode apresentar-se intra ou extraósseo, sendo o último a forma mais freqüente. Entre nossos casos todos foram diagnosticados como intra-ósseos e representaram 5,23\% e 3,51\% de todos os TOs diagnosticados no Brasil e no México, respectivamente.

Segunda a OMS não há predileção por gênero, assim como pudemos observar no Brasil e nos trabalhos de Arotiba, Ogunbiyi e Obiechina (1997) e de Mosqueda-Taylor et al. (1997). Contudo o número de casos estudados em ambos os trabalhos é relativamente pequeno. No México foi possível verificarmos uma maior prevalência de pacientes do gênero feminino (mas:fem=1,1,75), assim como descrito por Odukoya (1995), Ochsenius et al. (2002), Fernandes et al. (2005) e Avelar et al. (2008). Além disso, em inúmeros outros trabalhos sobre prevalência de TOs, foi possível verificarmos uma maior incidência nos pacientes do gênero masculino (JING et al., 2007; LADEINDE et al., 2005; LU et al., 1998; LUO; LI, 2009; OKADA; YAMAMOTO; TILAKARATNE, 2007; OLGAC; KOSEAGLU; AKSAKALLI, 2006; SRIRAM; SHETTY, 2008). A partir desses dados fica claro que a definição de um gênero mais afetado não é adequada. 
Foi possível verificar uma ampla faixa etária de distribuição dos pacientes, variando de 7 a 91 anos de idade no Brasil e de 7 a 62 anos no México, com idades médias muito semelhantes de 22,5 e 23,74 anos. Além disso, houve um pico de incidência na segunda década de vida. Nossos achados corroboram com aqueles descritos na literatura (BARNES et al., 2005; FERNANDES et al., 2005; JING et al., 2007; LADEINDE et al., 2005; LU et al., 1998; LUO; LI, 2009; OCHSENIUS et al., 2002; ODUKOYA, 1995; OKADA; YAMAMOTO; TILAKARATNE, 2007).

A partir da literatura, verificamos uma distribuição semelhante das lesões entre os ossos maxilares. Entretanto, na mandíbula a maior parte dos casos se localiza na região de pré-molares e molares enquanto na maxila as lesões aparecem mais freqüentemente na região de incisivos e caninos (BARNES et al., 2005; BUCHNER, 1991; LADEINDE et al., 2005; LUO; LI, 2009; MOSQUEDA-TAYLOR et al., 1997; OCHSENIUS et al., 2002; OLGAC, 2006). Nossos casos seguiram esse mesmo padrão de apresentação, corroborando com a literatura.

\section{$\checkmark$ TUMOR DENTINOGÊNICO DE CÉLULAS FANTASMAS}

O tumor dentinogênico de células fantasmas é um tumor sólido que pode se apresentar em uma forma tumoral intra-óssea agressiva ou em uma forma neoplásica extra-óssea não agressiva (LEDESMA-MONTES et al., 2008). Foi inicialmente categorizado por Prætórius et al. (1981) e hoje é visto como uma variante sólida do tumor odontogênico cístico calcificante (BARNES et al., 2005).

Essas lesões acometem com maior freqüência pacientes do gênero masculino, em várias faixas etárias e geralmente se apresentam localizadas nas regiões posteriores ao canino, tanto em maxila quanto em mandíbula (BARNES et al., 2005; JING et al., 2007; LEDESMA-MONTES et al., 2008; LUO; LI, 2009), características muito variadas que se assemelham, por isso, com todos os casos que diagnosticamos, apesar e muito variados. Provavelmente o pequeno número de casos descritos, considerando essa nova classificação, impossibilite a definição de um padrão mais específico. 


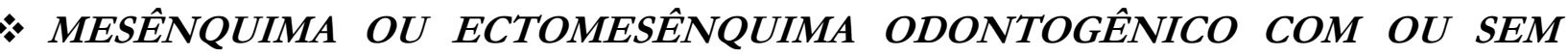
EPITÉLIO ODONTOGÊNICO

O terceiro grupo de tumores odontogênicos benignos é composto por três entidades diferentes os fibromas odontogênicos, os mixomas odontogênicos e os cementoblastomas. As modificações ocorridas na terceira classificação da OMS com relação a essas lesões foram a identificação de duas variantes microscópicas do fibroma odontogênico e a exclusão da denominação benigno dos cementoblastomas, alterações que não geraram grandes diferenças no contexto epidemiológico dessas lesões (REICHART; PHILIPSEN, 2004).

\section{$\checkmark$ FIBROMA ODONTOGENNICO}

Os fibromas odontogênicos apresentam uma variante intra-óssea e outra extra-óssea. Contudo, ainda existem muitas controvérsias em relação a verdadeira definição dessas lesões e por isso os achados epidemiológicos são muito controversos (BARNES et al., 2005; REICHART; PHILIPSEN, 2004).

\section{- FIBROMA ODONTOGENICO CENTRAL}

Dentre os casos diagnosticados como fibromas odontogênicos diagnosticados no Brasil e no México não verificamos um padrão de apresentação, ocorrendo grande variação quanto ao gênero e a localização. O único dado que se assemelhou foi um pico de incidência na segunda década de vida. Nossos dados podem ser usados para auxiliar em estudos epidemiológicos multicêntricos futuros uma vez que não há um padrão de apresentação descrito pela OMS que possa ser usado como comparação (BARNES et al., 2005; REICHART; PHILIPSEN, 2004). Além disso, avaliando os estudos epidemiológicos sobre TOs, os dados encontrados também são muito controversos, o que pode demonstrar uma falta de padronização quanto a 
definição dessa lesão (BARNES et al., 2005; FERNANDES et al., 2005; JING et al., 2007; LADEINDE et al., 2005; LU et al., 1998; LUO; LI, 2009; OCHSENIUS et al., 2002; ODUKOYA, 1995; OKADA; YAMAMOTO; TILAKARATNE, 2007; MOSQUEDA-TAYLOR et al., 1997).

\section{- FIBROMA ODONTOGÊNICO PERIFÉRICO}

Uma vez que a OMS não incluiu o fibroma odontogênico periférico na sua última classificação e que sua definição ainda é vista como uma questão conflituosa, nosso objetivo ao incluir essa lesão foi somente avaliar seu padrão de apresentação nos dois países e tentar definir um padrão de apresentação que pudesse corroborar com futuros estudos sobre essa lesão. Sendo assim, podemos afirmar baseados nos nossos achados que os fibromas odontogênicos periféricos são lesões raras, com freqüências relativas que não ultrapassam 3\%. Acometem mais freqüentemente pacientes do gênero feminino, em uma ampla faixa de idades, mas com pico de incidência entre a segunda e terceira décadas de vida. Ocorrem tanto em mandíbula quanto em maxila, preferencialmente na região anterior.

\section{$\checkmark$ MIXOMA ODONTOGÊNICO}

Os mixomas odontogênicos ou mixofribromas odontogênicos, denominação utilizada quando apresentam uma maior concentração de colágeno, compõem um grupo de TOs que é considerado por muitos autores como raro, mas que ocupada muitas vezes a segunda, terceira ou quarta posição entre os mais prevalentes tumores de origem odontogênica (ADEBAYO; AJIKE; ADEKEYE, 2005; AVELAR et al., 2008; FERNANDES et al., 2005; JING et al., 2007; LADEINDE et al., 2005; LU et al., 1998; LUO; LI, 2009; ODUKOYA, 1995; OKADA; YAMAMOTO; TILAKARATNE, 2007; OLGAC; KOSEAGLU; AKSAKALLI, 2006; MOSQUEDATAYLOR et al., 1997; MOSQUEDA-TAYLOR, 2008; SRIRAM; SHETTY, 2008). 
Segundo a OMS (BARNES et al, 2005) e inúmeros outros autores os mixomas são lesões que acometem mais freqüentemente pacientes do gênero feminino com idade variando entre a segunda e a quarta décadas de vida. Quanto à localização ocorrem mais comumente na mandíbula do que na maxila, mas em ambas, a região posterior é a mais acometida (BUCHNER; MERRELL; CARPENTER, 2006; FERNANDES et al., 2005; JING et al., 2007; LADEINDE et al., 2005; ODUKOYA, 1995; OKADA; YAMAMOTO; TILAKARATNE, 2007; SRIRAM; SHETTY, 2008). Nossos achados, em sua maioria, correspondem a esses descritos na literatura.

\section{$\checkmark$ CEMENTOBLASTOMA}

O cementoblastoma foi inicialmente descrito por Norberg (1930). É considerada a única neoplasia verdadeira que se origina do cemento. Como se trata de uma lesão rara (Brasil=1,87\% e México=1,04\%), as freqüências relativas apresentadas são muito variáveis, indo de $0,2 \%$ a 6,25 de todos os TOs (REICHART; PHILIPSEN, 2004).

São lesões que não apresentam predileção por um dos gêneros e podem ser encontradas em pacientes e qualquer faixa etária, havendo um pico de incidência na segunda década de vida (BARNES et al., 2005; BRANNON et al., 2002; BUCHNER; MERRELL; CARPENTER, 2006, CHIDZONGA; LOPEZ; ALVEREZ, 1996; JING et al., 2007; LUO; LI, 2009; MACDONALD-JANKOWSKI; WU, 1992; ODUKOYA, 1995; ULMASNSKY et al., 1994). Contudo, nos casos avaliados no México observamos uma marcada predileção pelo gênero feminino (84,62\%), assim como descrito por Santos et al. (2001), Tamme et al. (2004) e Fernandes et al (2005). Acreditamos que se trata de um achado eventual que não pode ser explicado baseando-nos nessa pequena amostra.

Também verificamos um maior acometimento da região posterior da mandíbula, seguida pela região posterior da maxila, como descrito na literatura (BARNES et al., 2005; BRANNON et al., 2002; BUCHNER; MERRELL; CARPENTER, 2006; JING et al., 2007; LUO; LI, 2009; MACDONALD-JANKOWSKI; ULMASNSKY; WU, 1992;). 


\section{$\checkmark$ TUMOR ODONTOGENNICO COMBINADO}

Dois casos de tumor odontogênico combinado foram diagnosticados, sendo uma das lesões composta em parte por um tumor odontogênico cístico calcificante e em parte por um fibroma ameloblástico, enquanto a outra era composta em parte por um tumor odontogênico adenomatóide e em parte por um tumor odontogênico epitelial calcificante.

A ocorrência do um tumor odontogênico cístico calcificante combinado a um fibroma ameloblástico já foi descrita anteriormente por alguns autores Não se sabe exatamente qual das lesões ocorre primeiro e cada um dos autores que a descreveu propõe uma possível relação entre a formação das duas variantes encontradas. Para Lin et al. (2004), a formação de outros tumores odontogênicos na parede dos tumores odontogênicos císticos calcificantes ou associados mais intimamente a eles parece ser mais freqüente do que é descrito na literatura e na verdade, devido ao número restrito de casos, não se pode estabelecer um padrão demográfico dessas lesões (FARMAN et al., 1978; PRAETORIUS et al., 1981; YOON et al., 2002).

Devido à complexidade do processo de odontogênese e do seu prolongado período de ocorrência, não é surpreendente que possam existir lesões com achados combinados de tipos diferentes de tumores e cistos odontogênicos. Essas lesões híbridas devem ser avaliadas segundo o comportamento biológico do tipo mais agressivo, sendo nesse caso o do tumor odontogênico cístico calcificante (LI; YU, 2003).

Revisando mais detalhadamente o segundo caso foi possível verificarmos que, apesar da lesão apresentar extensas áreas de ambos os tumores descritos, é possível que essa lesão corresponda a um tumor odontogênico adenomatóide com áreas que se assemelham a um tumor odontogênico cístico calcificante (calcifying epithelial odontogenc tumor-like areas), aspecto descrito inicialmente por LedesmaMontes em 1993 e posteriormente confirmado por outros autores (MOSQUEDATAYLOR et al., 2005). Sendo assim, essa lesão poderia ser incluída no grupo dos tumores odontogênicos adenomatóides e considerada como tal quando avaliamos seus aspectos demográficos. 


\section{$\checkmark$ TUMOR ODONTOGÊNICO NÃO CLASSIFICADO}

Três casos de tumor odontogênico não classificado foram diagnosticados. Todos apresentavam características de benignidade e se caracterizavam por aspectos microscópicos que não se enquadravam em nenhum dos aspectos descritos como um dos tumores já classificados pela OMS. Nosso intuito ao incluirlos no estudo foi corroborar com possíveis futuros estudos que apresentem lesões como as nossas.

\section{$\checkmark$ QUERATOAMELOBLASTOMA}

O queratoameloblastoma é uma lesão rara que foi descrita pela primeira vez por Siar e $\mathrm{Ng}$ em 1993. Trata-se de um tumor caracterizado pela ocorrência simultânea de um ameloblastoma com pronunciada queratinização e componentes císticos que se assemelham ao tumor odontogênico queratocístico (TAKEDA et al., 2001).

Whitt et al. (2006) revisaram os casos descritos na literatura e demonstraram que essa lesão ocorria mais freqüentemente em pacientes do gênero masculino, com uma idade média de 44 anos (ampla variação 26 a 76 anos de idade) e na região posterior de mandíbula. Nosso caso difere desse padrão somente em relação ao gênero. Entretanto, a pequena amostra não nos permite chegar a conclusões precisas.

\section{TUMORES MALIGNOS}

Os tumores odontogênicos malignos são lesões extremamente raras que correspondem geralmente a menos de $6,1 \%$ de todos os TOs (EVERSOLE, 1999; SLOOTWEG, 2002; GOLDENBERG et al., 2004; MOSQUEDA-TAYLOR et al., 
2003). Seu diagnóstico é complexo uma vez que sua baixa freqüência torna as informações sobre suas características clínicas e microscópicas escassas. Além disso, a semelhança que essas lesões apresentam com suas contrapartes benignas é muito grande, o que pode levar a erros diagnósticos (GOLDENBERG et al., 2004; MOSQUEDA-TAYLOR et al., 2003).

Além do pequeno número de estudos a respeito dessas lesões, alguns fatores também são relacionados à falta de uniformidade nos dados relacionados na literatura, como diferenças geográficas, étnicas, socioculturais e a fonte de obtenção dos dados, ou seja, escola ou hospital (MOSQUEDA-TAYLOR et al., 2003). Ainda é importante lembrar que a maior parte dos estudos publicados até hoje empregaram classificações diferentes da atual classificação de TOs da OMS, o que dificulta a comparação com nossos dados.

O que podemos inferir sobre nos casos é que os carcinomas odontogênicos são mais freqüentes do que os sarcomas, ocorreram em pacientes em uma faixa etária maior do que a dos pacientes com sarcoma e que tanto carcinomas quanto sarcomas ocorrem com igual distribuição entre os gêneros e maior freqüência na mandíbula. A maior parte de nossos achados se assemelha aos descritos na literatura (BARNES et al., 2005; GOLDENBERG et al., 2004; MOSQUEDA-TAYLOR et al., 2003, REICHART; PHILIPSEN, 2004).

Por tudo o que encontramos a respeito de cada um dos tumores podemos afirmar que os TOs são um desafio para os pesquisadores, patologistas e para os clínicos. Somente o trabalho em equipe levará, em última instância, a uma compreensão maior da etiopatogenia, desenvolvimento e comportamento dessas lesões, o que permitirá um diagnóstico precoce e tratamento mais adequado, além de uma classificação mais exata de cada uma dessas lesões. 
7 Conclusóes 


\section{CONCLUSÕES}

Com base no que foi exposto e discutido nos capítulos anteriores deste trabalho, pode-se concluir que:

- O padrão de apresentação dos tumores odontogênicos verificado nas instituições avaliadas tanto no Brasil quanto no México, se assemelhou muito ao padrão descrito pela OMS e pela maior parte dos estudos sobre prevalência desses tumores descritos na literatura

- A inclusão do queratocístico como tumor, causou uma modificação quantitativa relevante na prevalência dos tumores odontogênicos tanto no Brasil como no México. Entretanto, a controvérsia a respeito da natureza neoplásica dessa lesão nos faz crer que essa modificação pode não ser permanente.

- A falta de conhecimentos mais aprofundados com relação a existência de possíveis alterações genéticas e moleculares nos tumores odontogênicos dificulta compreender diferenças encontradas em relação à prevalência de algumas dessas lesões em países como a China, onde pudemos observar uma prevalência maior de tumores benignos e malignos. Possivelmente, o desenvolvimento de técnicas mais modernas em biologia molecular e genética nos levará a compreender melhor a natureza dessas lesões e sua patogenia, e conseqüentemente a modificações futuras na classificação dos tumores odontogênicos. 
Referências 


\section{REFERENCIAS}

Adebayo ET, Ajike SO, Adekeye EO. A review of 318 odontogenic tumors in Kaduna, Nigeria. J Oral Maxillofac Surg. 2005;63(6):811-9.

Adebiyi KE, Odukoya O, Taiwo EO. Ectodermal odontogenic tumours: analysis of 197 Nigerian cases. Int J Oral Maxillofac Surg. 2004;33(8):766-70.

Ahlfors E, Larsson A, Sjogren S. The odontogenic keratocyst: a benign cystic tumor? J Oral Maxillofac Surg. 1984;42(1):10-9.

Anand SV, Davey WW, Cohen B. Tumours of the jaw in West Africa. A review of 256 patients. Br J Surg. 1967;54(11):901-17.

Arotiba JT, Ogunbiyi JO, Obiechina AE. Odontogenic tumours: a 15-year review from Ibadan, Nigeria. Br J Oral Maxillofac Surg. 1997;35(5):363-7.

Avelar RL, Antunes AA, Santos Tde S, Andrade ES, Dourado E. Odontogenic tumors: clinical and pathology study of 238 cases. Braz J Otorhinolaryngol. 2008;74(5):668-73.

Baden E. Odontogenic tumors. Pathol Annu. 1971;6:475-568.

Barnes L, Eveson JW, Reichart PA, Sidransky D. Pathology and Genetics of Head and Neck Tumours, WHO Classification of Tumours; 2005.

Batsakis JG, Cleary KR. Squamous odontogenic tumor. Ann Otol Rhinol Laryngol. 1993;102(10):823-4.

Bhaskar SN. Oral pathology in the dental office: survey of 20,575 biopsy specimens. J Am Dent Assoc. 1968;76(4):761-6.

Bland-Sutton J. Odontomes. Trans Odont SocGreat Britain, New ser. 1888;20:32-87.

Brannon RB, Fowler CB, Carpenter WM, Corio RL. Cementoblastoma: an innocuous neoplasm? A clinicopathologic study of 44 cases and review of the literature with special emphasis on recurrence. Oral Surg Oral Med Oral Pathol Oral Radiol Endod. 2002;93(3):311-20. 
Brannon RB. The odontogenic keratocyst. A clinicopathologic study of 312 cases. Part II. Histologic features. Oral Surg Oral Med Oral Pathol. 1977;43(2):233-55.

Broca $P$. Recherches sur un nuveau grupe des tumeurs désignées sous le nom d'odontomes. Gaz Hedb Sci Med. 1868;5:1.

Buchner A, Merrell PW, Carpenter WM. Relative frequency of central odontogenic tumors: a study of 1,088 cases from Northern California and comparison to studies from other parts of the world. J Oral Maxillofac Surg. 2006b;64(9):1343-52.

Buchner A, Merrell PW, Carpenter WM. Relative frequency of peripheral odontogenic tumors: a study of 45 new cases and comparison with studies from the literature. $\mathrm{J}$ Oral Pathol Med. 2006a;35(7):385-91.

Buchner A. The central (intraosseous) calcifying odontogenic cyst: an analysis of 215 cases. J Oral Maxillofac Surg. 1991;49(4):330-9.

Cahn LR; Blum T. Ameloblastic odontoma, case report critically analysed (letter). J Oral Surg. 1952;10:169-170.

Chidzonga MM, Lopez VM, Alverez AP. Odontogenic tumours: analysis of 148 cases in Zimbabwe. Cent Afr J Med. 1996;42(6):158-61.

Chirapathomsakul D, Sastravaha $P$, Jansisyanont $P$. A review of odontogenic keratocysts and the behavior of recurrences. Oral Surg Oral Med Oral Pathol Oral Radiol Endod. 2006;101(1):5-9; discussion 10.

Crivelini MM, de Araújo VC, de Sousa SO, de Araújo NS. Cytokeratins in epithelia of odontogenic neoplasms. Oral Dis. 2003; 9(1):1-6.

Daley TD, Wysocki GP, Pringle GA. Relative incidence of odontogenic tumors and oral and jaw cysts in a Canadian population. Oral Surg Oral Med Oral Pathol. 1994;77(3):276-80.

Dodge OG. Tumors of the Jaw, Odontogenic Tissues and Maxillary Antrum (Excluding Burkitt Lymphoma) in Uganda Africans. Cancer. 1965;18:205-15.

Eversole LR. Malignant epithelial odontogenic tumors. Semin Diagn Pathol. 1999;16(4):317-24. 
Farman AG, Smith SN, Nortjé CJ, Grotepass FW. Calcifying odontogenic cyst with ameloblastic fibro-odontome: one lesion or two? J Oral Pathol. 1978;7(1):19-27.

Fernandes AM, Duarte EC, Pimenta FJ, Souza LN, Santos VR, Mesquita RA, et al. Odontogenic tumors: a study of 340 cases in a Brazilian population. J Oral Pathol Med. 2005;34(10):583-7.

Fregnani ER, Fillipi RZ, Oliveira CR, Vargas PA, Almeida OP. Odontomas and ameloblastomas: variable prevalences around the world? Oral Oncol. 2002;38(8):807-8.

Gabell DP, James W, Payne JL, Association BD. Report on Odontomes. London: John Bale, Sons \& Danielsson, Ltd.; 1914.

Gardner DG. Critique of the 1995 review by Reichart et al. of the biologic profile of 3677 ameloblastomas. Oral Oncol. 1999;35(4):443-9.

Goldenberg D, Sciubba J, Koch W, Tufano RP. Malignant odontogenic tumors: a 22year experience. Malignant odontogenic tumors: a 22-year experience. Laryngoscope. 2004;114(10):1770-4.

Gorlin RJ, Chaudhry AP, Pindborg JJ. Odontogenic tumors: classification, histopathology and clinical behavior in man and domesticated animals. Cancer. 1961;14:73-101.

Gorlin RJ, Pindborg JJ, Odont, Clausen FP, Vickers RA. The calcifying odontogenic cyst--a possible analogue of the cutaneous calcifying epithelioma of Malherbe. An analysis of fifteen cases. Oral Surg Oral Med Oral Pathol. 1962;15:1235-43.

Gunhan O, Erseven G, Ruacan S, Celasun B, Aydintug Y, Ergun E, et al. Odontogenic tumours. A series of 409 cases. Aust Dent J. 1990;35(6):518-22.

Gurol M, Burkes EJ Jr. Peripheral ameloblastoma. J Periodontol. 1995;66(12):10658.

Hansen LS, Ficarra G. Mixed odontogenic tumors: an analysis of 23 new cases. Head Neck Surg. 1988;10(5):330-43. 
Hong SP, Ellis GL, Hartman KS. Calcifying odontogenic cyst. A review of ninety-two cases with reevaluation of their nature as cysts or neoplasms, the nature of ghost cells, and subclassification. Oral Surg Oral Med Oral Pathol. 1991;72(1):56-64.

Jain S, Kherdekar M. A histopathological study of the Odontogenic Tumours, Jaw cysts \& Allied Lesions of the Jaw. Indian J Pathol Microbiol. 1980;23:39-44.

Jing $W$, Xuan $M$, Lin $Y$, Wu L, Liu L, Zheng $X$, et al. Odontogenic tumours: a retrospective study of 1642 cases in a Chinese population. Int J Oral Maxillofac Surg. 2007;36(1):20-5.

Jones AV, Craig GT, Franklin CD. Range and demographics of odontogenic cysts diagnosed in a UK population over a 30-year period. J Oral Pathol Med. 2006;35(8):500-7.

Kim S-G, Jang H-S, Kwang-Ju. Ameloblastoma a clinical, radiographic, and histopathologic amalysis of 71 cases. Oral Surg Oral Med Oral Pathol Oral Radiol Endod. 2001;91(6):649-53.

Knudson AG. Mutation and cancer: statistical study of retinoblastoma. Proc Natl Acad Sci U S A. 1971;68(4):820-3.

Koury ME, Stella JP, Epker BN. Vascular transformation in cherubism. Oral Surg Oral Med Oral Pathol. 1993;76(1):20-7.

Kovi J, Laing WN. Tumors of the mandible and maxilla in Accra, Ghana. Cancer. 1966;19(9):1301-7.

Kramer IR, Pindborg JJ, Shear M. The WHO Histological Typing of Odontogenic Tumours. A commentary on the Second Edition. Cancer. 1992;70(12):2988-94.

Ladeinde AL, Ajayi OF, Ogunlewe MO, Adeyemo WL, Arotiba GT, Bamgbose BO, et al. Odontogenic tumors: a review of 319 cases in a Nigerian teaching hospital. Oral Surg Oral Med Oral Pathol Oral Radiol Endod. 2005;99(2):191-5.

Ledesma CM, MOsqueda-Taylor A, Romero de León E, De la Piedra Garza M, Goldberg Jaulin P, Portilla Robertson J. Adenomatoid odontogenic tumour with features of calcifying epithelial odontogenic tumour (The so-called combined epithelial odontogenic tumour). Clinico-pathological report of 12 cases. Eur J Cancer B Oral Oncol. 1993;29B:221-4. 
Ledesma-Montes C, Gorlin RJ, Shear M, Prae Torius F, Mosqueda-Taylor A, Altini M et al. International collaborative study on ghost cell odontogenic tumours: calcifying cystic odontogenic tumour, dentinogenic ghost cell tumour and ghost cell odontogenic carcinoma. J Oral Pathol Med. 2008;37(5):302-8.

Levanat S, Gorlin RJ, Fallet S, Johnson DR, Fantasia JE, Bale AE. A two-hit model for developmental defects in Gorlin syndrome. Nat Genet. 1996;12(1):85-7.

Li TJ, Wu YT, Yu SF, Yu GY. Unicystic ameloblastoma. A clinicopathological study of 33 Chinese patients. Am J Surg Pathol. 2000;24(10):1385-92.

$\mathrm{Li} \mathrm{TJ}, \mathrm{Yu}$ SF. Clinicopathologic spectrum of the so-called calcifying odontogenic cysts: a study of 21 intraosseous cases with reconsideration of the terminology and classification. Am J Surg Pathol. 2003;27(3):372-84.

Lin CC, Chen $\mathrm{CH}$, Lin LM, Chen YK, Wright JM, Kessler HP, et al. Calcifying odontogenic cyst with ameloblastic fibroma: report of three cases. Oral Surg Oral Med Oral Pathol Oral Radiol Endod. 2004;98(4):451-60.

Lo Muzio L, Staibano S, Pannone G, Bucci P, Nocini PF, Bucci E, De Rosa G. Expression of cell cycle and apoptosis-related proteins in sporadic odontogenic keratocysts and odontogenic keratocysts associated with the nevoid basal cell carcinoma syndrome. J Dent Res. 1999;78(7):1345-53.

Lu Y, Xuan M, Takata T, Wang C, He Z, Zhou Z, et al. Odontogenic tumors. A demographic study of 759 cases in a Chinese population. Oral Surg Oral Med Oral Pathol Oral Radiol Endod. 1998;86(6):707-14.

Luo HY, Li TJ. Odontogenic tumors: A study of 1309 cases in a Chinese population. Oral Oncol. 2009.

MacDonald-Jankowski DS, Wu PC. Cementoblastoma in Hong Kong Chinese. A report of four cases. Oral Surg Oral Med Oral Pathol. 1992;73(6):760-4.

Meara JG, Li KK, Shah SS, Cunningham MJ. Odontogenic keratocysts in the pediatric population. Arch Otolaryngol Head Neck Surg. 1996;122(7):725-8.

Morgan TA, Burton CC, Qian F. A retrospective review of treatment of the odontogenic keratocyst. J Oral Maxillofac Surg. 2005;63(5):635-9. 
Mosadomi A. Odontogenic tumors in an African population. Analysis of twenty-nine cases seen over a 5-year period. Oral Surg Oral Med Oral Pathol. 1975;40(4):50221.

Mosqueda Taylor A, Meneses García A, Ruíz Godoy Rivera LM, Suárez Roa Mde L, Luna Ortiz K. Malignant odontogenic tumors. A retrospective and collaborative study of seven cases. Med Oral. 2003;8(2):110-21.

Mosqueda-Taylor A, Carlos-Bregni R, Ledesma-Montes C, Fillipi RZ, de Almeida OP, Vargas PA. Calcifying epithelial odontogenic tumor-like areas are common findings in adenomatoid odontogenic tumors and not a specific entity. Oral Oncol. 2005;41(2):214-5.

Mosqueda-Taylor A, Ledesma-Montes C, Caballero-Sandoval S, Portilla-Robertson J, Ruiz-Godoy Rivera LM, Meneses-Garcia A. Odontogenic tumors in Mexico: a collaborative retrospective study of 349 cases. Oral Surg Oral Med Oral Pathol Oral

Mosqueda-Taylor A. New findings and controversies in odontogenic tumors. Med Oral Patol Oral Cir Bucal. 2008;13(9):E555-8.

Myoung $\mathrm{H}$, Hong SP, Hong SD, Lee JI, Lim CY, Choung PH et al. Odontogenic keratocyst: Review of 256 cases for recurrence and clinicopathologic parameters. Oral Surg Oral Med Oral Pathol Oral Radiol Endod. 2001;91(3):328-33.

Norberg O. Zur Kenntnis der dysodontogenetischen Gsechwülste der Kieferknochen. Wschr Zahnheilkd. 1930;46:321-55.

Ochsenius G, Ortega A, Godoy L, Penafiel C, Escobar E. Odontogenic tumors in Chile: a study of 362 cases. J Oral Pathol Med. 2002;31(7):415-20.

Odukoya O. Odontogenic tumors: analysis of 289 Nigerian cases. J Oral Pathol Med. 1995;24(10):454-7.

Ogunsalu CO. Odontogenic tumours from two centres in Jamaica. A 15-year review. West Indian Med J. 2003;52(4):285-9.

Okada H, Yamamoto H, Tilakaratne WM. Odontogenic tumors in Sri Lanka: analysis of 226 cases. J Oral Maxillofac Surg. 2007;65(5):875-82. 
Olgac V, Koseoglu BG, Aksakalli N. Odontogenic tumours in Istanbul: 527 cases. Br J Oral Maxillofac Surg. 2006;44(5):386-8.

Ortega A, Farina V, Gallardo A, Espinoza I, Acosta S. Nonendodontic periapical lesions: a retrospective study in Chile. Int Endod J. 2007;40(5):386-90.

Philipsen HP, Reichart PA, Nikai H, Takata T, Kudo Y. Peripheral ameloblastoma: biological profile based on 160 cases from the literature. Oral Oncol. 2001;37(1):1727.

Philipsen HP, Reichart PA, Praetorius F. Mixed odontogenic tumours and odontomas. Considerations on interrelationship. Review of the literature and presentation of 134 new cases of odontomas. Oral Oncol. 1997;33(2):86-99.

Philipsen HP, Reichart PA, Siar $\mathrm{CH}, \mathrm{Ng} \mathrm{KH}$, Lau SH, Zhang X et al. An updated clinical and epidemiological profile of the adenomatoid odontogenic tumour: a collaborative retrospective study. J Oral Pathol Med. 2007;36(7):383-93.

Philipsen HP, Reichart PA, Zhang KH, Nikai H, Yu QX. Adenomatoid odontogenic tumor: biologic profile based on 499 cases. J Oral Pathol Med. 1991;20(4):149-58

Philipsen HP, Reichart PA. Adenomatoid odontogenic tumour: facts and figures. Oral Oncol. 1999 Mar;35(2):125-31.

Philipsen HP, Reichart PA. Classification of odontogenic tumours. A historical review. J Oral Pathol Med. 2006;35(9):525-9.

Philipsen HP, Reichart PA. Revision of the 1992-edition of the WHO histological typing of odontogenic tumours. A suggestion. J Oral Pathol Med. 2002;31(5):253-8.

Philipsen HP, Reichart PA. Squamous odontogenic tumor (SOT): a benign neoplasm of the periodontium. A review of 36 reported cases. J Clin Periodontol. 1996;23(10):922-6.

Pindborg JJ, Clausen F. Classification of odontogenic tumors; suggestion. Acta Odont Scandinav. 1958;16:293-301.

Pindborg JJ, Kramer JR. Histological Typing of Odontogenic Tumours, Jaw Cysts and Allied Lesions. 1th ed. Geneva: World Health Organization; 1971. 
Praetorius F, Hjørting-Hansen E, Gorlin RJ, Vickers RA. Calcifying odontogenic cyst. Range, variations and neoplastic potential. Acta Odontol Scand. 1981;39(4):227-40.

Rachanis CC, Shear M. Age-standardized incidence rates of primordial cyst (keratocyst) on the Witwatersrand. Community Dent Oral Epidemiol. 1978;6(6):296-9. Radiol Endod. 1997;84(6):672-5.

Regezi JA, Kerr DA, Courtney RM. Odontogenic tumors: analysis of 706 cases. J Oral Surg. 1978;36(10):771-8.

Reichart PA, Philipsen HP, Sciubba JJ. The new classification of Head and Neck Tumours (WHO)--any changes? Oral Oncol. 2006;42(8):757-8.

Reichart PA, Philipsen HP, Sonner S. Ameloblastoma: biological profile of 3677 cases. Eur J Cancer B Oral Oncol. 1995;31B(2):86-99.

Reichart PA, Philipsen HP. Odontogenic tumors and allied lesions. London: Quintessence Publising Co.; 2004.

Robinson HBG. Proceedings of Fifth Annual Meeting of American Academy of Oral Pathology, Stevens Hotel, Chicago, February 4, 1951. Oral Surg. 1952;5:177-8.

Santos JN, Pinto LP, de Figueiredo CR, de Souza LB. Odontogenic tumors: analysis of 127 cases. Pesqui Odontol Bras. 2001;15(4):308-13.

Sawyer DR, Mosadomi A, Page DG, Svirsky JA, Kekere-Ekun AT. Racial predilection of ameloblastoma? A probable answer from Lagos (Nigeria) and Richmond, Virginia (U.S.A.). J Oral Med. 1985;40(1):27-31.

Schmidseder R, Hausamen JE. Multiple odontogenic tumors and other anomalies. Oral Surg Oral Med Oral Pathol. 1975

Shear M, Singh S. Age-standardized incidence rates of ameloblastoma and dentigerous cyst on the Witwatersrand, South Africa. Community Dent Oral Epidemiol. 1978;6(4):195-9.

Shear M, Speight PM. Cysts of the Oral and Maxillofacial Regions. 4 ed. Oxford: Blackwell Munksgaard; 2007. 
Shear M, Speitght P. Cysts of the oral and maxillofacial regions. 4 ed. Oxford: Blackwell Munksgaard; 2007.

Shear M. The aggressive nature of the odontogenic keratocyst: is it a benign cystic neoplasm? Part 1. Clinical and early experimental evidence of aggressive behaviour. Oral Oncol. 2002;38(3):219-26.

Shear M. The aggressive nature of the odontogenic keratocyst: is it a benign cystic neoplasm? Part 2. Proliferation and geneticstudies. Oral Oncol. 2002;38(4):223-31.

Shear M. The aggressive nature of the odontogenic keratocyst: is it a benigncystic neoplasm? Part 3. Immunocytochemistry of cytokeratin and othereoithelial cell markers. Oral Oncol. 2002;38(5):407-15.

Shear M. The Unity of Tumours of Odontogenic Epithelium. $\mathrm{Br} \mathrm{J}$ Oral Surg. 1965;3:212-21.

Simon EN, Merkx MA, Vuhahula E, Ngassapa D, Stoelinga PJ. A 4-year prospective study on epidemiology and clinicopathological presentation of odontogenic tumors in Tanzania. Oral Surg Oral Med Oral Pathol Oral Radiol Endod. 2005;99(5):598-602.

Sriram G, Shetty RP. Odontogenic tumors: a study of 250 cases in an Indian teaching hospital. Oral Surg Oral Med Oral Pathol Oral Radiol Endod. 2008;105(6):e14-21.

Stypulkowska J. [Odontogenic tumors and neoplastic-like changes of the jaw bone. Clinical study and evaluation of treatment results]. Folia Med Cracov. 1998;39(12):35-141.

Takeda Y, Satoh M, Nakamura S, Ohya T. Keratoameloblastoma with unique histological architecture: an undescribed variation of ameloblastoma. Virchows Arch. 2001;439(4):593-6.

Tamme T, Soots M, Kulla A, Karu K, Hanstein SM, Sokk A, et al. Odontogenic tumours, a collaborative retrospective study of 75 cases covering more than 25 years from Estonia. J Craniomaxillofac Surg. 2004;32(3):161-5.

Tay AB. A 5-year survey of oral biopsies in an oral surgical unit in Singapore: 19931997. Ann Acad Med Singapore. 1999;28(5):665-71. 
Thoma KH, Goldman HM. Odontogenic tumors: classification based on observations of epithelial, mesenchymal, and mixed varieties. Am J Path. 1946;22:433-71.

Toida M. So-called calcifying odontogenic cyst: review and discussion on the terminology and classification. J Oral Pathol Med. 1998;27(2):49-52.

Toller PA. Origin and growth of cysts of the jaws. Ann R Coll Surg Eng. 1967; 40(5):306-36.

Tomas ML. [Benign maxillofacial tumours. Odontogenic tumours.]. An R Acad Nac Med (Madr). 2007;124(4):773-90; discussion 91-3.

Tomich CE. Benign mixed odontogenic tumors. Semin Diagn Pathol. 1999;16(4):30816.

Ulmansky M, Hjørting-Hansen E, Praetorius F, Haque MF. Benign cementoblastoma. A review and five new cases. Oral Surg Oral Med Oral Pathol. 1994;77(1):48-55.

Vedtofte $\mathrm{P}$, Praetorius F. Recurrence of the odontogenic keratocyst in relation to clinical and histological features. A 20-year follow-up study of 72 patients. Int J Oral Surg. 1979;8(6):412-20.

Whitt JC, Dunlap CL, Sheets JL, Thompson ML. Keratoameloblastoma: a tumor sui generis or a chimera? Oral Surg Oral Med Oral Pathol Oral Radiol Endod. 2007;104(3):368-76.

Wijn MA, Keller JJ, Giardiello FM, Brand HS. Oral and maxillofacial manifestations of familial adenomatous polyposis. Oral Dis. 2007;13(4):360-5.

Woolgar JA, Rippin JW, Browne RM. A comparative histological study of odontogenic keratocysts in basal cell naevus syndrome and control patients. J Oral Pathol. 1987;16(2):75-80.

Woolgar JA, Rippin JW, Browne RM. A comparative study of the clinical and histological features of recurrent and non-recurrent odontogenic keratocysts. J Oral Pathol. 1987;16(3):124-8. 
Woolgar JA, Rippin JW, Browne RM. The odontogenic keratocyst and its occurrence in the nevoid basal cell carcinoma syndrome. Oral Surg Oral Med Oral Pathol. 1987;64(6):727-30.

Wu PC, Chan KW. A survey of tumours of the jawbones in Hong Kong Chinese: 1963-1982. Br J Oral Maxillofac Surg. 1985;23(2):92-102.

Yoon JH, Kim HJ, Yook JI, Cha IH, Ellis GL, Kim J. Hybrid odontogenic tumor of calcifying odontogenic cyst and ameloblastic fibroma. Oral Surg Oral Med Oral Pathol Oral Radiol Endod. 2004;98(1):80-4. 
Anexos 
Anexo $A$ 
Planilha para coleta de dados

\begin{tabular}{|l|l|l|l|l|l|l|l|}
\hline BIÓPSIA & NOME & GÊNERO & IDADE & $\begin{array}{c}\text { DIAGNÓSTICO } \\
\text { CLÍNICO }\end{array}$ & $\begin{array}{c}\text { DIAGNÓSTICO } \\
\text { MICROSCÓPICO }\end{array}$ & $\begin{array}{l}\text { LOCALIZAÇÃO } \\
\text { CONFIRMAÇÃO } \\
\text { DIAGNÓSTICA }\end{array}$ \\
\hline & & & & & & & \\
\hline & & & & & & & \\
\hline
\end{tabular}


Anexo $\mathcal{B}$ 


\section{Universidade de São Paulo \\ Faculdade de Odontologia de Bauru}

Al. Dr. Octávio Pinheiro Brisolla, 9-75 - Bauru-SP - Brasil - CEP 17012-901 - C.P. 73 PABX (0XX14)3235-8000 - FAX (0XX14)3223-4679

Comitê de Ética em Pesquisa (3235-8356) e-mail: mferrari@fob.usp.br

Of. $n^{\circ}$ CEP/05 2008/FOB

Proc. CEP n $127 / 2007$

Bauru, 29 de fevereiro de 2008.

Senhor Professor,

Em atençăo ao atendimento do Parecer $n^{\circ} 968 / 2007$, emitido pela CONEP sobre o projeto de pesquisa "Estudo retrospectivo de tumores odontogênicos em dois centros de estudo no Brasil e três no México", de autoria de Melaine de Almeida Lawall, sob sua orientação, este Colegiado analisou e considerou APROVADO em reunião realizada no dia 26 de fevereiro de 2008.

Lembramos que após o envio do trabalho concluído, este Comitê enviará o parecer final, que será utilizado para a publicação do trabalho.

Atenciosamente,

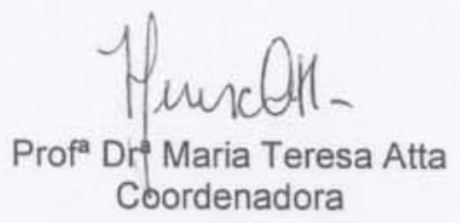

Prof. Dr. Luís Antônio de Assis Taveira

Docente do Departamento de Estomatologia 
Anexo $C$ 


\author{
MINISTEERIO DA SAÚDE \\ Conselho Nacional de Saúde \\ Comissåo Nacional de Etica em Pesquisa - CONEP
}

\title{
PARECER N॰ 968/2007
}

Registro CONEP: 14377 (Este n' deve ser cltado nas correspondenclas referentes a asto projeto)

CAAE $-0124.0 .224 .000-07$

Processo n' 25000,183071/2007-44

Projeto de Pesquisa: "Estudo retrospectivo de tumores odontogenicos em dois centros de estudo no Brasil e trés no México".

Pesquisador Responsável: Dra Melaine de Almeida Lawall

Instituiçáfo: Facuidade de Odontologia do Bauru/USP/SP

CEP de origem: Faculdade de Odontologia de Bauru - FOB/USPISP

Area Temática Especial: Cooperaçăo estrangeira

Patrocinador: Santander/Banespa

\section{Sumário geral do protocolo}

Os tumores odontogênicos constituem um grupo de doenças heterogêneas que variám de proliferaçōes teciduais hamartomatosas e nåo neoplásicas $\theta$ neoplásicas benignas ou mesmo tumores malignos corn potencial metastático.

Este projeto de pesquisa tem por objetivo fazer um estudo retrospectivo sobre tumores odontogênicos e determinar a freqüència dos diferentes tipos de tumores odontogênicos diagnosticados nos serviços de Anatomia Patolbgica de três centros de estudo no México (Universidade Nacional Autónoma do México - UNAM; Universidade Autônoma Metropolitana - UAM e laboratório privado PERICT) a dois centros no Brasil (FOB/USP e FOAUNESP), além de reclassifićs-los seguindo a nova Classificação da Organizaçäo Mundial de Saúde.

Serão utilizadas låminas prontas do arquivo e quando necessários novos cortes serão realizados. Dois patologistas calibrados avaliarăo as låminas $\theta$ definirăo os diagnósticos.

Os dados analisados serão o número de biópsia, idade, sexo, localizaçăo e tamanho da lesão, tempo de evoluçăo, achados radiográficos, diagnóstico microscópico prévio e diagnóstico definitivo. Os dados serăo planilhados e será feita análise estatística.

Consta declaraçăo de aceite de participaçăo dos centros de pesquisa do Brasil (FOB/USP e FOAUNESP).

Cumpre ressaltar que o levantamento de dados nos centros de estudo do México já foi executado. O pesquisador incluiu declaraçōes (espanhol e portugués) confirmando a participaçäo das duas universidades mexicanas, onde as mesmas afirmam que o projeto foi revisado e aprovado.

A Folha de Rosto está corretamente preenchida. estudo.

O curriculo vitae do pesquisador responsável o qualifica para a realizaçāo do

$O$ orçamento apresentado informa que o estudo será financiado pelo Banco Santander/Banespa, através do Programa de Mobilidade Internacional de PósGraduandos, consta que a pesquisadora responsável recebeu auxilio financeiro para passagens aéreas (SP/Cidado do México/SP) e bolsa de estudo mensal (setembro/março), totalizando $€ 5200$. 
No cronograma de execuçăo apresentado consta 0 detalhamento das atividades que serào realizadas desde o perlodo de junho/agosto/2006 a junto/dezembro/2008.

o vatamento dos dados é pertinente e nāo haverá envio de material biologlico para o exterior.

\section{Recomendação}

- projeto nầo apresenta Termo de Consentimento Livre e Esclarecido (TCLE) e nem justificativa para năo inclui-Jo. Recomenda-se observar o ltem IV 3.c da Resoluçăo CNS 2196/96: "nos cascs em que seja impossivel registrar o consentimento livre esclarecido, tal fato deve ser devidamente documentado, com explicaçào das causas da impossibilidade, e parecer do Comitè de Ética em Pesquisa".

Diante do exposto, a Comissăo Nacional de Ética em Pesquisa - CONEP, de acordo com as atribuięós definidas na Resolução CNS 196/96, manifestase pela aprovação do projeto de pesquisa proposto, devendo o CEP verificar o cumprimento da recomendação acima, antes do iníclo do estudo, e encaminhar a CONEP.

Situaçấo: Protocolo aprovado com recomendaçăo.

Brasilia. 17 de dezembro de 2007.

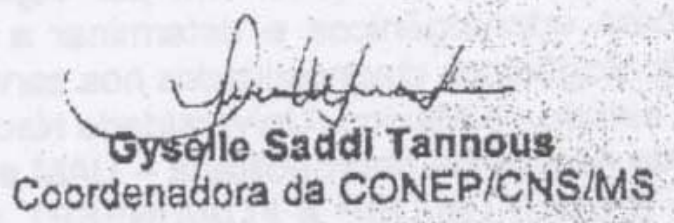

